\title{
MACROEVOLUTIONARY CHANGES OF PLANTS ON ISLANDS
}

\author{
BY \\ PATRICK HUGH KAVANAGH
}

A thesis submitted to

Victoria University of Wellington

in fulfillment of the requirements for the degree of

Doctor of Philosophy in Ecology and Biodiversity.

Victoria University of Wellington

2015 
This thesis was conducted under the supervision of:

Dr. Kevin Burns (Primary Supervisor)

Victoria University of Wellington,

Wellington, New Zealand 


\section{General abstract}

Insularity is known to produce predictable evolutionary changes in plants. For example, herbaceous plants often evolve woodiness and seeds tend to have reduced dispersal capabilities on islands. However, our understanding of how other plant traits may evolve on islands is lacking. Furthermore, plants are modular organisms and by investigating evolutionary changes in specific plant traits we may better understand macroevolutionary processes on islands.

In this thesis, I investigate evolutionary changes in a range of plant traits on islands. First, I tested for evolutionary changes in seed size on islands (Chapter 2). Island plants consistently produced larger seeds than mainland relatives. Furthermore, this result was consistent regardless of differences in dispersal mode, growth form and evolutionary history. Selection may favour increased seed size to reduce dispersal distances. Additionally, selection may favour larger seeds due to the competitive advantage conferred to developing seedlings.

Many animal taxa exhibit increased sexual size dimorphism (SSD) on islands, as predicted by the niche variation hypothesis. However, patterns of SSD among dioecious plants on islands are unknown. In Chapter 3 I tested for differences in SSD of dioecious plants that colonized four island groups from New Zealand (mainland). The degree of SSD did not vary predictable between island and mainland plants, contrary to predictions of the niche variation hypothesis. However, SSD was consistently female biased on the mainland and results suggest selection is acting to increase the size of both sexes on islands.

Evolutionary changes in island plants may be a response to herbivory by unique large browsers. For example, the divaricate growth form is common in the New Zealand flora and may have deterred browsing moa. In Chapter $4 \mathrm{I}$ tested for differences in traits associated with the divaricate growth form between plants from mainland New Zealand and Chatham Island. 
Results suggest that an absence of moa on Chatham Island has relaxed selection for traits associated with the divaricate growth form.

An emerging body of research suggests aposematism (warning signals to herbivores) may be common in plants. However, previous investigations have not appreciated the fact that the perspective of terrestrial herbivores changes as plants grown vertically. Furthermore, ontogenetic changes in the capacity of plants to defend themselves may influence the reliability of warning signals. In Chapter 5 I tested for ontogenetic changes in two potentially aposematic signals produced by Pseudopanax crassifolius. Aposematism on upper leaf surfaces peaked early in ontogeny, providing a dishonest signal of defense. Conversely, signaling on the underside of leaves peaked later in ontogeny and scaled positively with structural defenses.

The results of this thesis suggest selection is acting on specific plant traits on islands. Evolutionary pathways, such as the evolution of woodiness, may be better explained by considering selection acting on other plant traits. For example, selection acting on seed size may facilitate evolutionary size changes evident at later life-history stages. A lack of consensus exists regarding the role of insular herbivores in the evolution of island plants. The results of Chapters 4 and 5 suggest herbivory has played an important role in the evolution of novel morphology of island plants. Considering trait specific changes of plants on islands may further our understanding of prominent evolutionary pathways by pinpointing the action of selection. 


\section{Acknowledgments}

First, I would like to thank my supervisor KC Burns. KC has been an amazing mentor, providing me with support and direction while giving me enough independence to grow as a researcher. $\mathrm{KC}$ has been a great teacher, enlightened me to the 'tactics' of publishing, and instilled confidence through his famous 'pep-talks' and amazing analogies (including references to NBA legends, fishing, skateboarding and surfing).

I am grateful for my colleagues and friends in SBS. Mauricio Cifuentes, Rafael Barbieri, Mark Heath, Amanda Taylor, Kirsty Yule, Catarina Silva, Rachael Shaw, Iggy Menzies, Luke Cooney, Karl Yager, Gagandeep Jain. Thank you for putting up with my questions and interruptions. I would like to extend further thanks to Rafael for the discussions on statistics and the countless times he provided me advice on the use of $R$.

The administrative staff of SBS have been extremely helpful. I would like to thank Mary Murry and Sandra Taylor for answering questions, hooking me up with stationary, and always being so cheerful.

I would like to thank DoC staff on Chatham Island for all of their assistance while I was conducting fieldwork. Similarly, I would like to thank Tony Silbery from DoC Wairarapa for his assistance, and the staff of the botany departments at Te Papa, Landcare Research, and Auckland Museum for being so accommodating while I was using the herbaria. I am grateful for funding provided by Victoria University of Wellington and the Wellington Botanical Society.

I would like to thank my Mum (Sally Hiener) and Dad (Seamus Kavanagh) for being so supportive of my interest in science and always being proud of my achievements.

Lastly, I would like to thank my partner, Ashleigh Morris, for her support, advising me that wearing hoodies, skate shoes, and caps isn't always appropriate, and for listening to me talk about my work and fishing. 


\title{
Publications from this thesis
}

\author{
Journal articles
}

Kavanagh P.H. \& Burns K.C. (2014) The repeated evolution of large seeds on islands. Proceedings of the Royal Society B, 281, 20140675

- Author contribution: PHK collected data, ran analyses and wrote the manuscript. KCB conceived the study and assisted with writing of the manuscript.

Kavanagh P.H. \& Burns K.C. (2015) Sexual size dimorphism in island plants: the niche variation hypothesis and insular size changes. Oikos, 124, 717-723 doi: 10.1111/oik.01753

- Author contribution: PHK conceived the study, collected data, ran analyses and wrote the manuscript. KCB assisted with analytical techniques and writing of the manuscript.

Kavanagh P.H. (2015) Herbivory and the evolution of divaricate plants: structural defenses lost on an offshore island. Austral Ecology, 40, 206-211 doi: 10.1111/aec.12196

Kavanagh P.H., Shaw, R.C. \& Burns K.C. (In Prep) The ontogeny of signal honesty: new insights from an aposematic tree.

- Author contributions: PHK developed research direction, collected data, conducted analyses and wrote the manuscript. RCS assisted with data collection, development of research direction and writing. KCB conceived the study and assisted with writing. 


\section{Media articles}

Island gigantism, Natural History Magazine, Volume 122, number 6

Island life makes plant seeds bigger, ABC Science Online, 21 May 2014.

Island life promotes evolution of larger seeds, Science News, 26 May 2014

Bigger is better for island seeds, Today's Science, August 2014 


\section{Table of Contents}

Chapter 1 - General introduction ..............................................................1

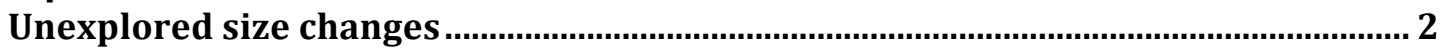

Insular herbivory ...................................................................................................

Thesis overview................................................................................................................... 5

Chapter 2 - The repeated evolution of large seeds on islands ................... 8

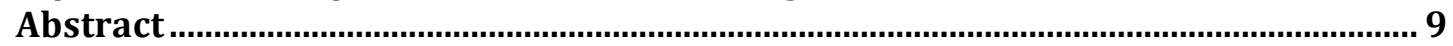

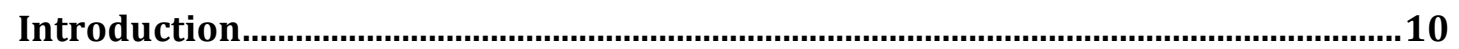

Methods................................................................................................................12

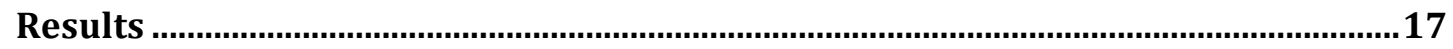

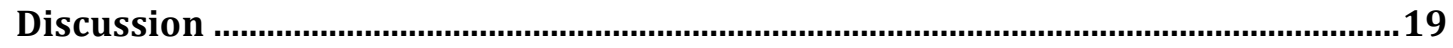

Chapter 3 - Sexual size dimorphism in island plants: the niche variation

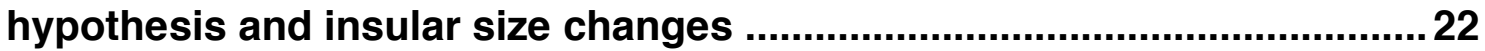

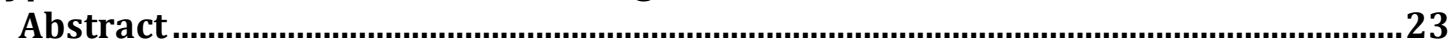

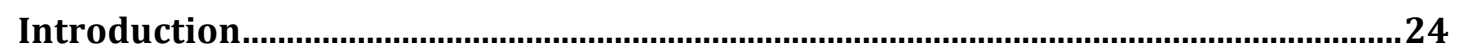

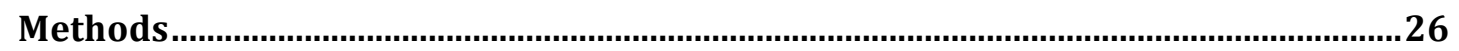

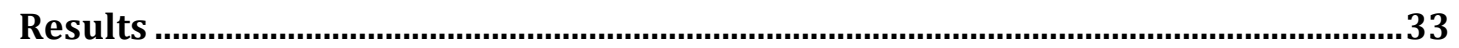

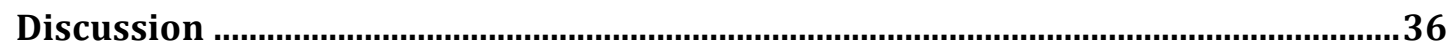

Chapter 4 - Herbivory and the evolution of divaricate plants: structural defenses lost on an offshore island........................................................39

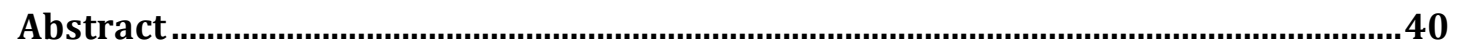

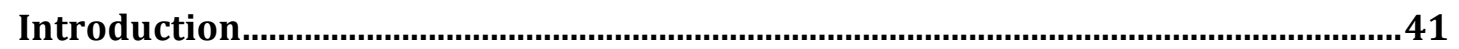

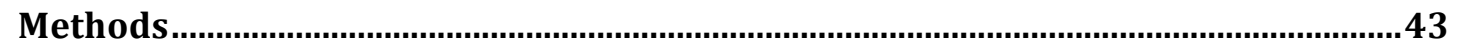

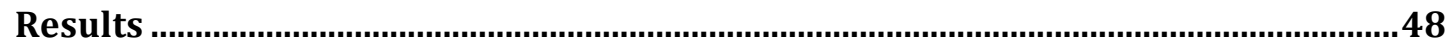

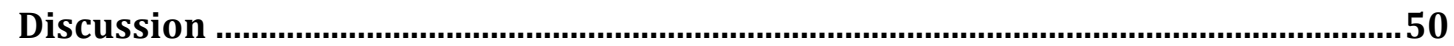

Chapter 5 - The ontogeny of signal honesty: new insights from an aposematic tree..........................................................................................53

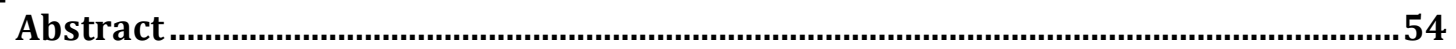

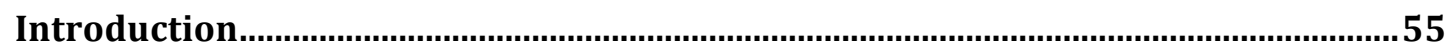

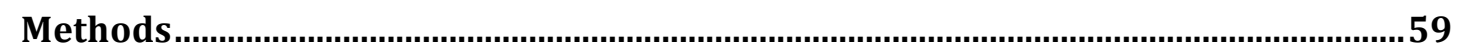

Upper leaf surface ….......................................................................................................................59

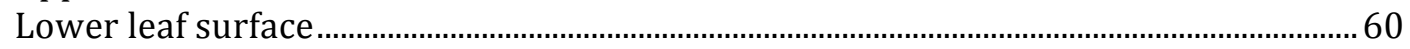

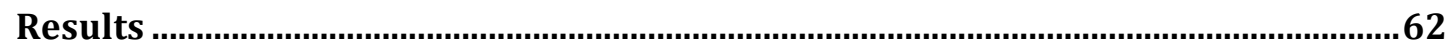

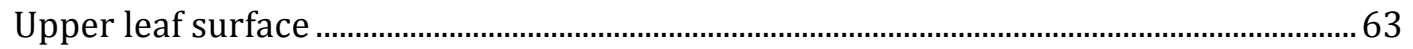

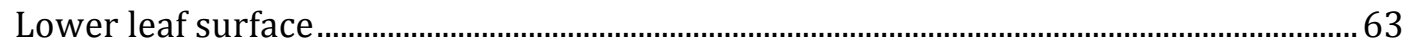

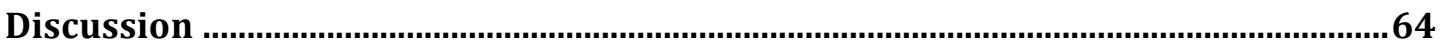

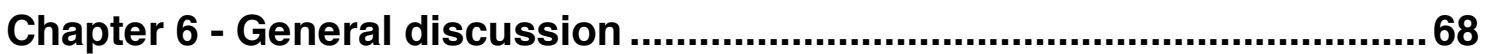

Insular size changes in plants..................................................................................69

Unique herbivores .....................................................................................................71

Conclusions \& Future directions ..............................................................................

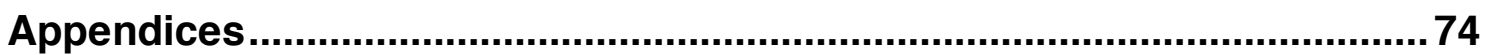

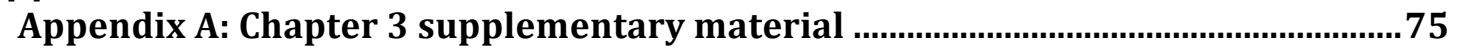

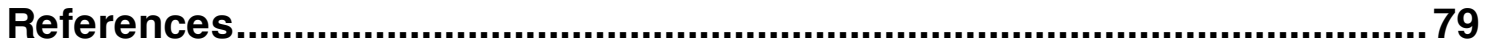




\section{Chapter 1 - General introduction}


Insularity often results in repeated evolutionary pathways. For example, island animals often evolve to become giants or dwarfs when compared to mainland relatives (Van Valen, 1973a; Case, 1978; Lomolino, 2005; Meiri et al., 2006; Meiri et al., 2008). Insular size changes are not restricted to animals. Many island trees are descended from small, herbaceous mainland plants (Carlquist, 1974). The evolution of 'woodiness' (arborescence) on islands was first noted by Darwin (1859) and modern phylogenetic approaches have confirmed its occurrence in a variety of plant lineages and island systems (Bohle et al., 1996; Panero et al., 1999; Percy \& Cronk, 2002). However, our understanding of the processes responsible for many trends exhibited by insular plants is incomplete. For example, a lack of consenus exists regarding the selective pressures responsible for the evolution of woodiness on islands (Darwin, 1859; Wallace, 1880; Carlquist, 1974; Bohle et al., 1996; Givnish, 1998). Furthermore, previous investigations have not appreciated the modularity of plant structure when investigated evolutionary changes in island plants (but see Burns et al., 2012). Thus, our understanding of how plants evolve on islands is incomplete.

\section{Unexplored size changes}

A reduction in the dispersal ability of seeds is common on islands (Carlquist, 1974; Cody \& Overton, 1996). Selection may favour reduced dispersibility to decrease propagule mortality due to seeds landing in the ocean (Darwin, 1859; Carlquist, 1974). Furthermore, the small size of islands may result in suitable habitat zones being smaller and favour dispersal of seeds within the limits of suitable conditions (Carlquist, 1974). Structural changes of seeds consistent with reduced dispersal ability have been documented in wind dispersed (Carlquist, 1974; Cody \& Overton, 1996), fleshy-fruited, and ectozoochorous (dispersed on the outside of animals) species (Carlquist, 1974). Reduced dispersal ability of seeds has been detected in as few as five generations after island colonization, suggesting strong selection pressures (Cody \& Overton, 1996).

Selection may favour increased seed sizes on islands to reduce dispersal distances (see Greene \& Johnson, 1993). Additionally, it may 
improve rates of establishment and confer a competitive advantage to developing seedlings (Leishman et al., 1995; Lord et al., 1995; Moles \& Westoby, 2004). Seed size also covaries with many other plant traits (Corner, 1949; Westoby et al., 1996). Therefore, selection acting on seed size may facilitate evolutionary changes in other plant traits. However, our understanding of how seed sizes may evolve on islands is lacking.

It is estimated that only $6-7 \%$ of angiosperm species worldwide are dioecious (separate male and female individuals; Renner \& Ricklefs, 1995). However, many island floras are characterized by having relatively large proportions of dioecious plant taxa. For example, $14.7 \%$ of species in the native Hawaiian flora (Sakai et al., 1995) and 13\% of species in New Zealand are dioecious (Godley, 1979). Sexual Size Dimorphism (SSD) is common in dioecious plants (Bond \& Midgley, 1988; Obeso, 2002; Kavanagh et al., 2011; Barrett \& Hough, 2013) and the niche variation hypothesis predicts the degree of SSD to increase on islands (Van Valen, 1965; Ebenman \& Nilsson, 1982; Meiri et al., 2005). Insular populations face fewer competing species and increasing SSD (and consequently, morphological variability within a population) may facilitate occupation of available niche space (as advocated to explain size changes of insular animals, Grant, 1965; Lomolino, 2005). Additionally, SSD may increase in response to elevated levels of intraspecific competition (Rothstein, 1973; Shine, 1989). Many animals conform to the prediction of increased SSD on islands (Ebenman \& Nilsson, 1982; Dayan \& Simberloff, 1998; Simberloff et al., 2000; Pearson et al., 2002). However, insular patterns of SSD in plants have yet to be investigated.

\section{Insular herbivory}

Large mammalian herbivores are uncommon on islands due to being poor overwater dispersers (Whittaker \& Fernandez-Palacios 2007). However, large browsing birds are often dominant components of insular herbivore communities (Olson \& James, 1982; Atkinson \& Greenwood, 1989a; Livezey, 1993; Givnish et al., 1994; Bond \& Silander, 2007). Herbivory pressure often selects for unique changes in plant morphology (e.g. thorns and spines - 
Cooper \& Owensmith, 1986) and the unusual herbivore communities on islands may play an important role in the evolution of insular flora. For example, heteroblasty (ontogenetic changes in leaf morphology) is common to many unrelated plants in New Zealand and may be an adaptation to deter extinct browsing birds (Moa - Aves: Dinornithiformes; Greenwood \& Atkinson, 1977). The divaricate growth form (small, widely spaced leaves, narrow stems and high branching angles) is another common feature of the New Zealand flora (Greenwood \& Atkinson, 1977). Plants sharing similar traits are also common in Madagascar (Bond \& Silander, 2007). This unique growth form may also be an adaptation to deter herbivory by extinct browsing birds (Greenwood \& Atkinson, 1977; Bond et al., 2004; Bond \& Silander, 2007). Alternatively, both heteroblasty and the divaricate growth form may be adaptations to environmental conditions (McGlone \& Webb, 1981; Day, 1998).

The isolation of islands often results in depauperate herbivore communities (Carlquist, 1974; Whittaker \& Fernández-Palacios, 2007). Therefore, a reduction in herbivory pressure may be common on islands and lead to predictable evolutionary changes in plants. For example, antiherbivore defenses may be under strong selection on the mainland, however selection for these traits may be relaxed after island colonization. Chemical defenses are often absent or less effective in island plants when compared to mainland relatives (Bowen \& VanVuren, 1997; Vourc'h et al., 2001). Plant-ant mutualisms that deter insect herbivores are often lost after island colonization (Janzen, 1973; Rickson, 1977). Furthermore, structural defenses such as prickles or thorns are often greatly reduced in island plants (Bowen \& VanVuren, 1997; Burns, 2014). The floras of the offshore islands surrounding mainland New Zealand (North and South Islands) are derived primarily from taxa that have dispersed overwater from the main islands (Wardle, 1991). Furthermore, moa were absent from many of these offshore islands (see Greenwood \& Atkinson, 1977). Therefore, a reduction in herbivory pressure may have relaxed selection for anti-herbivory traits that had evolved on the New Zealand mainland. This offers a unique opportunity to test anti-herbivore 
hypotheses for the evolution of unique morphology, such as the divaricate growth form.

Recent research suggests some plants produce aposematic (warning) signals (Lev-Yadun, 2001; Lev-Yadun \& Ne'eman, 2004; Lev-Yadun \& Gould, 2007; Fadzly et al., 2009; Cooney et al., 2012). Furthermore, Fadzly et al. (2009) suggest that aposematism may occur in response to extinct avian browsers. Aposematic signals tend to be reliable advertisements of defense (Summers \& Clough, 2001; Lev-Yadun, 2003; Bezzerides et al., 2007; Cooney et al., 2012). However, dishonesty is common in animal signaling systems and rates of dishonesty often decline through ontogeny (Saetre \& Slagsvold, 1996; Bee et al., 2000; Whiting et al., 2009; Hawkins et al., 2012; Valkonen et al., 2014). Pseudopanax crassifolius displays are remarkable series of morphological transitions as it develops (Gould, 1993). Seedlings are camouflaged against background leaf-litter, saplings produce leaves with marginal teeth and associated aposematic spots, and adult leaves lack structural defenses (Gould, 1993; Fadzly et al., 2009). The reliability of aposematic signals may vary through ontogeny in response to changes in defense and herbivory pressure. However, signal reliability through ontogeny in plants has not been investigated.

\section{Thesis overview}

In this thesis, I investigated evolutionary patterns in a variety of plant traits on islands. I used an island-mainland comparison approach, where insular taxa were compared to sister taxa on the mainland. Specifically, data were collected from plants on the main islands of New Zealand (North and South Island 'mainland') and offshore islands surrounding the New Zealand mainland. I also tested for novel patterns of aposematic signaling by a species endemic to the New Zealand mainland, where moa were once a dominant component of the fauna. Each chapter of this thesis was written as a stand-alone manuscript for publication. Therefore, there may be some repetition in the information presented in the introduction and method sections of some chapters. 
In chapter 2, I tested for differences in seed size between related island and mainland plants. Seed size data were collected in the field and augmented with published seed descriptions to produce a comprehensive dataset of 40 island-mainland taxonomic parings. First, I tested for overarching changes in seed size on islands. Secondly, I tested for any effects of evolutionary history, growth form, and dispersal mode on the island-mainland seed size relationship.

In chapter 3, I investigated patterns of sexual size dimorphism (SSD) in dioecious plants from four island groups surrounding New Zealand. Leaf and stem sizes were quantified on herbarium specimens of 28 dioecious taxa allowing for 14 island-mainland taxonomic comparisons. First, I tested for an increase in the degree of SSD, as predicted under the niche variation hypothesis. I then developed a novel analytical technique to test for differences in the direction (which sex is larger) of SSD between related island and mainland plants. Lastly I tested for sex specific size changes of plants on islands.

In chapter 4, I tested for differences in traits associated with the divaricate growth form between plants from Chatham Island and the New Zealand mainland. The divaricate growth form is suggested to be an adaptation to deter herbivory by extinct avian browsers (moa). However, moa never reached Chatham Island. Therefore, I predicted Chatham Island plants to have lost morphological adaptations that may have deterred moa herbivory.

In chapter 5, I investigated patterns of aposematic signaling in $P$. crassifolius. First, I develop predictions based upon the changing perspective of terrestrial herbivores as plants grow vertically. Second, I used an avian vision model to whether variation in the colour of abaxial (lower) leaf surfaces may be aposematic. Third, I tested the following predictions: aposematic signals on upper leaf surfaces will peak early in ontogeny, when structural defenses are poorly developed, providing a dishonest signal. Conversely, aposematism on the underside of leaves will peak later in ontogeny and be reliable.

In chapter 6, I synthesized my findings. Overall, this thesis furthers our understanding of insular evolution by examining trait specific changes of plants 
on islands. Furthermore, results benefit our understanding of insular size changes and highlight the role herbivores play in the evolution of island plants 


\section{Chapter 2 - The repeated evolution of large seeds on islands}

Publication: Kavanagh, P. H. and Burns, K. C. (2014) The repeated evolution of large seeds on islands. Proceedings of the Royal Society B. 281: 20140675 


\section{Abstract}

Several plant traits are known to evolve in predictable ways on islands. For example, herbaceous species often evolve to become woody and species frequently evolve larger leaves, regardless of growth form. However, our understanding of how seed sizes might evolve on islands lags far behind other plant traits. Here, I conduct the first test for macroevolutionary patterns of seed size on islands. I tested for differences in seed size between 40 islandmainland taxonomic pairings from four island groups surrounding New Zealand. Seed size data were collected in the field and then augmented by published seed descriptions to produce a more comprehensive dataset. Seed sizes of insular plants were consistently larger than mainland relatives, even after accounting for differences in growth form, dispersal mode and evolutionary history. Selection may favour seed size increases on islands to reduce dispersibility, as long-distance dispersal may result in propagule mortality at sea. Alternatively, larger seeds tend to generate larger seedlings, which are more likely to establish and outcompete neighbours. My results indicate there is a general tendency for the evolution of large seeds on islands, but the mechanisms responsible for this evolutionary pathway have yet to be fully resolved. 


\section{Introduction}

Seed size varies greatly among plant species, from tiny wind-dispersed orchid seeds to the massive double coconut (Lodoicea maldivica) (Harper et al., 1970), and has important consequences for reproductive success (Leishman et al., 1995; Lord et al., 1995; Moles \& Westoby, 2004). Seedling survival is directly influenced by seed size (Leishman \& Westoby, 1994; Moles \& Westoby, 2004) and many functional traits covary with the size of seeds. These traits include dispersal mode, growth form, specific leaf area, and seed number (Corner, 1949; Westoby et al., 1996). Many of these other traits evolve predictably on islands (e.g. growth form and leaf area - Carlquist, 1974; Burns et al., 2012), however detailed quantitative investigations of how seed size is affected by insularity are lacking.

A reduction in the dispersal ability of seeds is a common evolutionary pathway for plants on islands (Carlquist, 1974; Cody \& Overton, 1996). For example, wind-dispersed members of the family Asteraceae typically display a reduction in pappus size relative to achene size on islands (Carlquist, 1974; Cody \& Overton, 1996). Animal-dispersed taxa (such as Bidens), which produce structures that promote ectozoochory, illustrate a similar pattern, with a reduction in the size of hooks and awns relative to achene size (Carlquist, 1974). Furthermore, fleshy-fruited members of the family Araliaceae tend to produce larger fruits and seeds on islands (Carlquist, 1974). The evolution of reduced dispersibility has also been detected in as few as five generations, suggesting strong selection pressures (Cody \& Overton, 1996).

One explanation for potential changes in seed size on islands is that the small size and isolation of islands may select against dispersal to reduce propagule mortality at sea (Darwin, 1859; Carlquist, 1974). Selection acting to increase seed size may reduce wind dispersal distances in anemochorous species (Greene \& Johnson, 1993). The same may be true for fleshy-fruited plants, although tests for directional changes in seed size of fleshy-fruited species have yet to be conducted.

Selection may favour larger seed size on islands for reasons other than dispersal ability. For example, most islands house fewer species than 
comparable communities on the mainland. Therefore, a germinating seedling on an island is more likely to be adjacent to a conspecific, leading to greater levels of intraspecific competition (Grant, 1965; Case, 1978). Larger seeds are more competitive than small seeds, all else being equal (Leishman \& Westoby, 1994; Leishman et al., 1995; Moles \& Westoby, 2004). Therefore, higher levels of intraspecific competition on islands may also select for increases in seed size.

Here, I conduct the first macroevolutionary test for increased seed size on islands. By collecting specimens in the field and using published seed descriptions I compiled a diverse dataset, consisting of 40 island-mainland taxonomic pairings from four island systems surrounding mainland New Zealand. To test for overarching changes in seed size on islands, I first compared seed sizes on islands to seed sizes on the mainland using reduced major axis regression. Secondly, I used a mixed-effects modelling approach to test for effects of evolutionary history, growth form, and dispersal mode on the island-mainland seed size relationship. 


\section{Methods}

New Zealand has a long history of geological isolation. It separated from Gondwana 80 million years ago and has been isolated in the southwest Pacific since. The three main islands (North, South and Stewart Islands) are encircled by numerous smaller islands (Gibbs, 2006), the flora of which consists mainly of taxa that have dispersed overwater from New Zealand. Although many of these islands were once connected by land bridges, I focused on four island groups that remained isolated from the main islands during the Pleistocene (Kermadec, Three Kings, Chatham and Sub Antarctic Islands - see Wallis \& Trewick, 2009). In particular I focused on the Chatham group $\left(176^{\circ} \mathrm{W}, 44^{\circ} \mathrm{S}\right)$, situated $850 \mathrm{~km}$ east of the main islands (see figure 2.1).

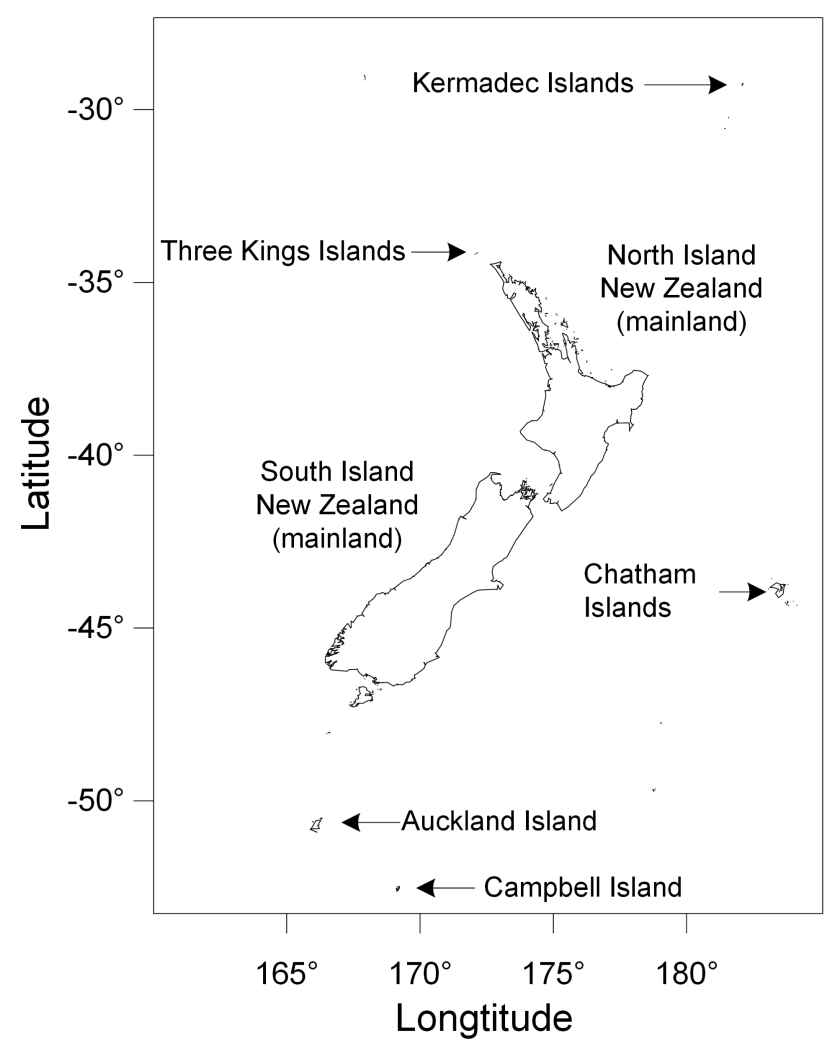

Figure 2.1 Map of study islands surrounding New Zealand 
To maximise the number of species in the dataset, the Chatham Islands were visited twice, at different times of year. This allowed the inclusion of species with different fruiting phenologies. Seed sizes were measured on Chatham Island taxa in January 2008 (Burns et al., 2012) and March 2012.

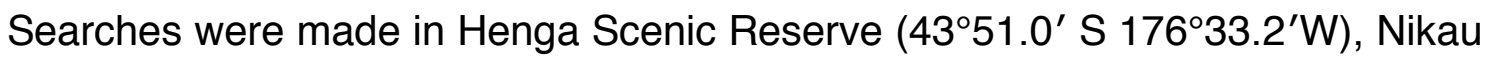
Forest Reserve $\left(43^{\circ} 45.7^{\prime} \mathrm{S} 176^{\circ} 34.8^{\prime} \mathrm{W}\right)$, and Rangaika Scenic Reserve ( $44^{\circ} 3^{\prime}$ $\left.37.0182^{\prime \prime} \mathrm{S} 176^{\circ} 26^{\prime} 6.0792^{\prime \prime} \mathrm{W}\right)$. Mainland samples were collected from Otari Wilton's Bush ( $\left.41^{\circ} 14^{\prime} \mathrm{S}, 174^{\circ} 45^{\prime} \mathrm{E}\right)$, Moa Point $\left(41^{\circ} 20^{\prime} \mathrm{S}, 174^{\circ} 49^{\prime} \mathrm{E}\right)$, and Nelson Lakes National Park $\left(41^{\circ} 48^{\prime} \mathrm{S}, 172^{\circ} 50^{\prime} \mathrm{E}\right)$. Fruits were randomly selected from each individual, collecting five or more from at least five individuals (following Cornelissen et al., 2003). This was not always achievable; therefore a variable number of seeds were used to characterize seed size (see Table 2.1). Seed size was estimated as the product of seed length (length of the longest axis) $x$ seed width (maximum distance perpendicular to the length measurement at the widest point of the seed).

To allow for the greatest number of island-mainland comparisons possible, I supplemented field data (25 taxa) with seed measurements contained in Seeds of New Zealand gymnosperms and dicotyledons ('seed atlas' from here after; Webb \& Simpson, 2001). Seed descriptions in the seed atlas result from the examination of at least 10 seeds from each of 10 collections of fruiting material for each species. I obtained the median value from seed dimension ranges when compiling data from within the seed atlas. To justify the use of seed atlas data and to promote accuracy, I ran Ordinary Least Squares (OLS) regression of field measures against data from the seed atlas. Measurements for two Hebe species were not contained in the seed atlas and seed sizes were obtained from An Illustrated Guide to New Zealand Hebes (Bayly \& Kellow, 2006). In many cases (42 taxa) the literature only provided length dimensions for seed size. I therefore ran OLS regression of area (length $\mathrm{x}$ width, as described above) against length, for the 36 taxa where both length and width parameters were available. Regression parameters were then used to estimate area for those taxa where only a length dimension was available. ANOVA of observed versus predicted values was carried out to test 
the robustness of seed area predictions. Variables were log transformed prior to analysis.

Determining mainland relatives for insular species was simple when taxa were undifferentiated (see Table 2.1). For Chatham Island endemics, the recent molecular analysis by Heenan et al. (2010) was utilised where possible. In this study DNA sequence data was used to identify the closest relatives for 35 taxa endemic to the Chatham Islands. For taxa from other island systems, phylogenetic analyses were used where available (Winkworth et al., 2002; Glenny, 2004; Wagstaff et al., 2006; Perrie \& Shepherd, 2009; Wagstaff et al., 2011; Himmelreich et al., 2012). When multiple mainland taxa were identified as being equally related to an island endemic, the average seed size of the mainland taxa was used (Myrsine chathamica - see Stockler, 2001; Leptinella plumosa and L. lanata - see Himmelreich et al., 2012). Where taxa were differentiated at species but not genus level the mainland taxon chosen is the most likely relative based on morphological similarities (e.g. Macropiper melchior and M. excelsum; Coprosma acutifolia and C. tenuifola - see Dawson \& Lucas, 2011). In other cases insular taxa were a variety or subspecies of well-known mainland species.

To test for differences in seed size among island and mainland taxa a variety of statistical methods could be used. Regressing mean values for insular taxa against mainland taxa is one option. The slope and intercept parameters providing information on the relationship (slope $>1$ and intercept $>$ $0=$ island taxa with larger seeds; slope $<1$ and intercept $<0=$ mainland seed size larger). However, the use of OLS regression minimizes the sum of squared variation in the $\mathrm{Y}$ (in this case, island) direction and is not appropriate when measurement error in $X$ and $Y$ variables is likely. To avoid these confounding sources of bias, I ran Reduced Major Axis (RMA) regression. RMA was used to obtain slope and intercept parameters along with 95\% confidence intervals.

Phylogenetic relatedness between island-mainland taxonomic pairs creates a lack of independence in the dataset. To overcome this, I ran a mixed effects model treating seed size as the dependent variable, location (island or mainland) as a fixed factor, and 'species-pair' (island-mainland taxonomic 
pairing) as a random factor. Many of the taxonomic pairings are separated at species level, potentially indicating more evolutionary divergence than conspecific pairings. I therefore included a second random effect of nested taxonomy (with two levels: undifferentiated at species level, or differentiated at species level) in the model structure. Seed dispersal mode and plant growth form were included as fixed factors to test for effects they may have on the island-mainland seed size relationship.

The majority of taxa in the dataset were either wind dispersed or fleshyfruited plants. I therefore defined dispersal modes as either 'dry-fruited' (wind, water, ballistic/wind) or 'fleshy-fruited'. Only two island-mainland taxonomic pairings were vines, I therefore removed these taxa from the growth form analysis. I am specifically interested in whether dispersal mode or growth form influences seed size differences between 'locations' (island or mainland). Therefore, the two-way interactions between location and these two factors were maintained in the model structure. I calculated the ratio of island seed size to mainland seed size to visualise whether seeds tended to be larger on islands for each level of dispersal mode and growth form. Ratios greater than one indicate a tendency for larger island seeds (see Fig 2.4). Kruskal-Wallis tests were then used to compare ratios between dispersal modes and growth forms. Robust tests for the effect of island system were not possible due to uneven sample sizes between islands.

All analyses were conducted in the $\mathrm{R}$ environment for statistical computing (R-Development-Core-Team, 2011). RMA analyses were conducted with the SMATR package (Warton et al., 2012a), and the CAR package (Fox \& Weisberg, 2011) was used to carry out a likelihood ratio test for the mixed effects model. Seed size data were logarithm transformed to conform to normality assumptions. 
Table 2.1 Average seed area for insular species and mainland relatives $\left(\mathrm{mm}^{2}\right)$. Numbers in parentheses refer to the number of individuals and seeds sampled, respectively. Italicised letters in parentheses indicates data acquired from published sources (a - Webb \& Simpson, $2001 ; ;$ h - Bayly \& Kellow, 2006). † Indicates cases where seed area was estimated from length measurements (see methods).

\begin{tabular}{|c|c|c|c|c|c|}
\hline Insular taxa & $\begin{array}{c}\text { Seed size } \\
\left(\mathrm{mm}^{2}\right)\end{array}$ & $\begin{array}{l}\text { Growth } \\
\text { form }\end{array}$ & $\begin{array}{c}\text { Dispersal } \\
\text { mode }\end{array}$ & Mainland taxa & $\begin{array}{l}\text { Seed size } \\
\quad\left(\mathrm{mm}^{2}\right)\end{array}$ \\
\hline Olearia chathamica & $19.94(5,25) \dagger$ & tree & wind & Pleurophyllum criniferum & $14.56(a) \dagger$ \\
\hline Olearia traversiorum & $3.26(6,30) \dagger$ & tree & wind & Olearia virgata & $1.27(a) \dagger$ \\
\hline Ripogonum scandens & $71.78(7,48)$ & vine & fleshy fruit & Ripogonum scandens & $55.40(3,22)$ \\
\hline \multirow[t]{2}{*}{ Myrsine chathamica } & $39.30(7,67)$ & shrub & fleshy fruit & Myrsine argentea & $8.7(a)$ \\
\hline & & & & Myrsine divaricata & $8.1(a)$ \\
\hline Corokia macrocarpa & $40.44(8,66)$ & shrub & fleshy fruit & Corokia cotoneaster & $18.01(3,16)$ \\
\hline Leptecophylla robusta & $18.63(6,49)$ & shrub & fleshy fruit & Leptecophylla juniperina & $5.93(6,46)$ \\
\hline Coprosma propinqua var. martinii & $13.93(8,84)$ & shrub & fleshy fruit & Coprosma propinqua var. propinqua & $11.75(1,30)$ \\
\hline Melicytus chathamicus & $20.43(7,118)$ & shrub & fleshy fruit & Melicytus aff. alpinus & $9.04(2,12)$ \\
\hline Coprosma acerosa & $9.87(5,58)$ & shrub & fleshy fruit & Coprosma acerosa & $3.26(1,30)$ \\
\hline Macropiper excelsum & $3.94(3,32)$ & shrub & fleshy fruit & Macropiper excelsum & $3.59(3,30)$ \\
\hline Apium prostratum subsp. denticulatum & $2.93(5,38)$ & herb & water & Apium prostratum subsp. prostratum & $4.05(3,30)$ \\
\hline Rhopalostylis aff. sapida & $175.83(3,24)$ & tree & fleshy fruit & Rhopalostylis sapida & $80.79(3,30)$ \\
\hline Muehlenbeckia australis & $9.10(3,35)$ & vine & fleshy fruit & Muehlenbeckia australis & $6.98(3,30)$ \\
\hline Tetragonia implexicoma & $28.85(2,24)$ & herb & fleshy fruit & Tetragonia implexicoma & $14.26(3,30)$ \\
\hline Coprosma chathamica & $38.76(a)$ & tree & fleshy fruit & Coprosma repens & 21.61 (a) \\
\hline Hebe dieffenbachii & 1.17 (a)† & shrub & wind & Hebe elliptica & $1.83(a) \dagger$ \\
\hline Pseudopanax chathamicus & 19.92 (a)† & tree & fleshy fruit & Pseudopanax crassifolius & $6.74(a) \dagger$ \\
\hline Pseudopanax kermadecensis & $12.03(a) \dagger$ & tree & fleshy fruit & Pseudopanax arboreus & 11.14 (a)† \\
\hline Alectryon excelsus subsp. grandis & $55.4(a) \dagger$ & tree & fleshy fruit & Alectryon excelsus & $45.52(a) \dagger$ \\
\hline Streblus smithii & 43.52 (a)† & tree & fleshy fruit & Streblus banksii & $26.96(a) \dagger$ \\
\hline Myoporum kermadecense & 31.57 (a)† & tree & fleshy fruit & Myoporum laetum & $35.52(a) \dagger$ \\
\hline Metrosideros kermadecensis & 11.44 (a)† & tree & wind & Metrosideros excelsa & 12.95 (a)† \\
\hline Macropiper melchior & $5.23(a) \dagger$ & shrub & fleshy fruit & Macropiper excelsum & $4.42(a) \dagger$ \\
\hline Ascarina lucida var. lanceolata & $1.6(a) \dagger$ & tree & fleshy fruit & Ascarina lucida var. lucida & $2.35(a) \dagger$ \\
\hline Coprosma acutifolia & 15.93 (a) & shrub & fleshy fruit & Coprosma tenuifolia & 17.39 (a) \\
\hline Stilbocarpa polaris & 4.27 (a)† & herb & fleshy fruit & Stilbocarpa lyalii & $5.03(a) \dagger$ \\
\hline Olearia lyallii & $38.63(a) \dagger$ & shrub & wind & Olearia colensoi & $21.88(a) \dagger$ \\
\hline Myosotis capitata & 2.87 (a) & herb & wind & Myosotis australis & 1.44 (a) \\
\hline Gentianella cerina & 0.51 (a)† & herb & wind & Gentianella saxosa & $0.89(a) \dagger$ \\
\hline \multirow[t]{3}{*}{ Leptinella plumosa } & $3.57(a) \dagger$ & herb & wind & Leptinella nana & $0.73(a) \dagger$ \\
\hline & & & & Leptinella minor & $1.07(a) \dagger$ \\
\hline & & & & Leptinella filiformis & $0.73(a) \dagger$ \\
\hline \multirow[t]{3}{*}{ Leptinella lanata } & $3.4(a) \dagger$ & herb & wind & Leptinella nana & 0.73 (a)† \\
\hline & & & & Leptinella minor & $1.07(a) \dagger$ \\
\hline & & & & Leptinella filiformis & $0.73(a) \dagger$ \\
\hline Abrotanella rosulata & $2.08(a) \dagger$ & herb & wind & Abrotanella rostrata & $4.27(a) \dagger$ \\
\hline Abrotanella spathulata & $2.78(a) \dagger$ & herb & wind & Abrotanella rostrata & 4.27 (a)† \\
\hline Pennantia baylisiana & 43.52 (a)† & tree & fleshy fruit & Pennantia corymbosa & $23.93(a) \dagger$ \\
\hline Embergeria grandifolia & 17.32 (a)† & herb & wind & Kirkianella novae-zelandiae & $12.64(a) \dagger$ \\
\hline Hebe chathamica & $1.54(h)$ & shrub & wind & Hebe elliptica & 1.74 (a) \\
\hline Hebe barkeri & $1.86(h)$ & tree & wind & Hebe elliptica & 1.74 (a) \\
\hline Leptinella featherstonii & $1.27(a) \dagger$ & herb & wind & Leptinella serrulata & $1.48(a) \dagger$ \\
\hline Geranium traversii & $5.23(a) \dagger$ & herb & wind & Geranium brevicaule & $3.08(a) \dagger$ \\
\hline Brachyglottis huntii & $5.23(a) \dagger$ & tree & wind & Brachyglottis stewartiae & 7.92 (a)† \\
\hline
\end{tabular}




\section{Results}

Field measurements scaled positively with those contained in the seed atlas (OLS regression: $R^{2}=0.912 ; p<0.001$ ). Slope and intercept parameters were not significantly different from one and zero respectively (Slope: $0.971,95 \%$ confidence interval $=0.811-1.131, p=0.698$; Intercept: $-0.054,95 \%$ confidence interval $=-0.373-0.266, p=0.721$ ), indicating that published seed sizes accurately reflect field measurements. OLS regression showed seed lengths scaled strongly with seed surface area $\left(R^{2}=0.928 ; p<0.001\right.$, see figure 2.2). Seed area estimates calculated using the regression equation did not differ significantly from observed values $\left(F_{1,70}=0.086, p=0.770\right)$, indicating that estimates accurately reflected real seed sizes.

Figure 2.2 Relationship between seed length $(\mathrm{mm})$ and seed surface area (length and width, $\mathrm{mm}^{2}$ ) for 36 taxa. Solid line is the result of OLS regression analysis. Open circles are observed values; closed circles are predicted values (based on regression parameters). Data are natural logarithm transformed.

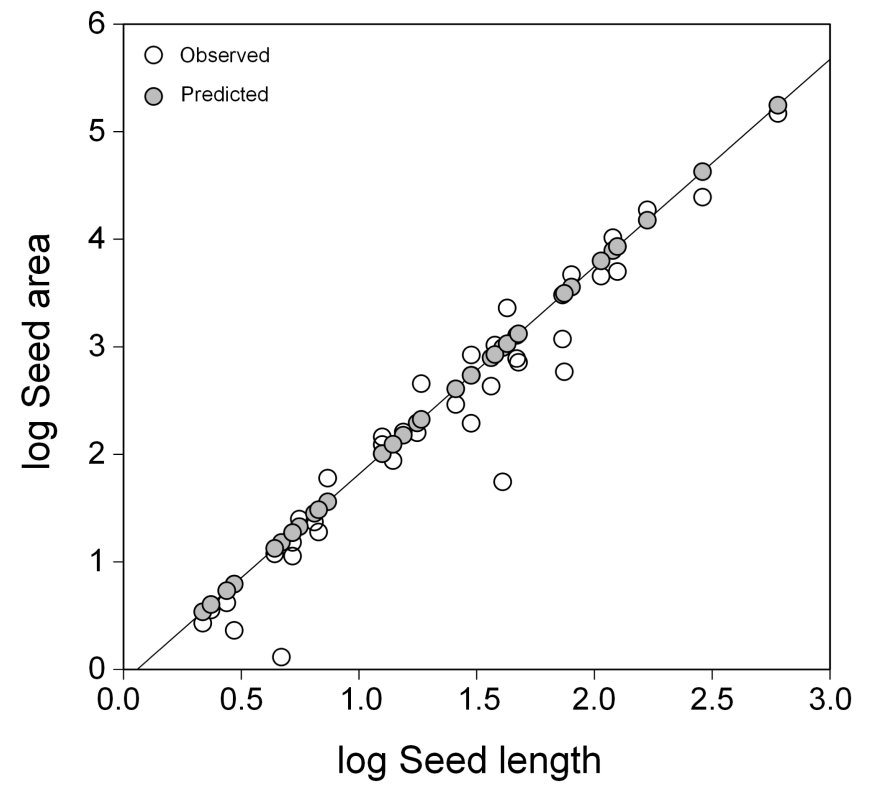

Island seed sizes scaled positively with mainland seed sizes (RMA analysis: $\mathrm{R}^{2}=0.854, p<0.001$, see figure 2.3). However, the island-mainland seed size relationship had a slope greater than one $(1.18 ; 95 \%$ confidence interval $=1.041-1.338)$ and an intercept marginally less than zero $(-0.021$; $95 \%$ confidence interval $=-0.166-0.123)$. This indicates a tendency for insular taxa to produce larger seeds than mainland relatives, particularly at the larger end of the seed size spectrum. 
Figure $\quad 2.3 \quad$ Relationship between island and mainland seed size. Each point represents a taxonomic pairing between an insular taxon and its corresponding mainland relative. Circles represent trees, squares are shrubs, and triangles are herbs. Closed symbols indicate fleshy-fruited taxa and open symbols dry-fruited. The dashed line represents isometry and the solid line is the result of RMA regression ( $\mathrm{y}=1.180 \mathrm{x}-0.021)$. Both axes are logarithm transformed.

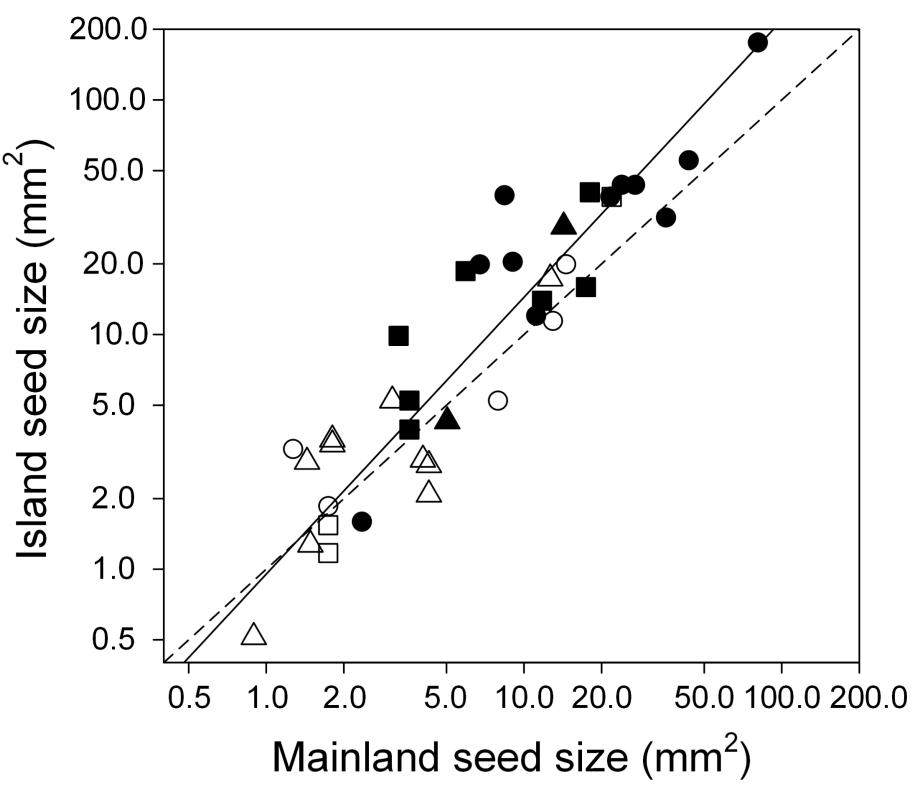

The likelihood ratio test from the mixed effects model showed no significant effect of plant growth form on the island to mainland seed size relationship $\left(\chi^{2}=7.32\right.$, d.f $\left.=4, p=0.120\right)$. However, there was a significant effect of dispersal mode $\left(\chi^{2}=14.328\right.$, d. $\left.f=2, p<0.001\right)$. Seed sizes did differ significantly by location (island or mainland) $\left(\chi^{2}=12.562\right.$, d.f. $\left.=1, p<0.001\right)$, consistent with results of the RMA analysis, and all dispersal modes and growth forms displayed a tendency for larger seed sizes on islands (see figure 2.4 a \& b). 

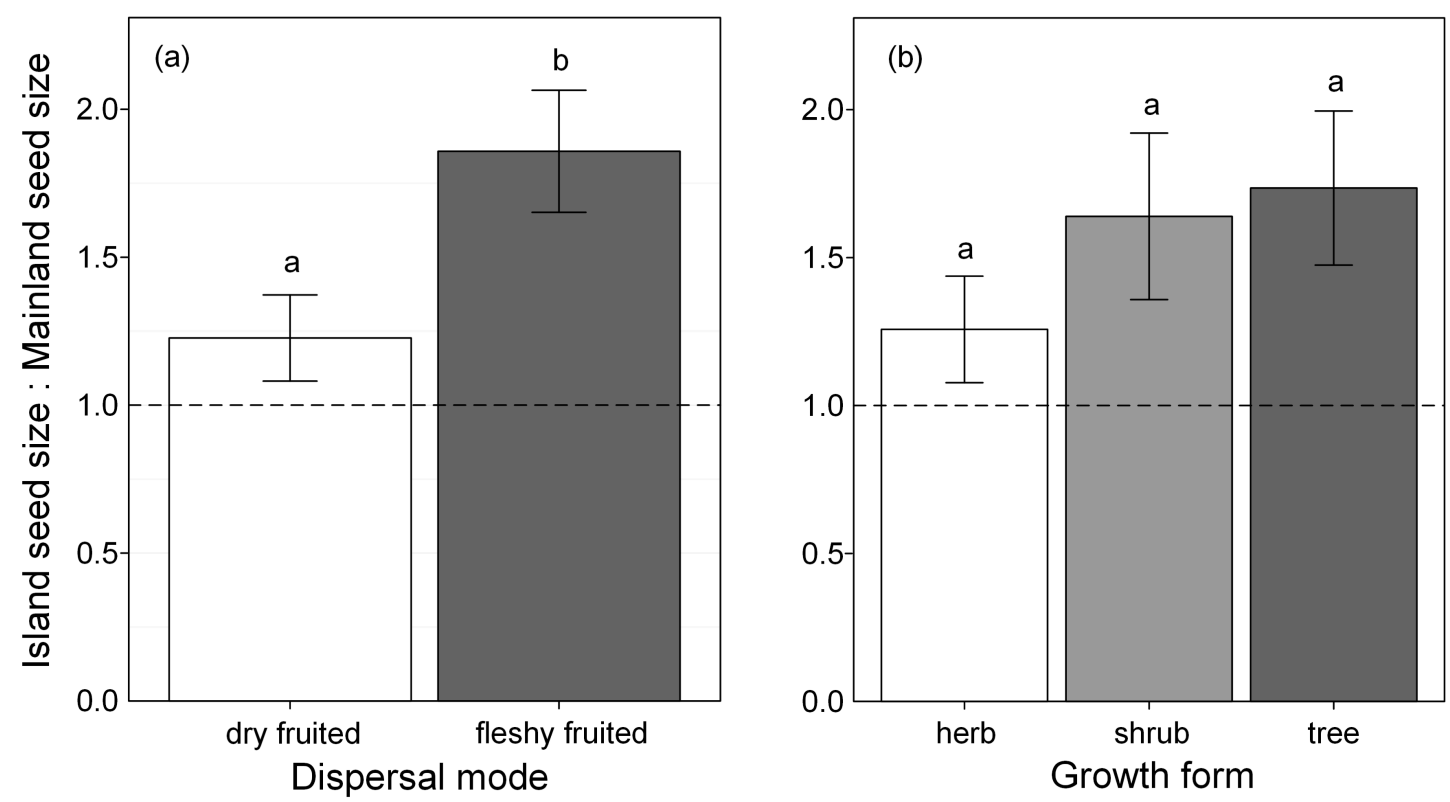

Figure 2.4 Average island seed size to mainland seed size $\left(\mathrm{mm}^{2}\right)$ ratio by (a) dispersal mode and (b) growth form. The dashed horizontal line represents equal island and mainland seed size (ratio $=1$; ratio $>1$ indicates larger seeds on islands, ratio $<1$ indicates larger mainland seeds). Error bars are standard error. Letters indicate whether average island to mainland seed size ratios are different between dispersal modes and growth forms (Kruskal-Wallis test: (a) $\chi^{2}=5.61$, d.f $=1, p=0.018$; (b) $\chi^{2}=2.28$, d.f $=2, p=0.321$ ).

\section{Discussion}

Seeds of insular taxa were consistently larger than those of their mainland relatives. Furthermore, this result was consistent regardless of dispersal mode and growth form. Increasing seed size reduces dispersibility in anemochorous species, as large seeds are likely to disperse over shorter distances than small seeds (Harper et al., 1970; Augspurger, 1986; Greene \& Johnson, 1993; Benkman, 1995; Cody \& Overton, 1996). In the case of fleshy-fruited plants, this is the first time an increase in seed size on islands has been demonstrated quantitatively. Larger seeds in fleshy-fruits may limit the range of dispersal vectors available to a plant as well as reducing the number of fruits eaten during a feeding period (Wheelwright, 1985; Levey, 1987). Furthermore, seed number scales negatively with seed size (Niklas, 1994; Henery \& Westoby, 2001) and producing fewer seeds reduces the likelihood of long distance dispersal (Nathan, 2006). 
RMA regression of island seed size against mainland seed size produced a scaling relationship that differed from isometry. In particular, a slope parameter greater than one suggests the size of insular seeds increases disproportionately with increasing seed size. The majority of small seeded taxa in the dataset rely on wind dispersal while species with larger seeds generally produced fleshy fruits. Anemochorous species may experience stronger constraints on maximum seed size due to the aerodynamics of wind dispersal (Greene \& Johnson, 1993). While in fleshy fruited species (and zoochorous species in general) seed size may be less tightly constrained, allowing greater size increases without impeding the probability of successful dispersal. Birds often display size increases on islands and size coupling between fruits and frugivores is common (Clegg \& Owens, 2002; Burns, 2013). Therefore, putative selection pressures for increased seed size may be less constrained in fleshyfruited taxa. Analysis of dispersal mode reflected this, as fleshy-fruited taxa showed greater size increases on islands than dry-fruited taxa. However, dryfruited taxa still displayed a tendency for larger seeds on islands. Furthermore, patterns in seed size persisted even after accounting for differences in taxonomic distance and phylogeny between island-mainland pairings, suggesting selection for increased in seed size is strong on islands (see Cody \& Overton, 1996).

Work on animals suggests the depauperate nature of island communities may increase intraspecific competition and promote insular size changes (Grant, 1965; Case, 1978; Lomolino, 2005). This situation may also apply to plants. Larger seed sizes may promote a competitive advantage due to the increased nutrient reserves, which produce larger, more competitive seedlings (Leishman et al., 1995; Moles \& Westoby, 2004). Evidence also suggests that larger seed sizes increase plant survival at later life stages (e.g. sapling stage Moles \& Westoby, 2004).

Selection early in ontogeny may also influence size patterns evident at later life stages. In animals, adult body size is strongly influenced by size at birth and a recent investigation suggests body size patterns on islands may reflect selection acting on birth size (Aubret, 2012). A parallel situation may be 
occurring in plants. The probability of seedling establishment increases with seed size (Moles \& Westoby, 2004). Seed size is strongly correlated with traits evident later in ontogeny, such as plant height and stem size (Corner, 1949; Leishman et al., 1995; Moles \& Westoby, 2004). Many herbaceous lineages develop woodiness on islands and recent research suggests an increase in leaf size is common (Carlquist, 1974; Burns et al., 2012). As a result, it could be that selection first acting on seeds may facilitate evolutionary changes at later life history stages.

My results suggest that selection favours increased seed size on islands, regardless of dispersal mode, growth form and evolutionary history. Several processes may explain this macroevolutionary trend. First, increasing seed size may reduce propagule mortality associated with unfavourable dispersal into the ocean (see Darwin, 1859; Carlquist, 1974). Second, it may provide competitive advantages post-dispersal and increase the likelihood of establishment. The sizes of plant traits are also known to scale allometrically with one another (Niklas, 1994), so selection acting on seeds may facilitate size changes in other traits and this deserves further attention. Direct investigations of potential processes are now needed, in addition to global analyses of seed size to establish whether the observed pattern is universal. 


\section{Chapter 3 - Sexual size dimorphism in island plants: the niche variation hypothesis and insular size changes}

Publication: Kavanagh P.H. \& Burns K.C. (2015) Sexual size dimorphism in island plants: the niche variation hypothesis and insular size changes. Oikos, 124, 717-723, doi: 10.1111/oik.01753 


\section{Abstract}

The niche variation hypothesis predicts insular populations exhibit increased sexual size dimorphism (SSD), to minimize intraspecific competition. Although many animal taxa conform to this prediction, insular patterns of SSD have yet to be investigated in plants. Here, I tested for differences in SSD of dioecious plants that colonised four island groups (Kermadec, Three Kings, Chatham, and Auckland Islands) from New Zealand. Using herbarium collections, I quantified leaf and stem sizes of 263 individuals from 28 dioecious taxa. I developed a novel analytical technique to explore changes in the direction of SSD on islands. Lastly, I tested for evolutionary size changes of male and female plants on islands. The degree of SSD did not vary predictably between insular and mainland taxa, contrary to predictions of the niche variation hypothesis. Furthermore, the direction of SSD was not predictable on islands, while it was consistently female biased on the mainland. Our results suggest that selection favours increased size of both sexes on islands and that SSD is unpredictable for insular plants. 


\section{Introduction}

Sexual size dimorphism (SSD) is common in birds (Santiago-Alarcon \& Parker, 2007; Székely, 2007), insects (Stillwell et al., 2010), reptiles (Wikelski \& Trillmich, 1997; Pearson et al., 2002), and mammals (Dayan \& Simberloff, 1998; Lindenfors, 2007). Morphological differences between the sexes are often striking and become more pronounced on islands (Ebenman \& Nilsson, 1982; Dayan et al., 1989; Dayan \& Simberloff, 1998; Pearson et al., 2002). SSD is also common in many species of dioecious plants (separate male and female individuals, Bond \& Midgley, 1988; Obeso, 2002; Kavanagh et al., 2011; Barrett \& Hough, 2013). Islands typically house high numbers of dioecious taxa and insularity is known to promote distinct evolutionary changes in island plant populations (Carlquist, 1966, 1974; Bawa, 1980, 1982; Baker \& Cox, 1984; Thomson \& Brunet, 1990). However, insular patterns of SSD associated with dioecy remain unknown.

The niche variation hypothesis predicts that morphological variability scales positively with niche breadth (Van Valen, 1965). A further prediction under this hypothesis is that morphological variability increases on islands (see Meiri et al., 2005). Insular populations face fewer competing species and increasing morphological variability may facilitate occupation of available niche space (as advocated to explain size changes of insular animals, Grant, 1965; Lomolino, 2005). SSD is a major component of morphological variability within a population and is also predicted to increase on islands (Ebenman \& Nilsson, 1982; Meiri et al., 2005). Additionally, SSD may increase in response to elevated levels of intraspecific competition (Rothstein, 1973; Shine, 1989). The prediction of increased SSD on islands is supported in studies of birds (Ebenman \& Nilsson, 1982), mammals (Dayan \& Simberloff, 1998; Simberloff et al., 2000) and snakes (Pearson et al., 2002). Alternatively, SSD may become less pronounced on islands, contrary to predictions of the niche variation hypothesis. This may result from reduced habitat diversity, resource abundance, gene flow, or taxon cycle fluctuations (see Ricklefs \& Bermingham, 2002; Meiri et al., 2005). 
The niche variation hypothesis makes specific predictions regarding morphological variation associated with niche breadth. Therefore, tests for increased SSD on islands should consider traits that are related to niche occupation (e.g canine size in carnivores, Meiri et al., 2005). In plants, leaf size is a suitable trait as it is correlated with climatic conditions and competitive ability (Parkhurs \& Loucks, 1972; Grime et al., 1997; Diaz et al., 1998; Moles \& Westoby, 2000; Westoby et al., 2002; Thuiller et al., 2004; Ackerly \& Cornwell, 2007). SSD in leaf size is also common in many unrelated groups of dioecious plants (Bond \& Midgley, 1988; Kavanagh et al., 2011; Barrett \& Hough, 2013). Investigating SSD of stem diameter ('stem size' hereafter) may also be informative. Leaf and stem sizes are often related allometrically (Corner, 1949; Niklas, 1994) and differences in SSD between leaves and stems may help elucidate the action of selection.

Here, I provide the first test for differences in SSD between related island and mainland plants. I measured leaf and stem sizes of 28 dioecious taxa, comprising 14 island-mainland comparisons, from four island groups (Kermadec, Three Kings, Chatham, and Auckland Islands) surrounding New Zealand. First, I tested for an increase in the degree of SSD on islands, as predicted by the niche variation hypothesis. Second, I developed a novel analytical technique to test for differences in the direction of SSD (female or male biased) between related mainland and insular plants. Lastly, I tested for sex specific size changes of plants on islands as differences between the sexes may provide insight into patterns of insular SSD. 


\section{Methods}

The three main islands of New Zealand (North, South and Stewart Islands) are encircled by numerous smaller islands, that vary in age (Gibbs, 2006). The flora of these offshore islands consists mainly of taxa that have dispersed overwater from New Zealand (Wardle, 1991). Although many of these islands were once connected by land bridges, I focused on the Kermadec, Three Kings, Chatham and Auckland islands, as they remained isolated from the main islands during the Pleistocene (see Appendix A1). Specifically, populations from Raoul Island (Kermadec group), Great Island (Three Kings group), Chatham Island (Chatham group), and Auckland Island (Auckland group) were included (see figure 3.1).

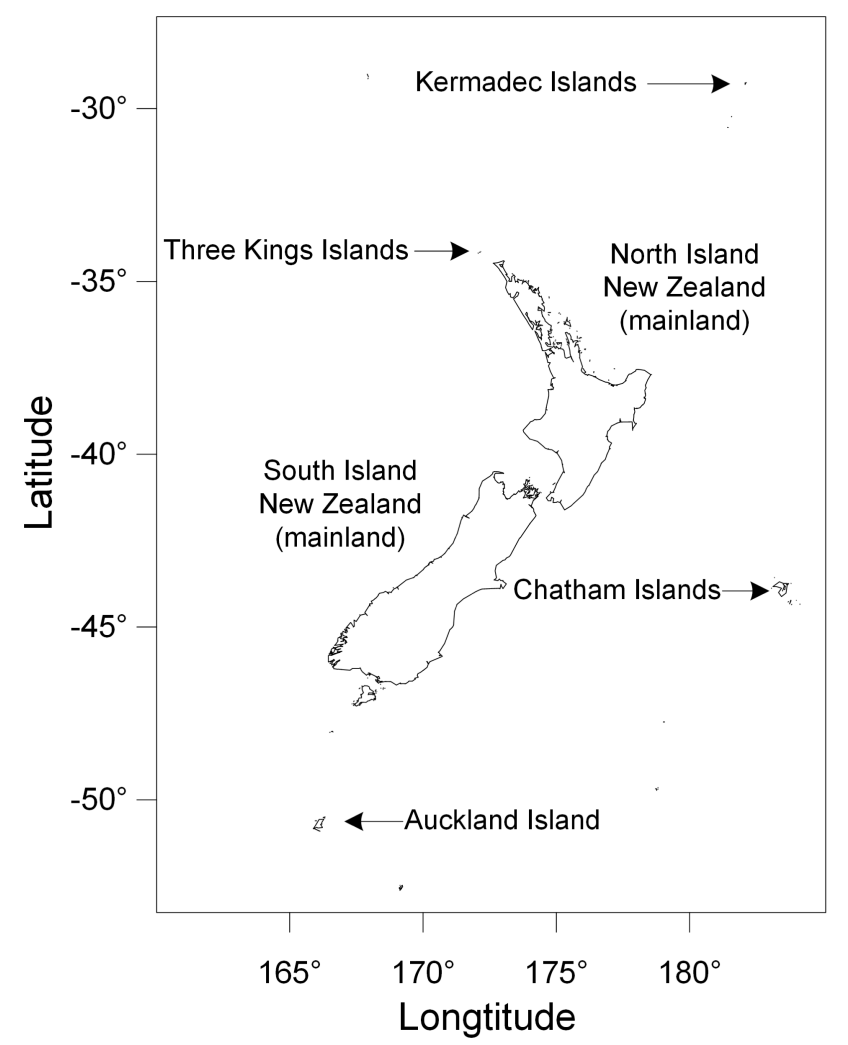

Figure 3.1 Map of study islands surrounding New Zealand 
To characterize SSD in insular and mainland plants, I used herbarium material. This allowed efficient collection of a diverse dataset. Material was examined from the national herbarium at Te Papa Tongarewa (the National Museum of New Zealand), the herbarium at Auckland Museum and the Allan Herbarium at Landcare Research. Analysis was restricted to dioecious woody taxa in an effort to mitigate any effect drying may have on stem measurements. I sampled insular taxa with conspecific mainland populations and island endemics with known mainland relatives. This allowed for a broad scale test incorporating the greatest number of island-mainland comparisons possible. I ascertained mainland relatives for Chatham Island species using the recent molecular analysis by Heenan et al. (2010). In this study, DNA sequence data were used to identify the closest relatives for 35 taxa endemic to the Chatham Islands. In other cases, phylogenetic analyses were not available to help determine insular and mainland relatives. Two pairings were separated at species but not genus level. In these cases, the mainland taxon chosen is the most likely relative based on morphological similarities (Piper melchior and $P$. excelsum; Coprosma acutifolia and C. tenuifolia - see Dawson \& Lucas, 2011). In all other instances, the insular taxa were a variety or subspecies of wellknown mainland species (Allan, 1961). When collating mainland data, I only included specimens collected from mainland areas as close as possible to the island in question in an effort to minimise any effect of environmental differences associated with latitude. The dataset consisted of 263 specimens, representing 14 island-mainland taxonomic pairings (see Table 3.1).

Due to the modularity of plant structure, a single parameter is difficult to obtain when quantifying plant size. Additionally, when testing predictions of the niche variation hypothesis it is important to consider traits that are related to niche occupation. I chose to use the size of leaves and stems (diameter) as these measures are easily obtained from herbarium sheets, leaf size is correlated with climatic conditions and competitive ability, and SSD in leaf size is common (Corner, 1949; White, 1983; Bond \& Midgley, 1988; Midgley \& Bond, 1989; Grime et al., 1997; Diaz et al., 1998; Thuiller et al., 2004; Ackerly \& Cornwell, 2007; Kavanagh et al., 2011). Stems must support the weight of 
leaves, so leaf and stem sizes are likely to be associated allometrically (Corner, 1949; Niklas, 1994). Stems must also support flowers, fruits and dispersers. Investigating differences in SSD between leaves and stems may provide insight into the processes responsible for observed patterns. As destructive sampling (i.e. removal of leaves) would restrict the use of specimens in the future, digital vernier callipers were used when making measurements (accurate to $0.01 \mathrm{~mm}$ ). Leaf size was estimated by quantifying leaf length (linear distance between leaf tip and base of petiole) and leaf width (maximum distance perpendicular to length measurement at widest point of leaf) on four randomly selected, fully expanded, leaves per specimen. The area of an ellipsoid $(A=\pi \times L / 2 \times W / 2)$ was then used to approximate leaf area. Differences in leaf shape between study taxa may complicate the use of certain leaf area estimation techniques. However, all island-mainland comparisons are made between closely related taxa making any difference in shape minimal (see analyses described below). Stem diameters were measured $10 \mathrm{~mm}$ towards the base of the specimen from the point of petiole attachment of the second and fourth randomly selected leaves. Leaf and stem measurements were then averaged within each specimen prior to analyses.

Due to the nature of herbarium collections, species were represented by a variable number of specimens. Collections for dioecious plants also contain a variable number of specimens for each sex. At least five specimens of each sex were measured (see Cornelissen et al., 2003), where possible, for all study $\operatorname{taxa}($ mean $\pm \mathrm{SE}=4.7 \pm 0.125)$. The use of herbarium specimens allowed a diverse dataset to be utilised, however environmental effects are difficult to discount. Analyses were conducted that accounted for individual variation within taxa to minimise any effect of differences in sampling technique and environmental conditions between individual herbarium specimens (see analyses described below). Although all major herbaria in New Zealand were visited, sample sizes for males within a few study taxa were not ideal. In order to assess the significance of this, I ran Levene tests for homogeneity of variance between male and female data for each study taxa individually. There was no significant difference in variance between male and female leaf size 
data for any study taxa. Three taxa displayed unequal variance between male and female stem size data. In all three cases only two specimens represented males. Therefore, I ran all analyses a second time, only including taxa with at least three samples or more for each sex.

SSD can be quantified many different ways. A common technique is to calculate the ratio of male size to female size (e.g. Delph et al., 1996; Wikelski \& Trillmich, 1997; Meiri et al., 2005). However the analysis of SSD ratios can be problematic, particularly when a dataset displays both male and female biased SSD. Therefore, I followed the recommendations of Smith (1999) and quantified SSD as the ratio of the larger sex to that of the smaller sex. Ratios were then subtracted from one to provide an index of the degree of SSD (Lovich \& Gibbons, 1992; Fairbairn \& Shine, 1993; Smith, 1999; Santiago-Alarcon \& Parker, 2007). Mean values for female and male traits could be used, however, the use of mean values may be problematic. As SSD may arise from differences in maturation rates between the sexes, incorporating individual variation may be important (the use of mean values per sex would not account for this). Therefore, I implemented a bootstrapping procedure, which randomly selected one individual of each sex when calculating ratios. After 10,000 iterations mean ratios for each of our study taxa were calculated. Differences in SSD between mainland and insular pairings were tested for with the Wilcoxon matched pairs test. Phylogenetic relatedness between pairs in our dataset makes a phylogenetic correction method appropriate (Felsenstein, 1985). However, a lack of phylogenetic hypotheses for our study taxa precluded the use of such techniques. Eight of the insular-mainland pairings in our dataset were from the genus Coprosma. I chose to analyse these taxa alone, as well as the pooled dataset, to test for any effect this may have on overall results. 


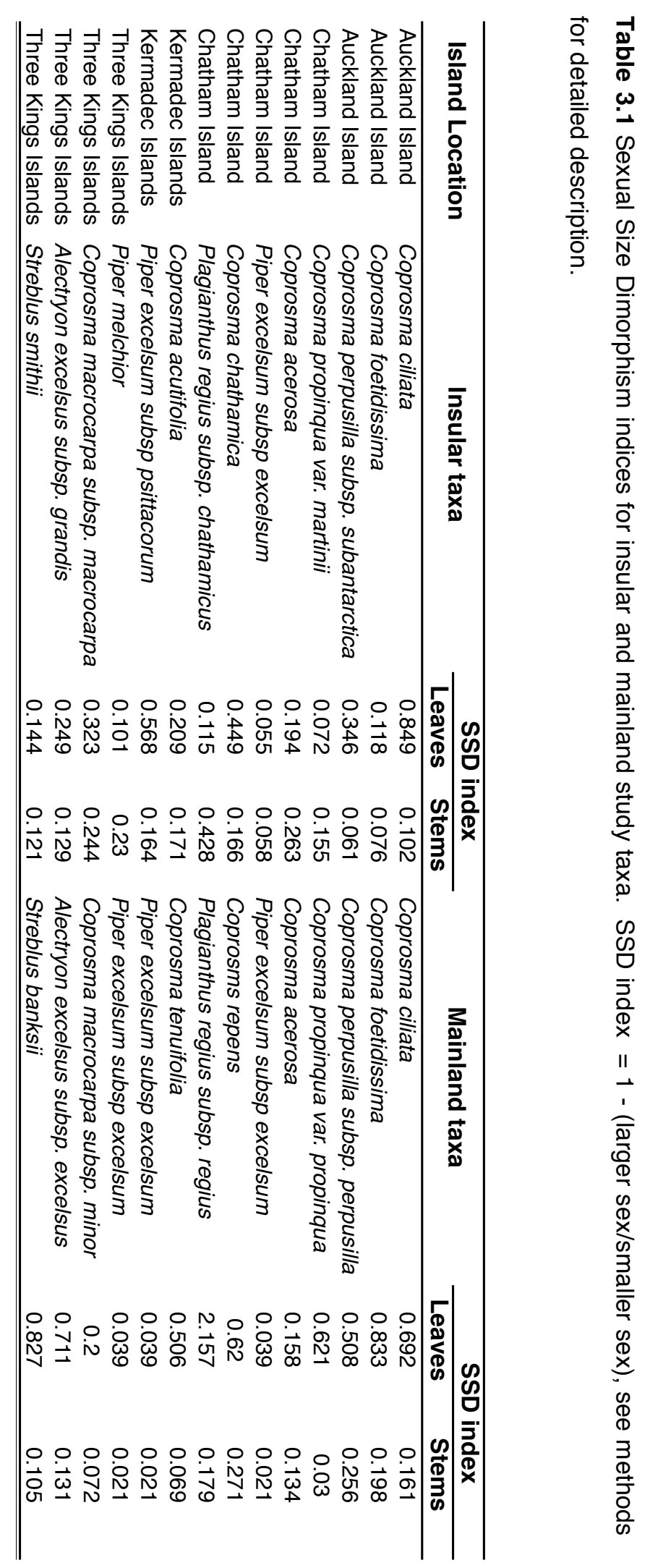


While the analyses described above test for differences in the degree of SSD between mainland and island pairings, changes in which sex is larger (direction of SSD) are not accounted for. I implement a novel analytical technique to identify the direction of SSD for related insular and mainland taxa (Fig. 2). The angle, $a$, of a line connecting male and female points can take any value in the range $0-360^{\circ}$ and describes which sex is larger in island and mainland settings. For example, angles less than 90 degrees indicate that SSD is female biased for both mainland and insular taxa (females have larger size on mainland (x-axis) and on island (y-axis) - see Fig 3.2). While angles between 90 and 180 degrees indicate male biased SSD on islands and female biased SSD on the mainland (male point higher than female on y-axis, female point higher than male on $\mathrm{x}$-axis). After calculating angles connecting male and female points (14 male-female pairings) for both leaves and stems, I conducted Rayleigh's test of uniformity to test whether the distribution of angles was nonrandom. I then calculated the circular mean and von Mises bootstrapped 95\% confidence intervals.

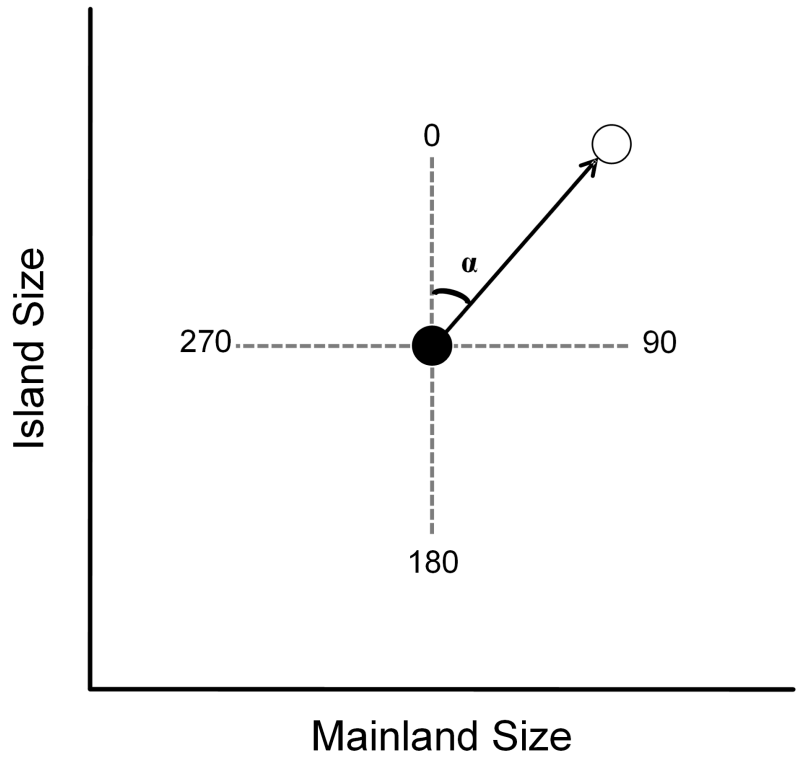

Figure 3.2 Diagrammatical representation of insular and mainland SSD. The closed circle represents males and open circle females, for a hypothetical species. The angle of the line between male and female points, a, describes which sex is larger in mainland and island situations. 
Lastly, I ran reduced major axis regression (RMA) of island size (leaves and stems) against mainland size, separately for males and then females. Differences in environmental conditions between specimens may influence leaf size and variation in stem age between specimens may influence stem diameter. Therefore, a bootstrapping procedure was implemented to account for among individual variation. One male and female individual were randomly selected from each taxon and then RMA used to calculate slope and intercept parameters. After 10,000 iterations, mean slope and intercept parameters were calculated. Data were logarithmically transformed prior to analysis to conform to normality assumptions. Incorporating this analysis allowed for differences in mainland-to-island size change between the sexes to be detected. All analyses were carried out in the $\mathrm{R}$ environment for statistical computing and circular statistics were calculated using the R packages Circular and CircStats (Lund \& Agostinelli, 2009; Agostinelli \& Lund, 2011; R-Development-Core-Team, 2011). RMA analyses were conducted using the package smatr (Warton et al., 2012b). 


\section{Results}

There was no consistent difference in degree of SSD of leaves between island and mainland pairings (Figure 3.3A). Wilcoxon matched pairs test showed there to be no significant difference in SSD of leaves between islands and mainland for either the pooled dataset or Coprosma taxa (W = 80, $P=0.0906$; Coprosma, $\mathrm{W}=30, P=0.1094)$. Similarly, degree of SSD of stems displayed no discernable pattern when insular and mainland pairs were compared (Figure 3.3B). Wilcoxon matched pairs test showed there to be no significant difference in SSD of stems between islands and mainland ( $\mathrm{W}=30, P=0.1726$; Coprosma, $\mathrm{W}=16, P=0.8438$ ).

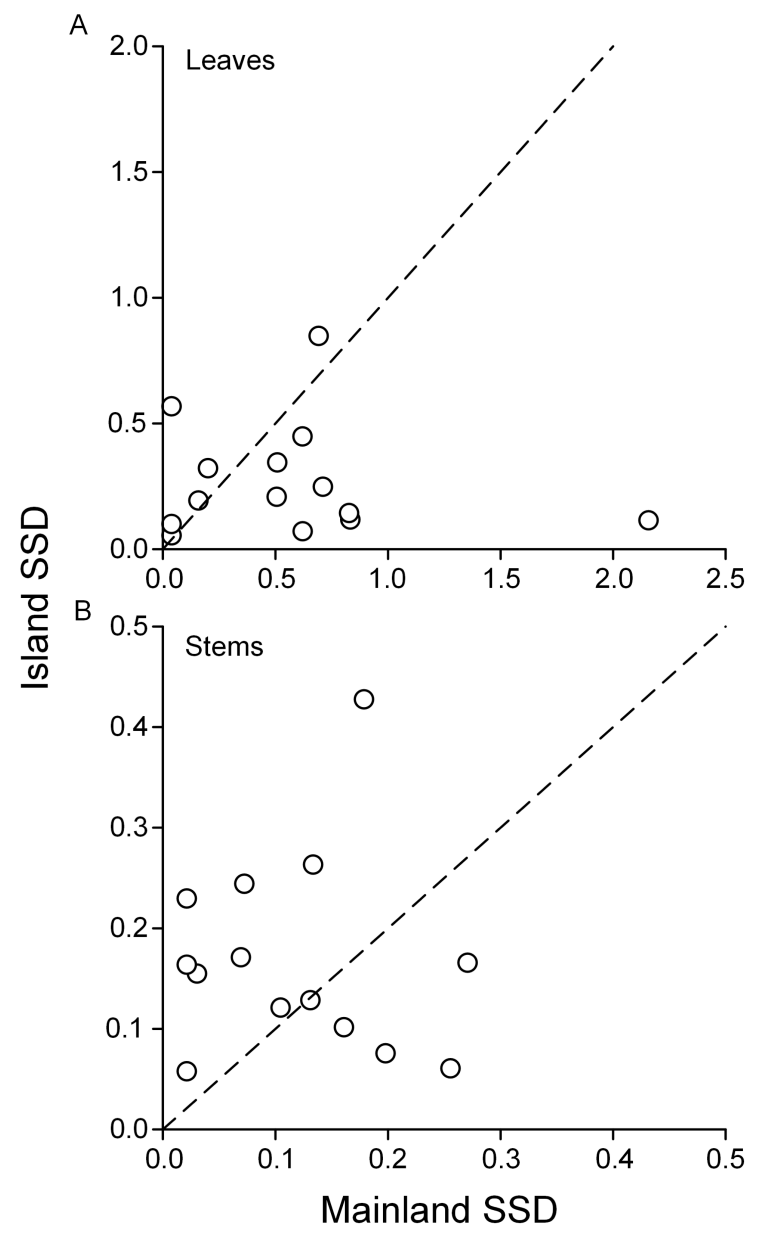

Figure 3.3 Relationship between degree of SSD in leaf (A) and stem size (B) of insular taxa and their corresponding mainland relative. SSD $=1$ - (larger sex/ smaller sex). The dotted line represents isometry (points above the line indicate greater degree of SSD on islands; points below the line indicate greater degree of SSD on the mainland). 
Results of Rayleigh's test of Uniformity indicated lines joining male and female points did cluster about a mean direction, for both leaf and stem analyses (leaves, $P=0.0037$; stems, $P=0.011$; see Figure $3.2 \& 3.4$ ). The confidence interval of the mean direction for leaves encompasses $90^{\circ}$, suggesting SSD in leaf size is not consistently female or male biased on islands $($ mean $=86.178 ; 95 \% \mathrm{Cl}=56.568-113.840)$. However, it suggests female leaves are consistently larger for mainland taxa as angles higher than $180^{\circ}$ are outside of the $95 \%$ confidence interval (see Figure 3.4A). Analysis of stem size data produced analogous results. SSD in stem sizes was not consistently male or female biased on islands ( mean $=63.492 ; 95 \% \mathrm{Cl}=35.917-110.293$ ). However, as values above $180^{\circ}$ are not contained within the confidence interval, this suggests female stem size is consistently larger than male stem size on the mainland (Figure 3.4B).

Figure 3.4 The direction of SSD for insular and mainland leaf (A) and stem size (B). Arrows represent lines between male and female points, the angle of the line indicating the direction of SSD for related mainland and insular taxa (see Figure 1). Rose diagrams display the frequency distribution of line angles.

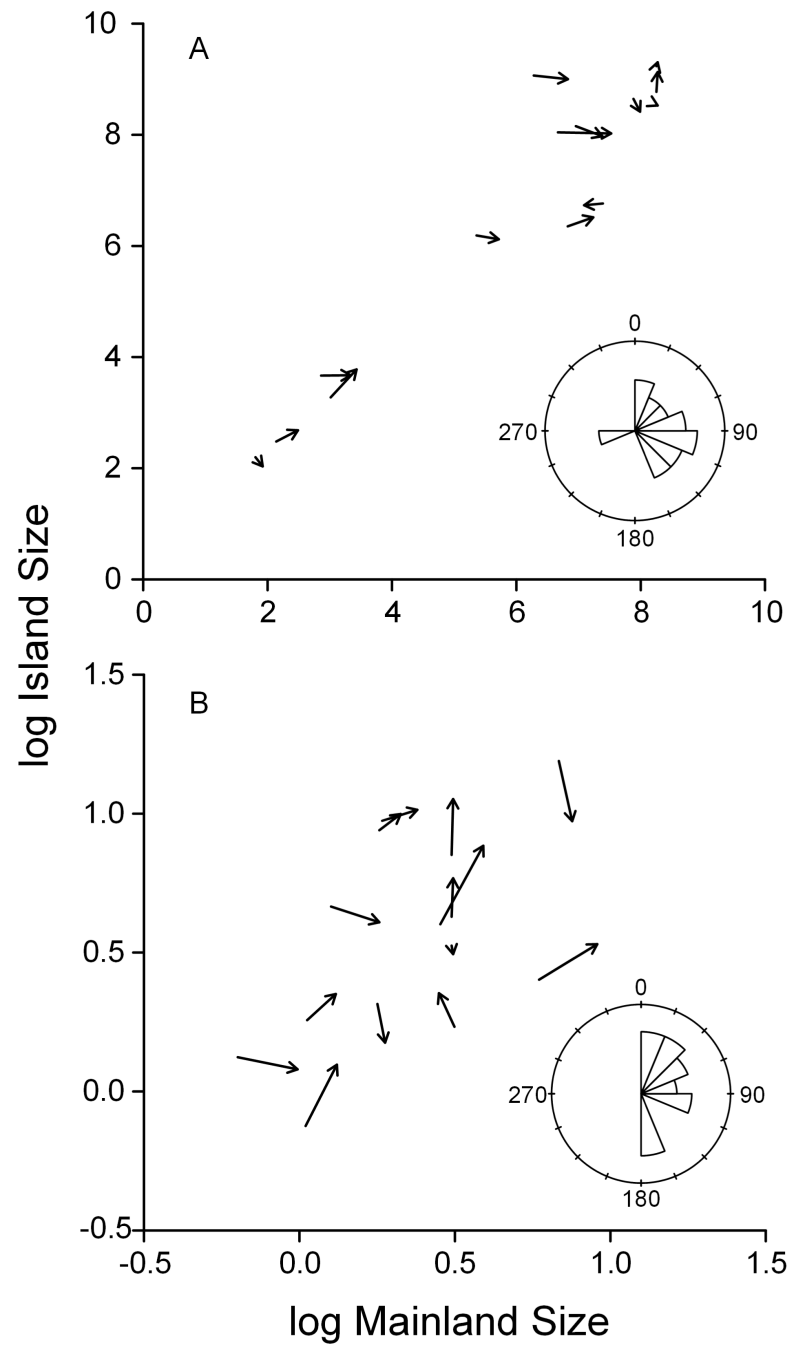


Male and female leaf sizes were consistently larger on islands. The slope of the RMA analysis was greater than one and the majority of points fall above the line of isometry (see Table 3.2 \& Figure 3.5A). However, the intercept for female values is slightly below zero, while the intercept for male values is marginally greater than zero. Stem sizes were also larger on islands for both males and females, with slope parameters greater than one for both sexes (see Table 3.2 \& Figure 3.5B).

Analyses only including taxa with at least three or more specimens for each sex produced identical results (see Appendix A2).

Figure 3.5 Relationship between leaf (A) and stem size (B) of 14 islandmainland comparisons. Males are represented by closed circles, females by open circles. The dotted line represents isometry (points above the line of isometry indicate larger size on islands; points below the line indicate larger mainland size). Solid lines are result of RMA regression, black lines represent males and grey lines represent females (see Table 3.3).

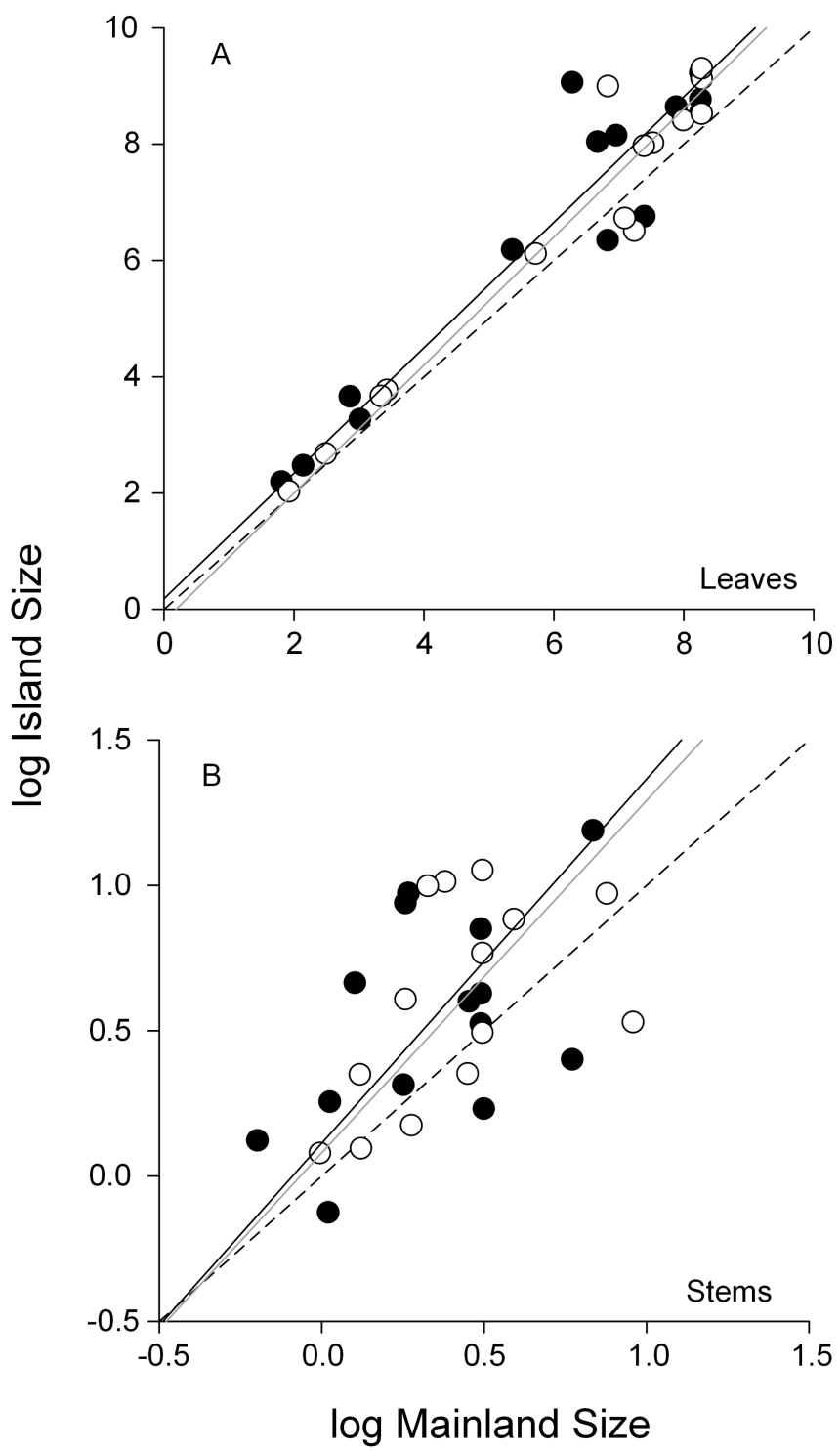


Table 3.3 Results from RMA analyses of insular and mainland leaf and stem sizes. Slope and intercept parameters are given for male and female individuals.

\begin{tabular}{llll}
\hline & & Slope & Intercept \\
\cline { 3 - 4 } Trait & Sex & Mean value \pm SD $(95 \% \mathrm{Cl})$ & Mean value $\pm \mathrm{SD}(95 \% \mathrm{Cl})$ \\
\hline Leaves & & \\
& Female & $1.101 \pm 0.046(1.100-1.102)$ & $-0.203 \pm 0.303(-0.209$ to -0.197$)$ \\
& Male & $1.079 \pm 0.045(1.079-1.080)$ & $0.184 \pm 0.278(0.178-0.189)$ \\
Stems & & & $0.080 \pm 0.186(0.077-0.084)$ \\
& Female & $1.212 \pm 0.416(1.204-1.220)$ & $0.113 \pm 0.133(0.110-0.0115)$ \\
& Male & $1.253 \pm 0.315(1.246-1.259)$ & \\
\hline \hline
\end{tabular}

\section{Discussion}

SSD did not vary predictably between islands and the mainland. This is inconsistent with predictions of the niche variation hypothesis, suggesting it does not apply to dioecious plants. However, SSD was consistently femalebiased on the mainland. Female plants often outcompete males and leaf size scales positively with competitive ability (Thuiller et al., 2004; Sanchez-Vilas et al., 2011; Barrett \& Hough, 2013). Selection may also favour larger stems in females in order to support the weight of seeds and structures that aid the seed dispersal process (Kavanagh et al., 2011). This may promote SSD in leaf size due to allometry between leaves, stems and accessory structures (Corner, 1949). Alternatively, selection for differences in plant architecture between the sexes may promote efficient pollen capture and dispersal (see Midgley, 2010).

Both the direction and the degree of SSD were not predictable for insular plants. Environmental differences between islands may be important, as many plant traits vary predictably along environmental gradients (Diaz et al., 1998). Environmental variables scale strongly with latitude (Clarke \& Gaston, 2006; Kreft \& Jetz, 2007), however a recent test found consistent size increases of plants on islands separated by more than $20^{\circ}$ latitude (see Burns et al., 2012). Similarly, my results displayed consistent increases in the size of both sexes, 
across all islands. Experiments on Drosophila suggest changes in SSD are not predictable when both sexes are under selection for increased size simultaneously (Reeve \& Fairbairn, 1996). This may also apply to dioecious plants.

In dioecious species, reproductive costs are higher for females than males (Bazzaz et al., 1987). For example, males may allocate 10-15\% of resources to reproduction while this figure can reach $40 \%$ in females (Wallace \& Rundel, 1979). Differences in growth rates between the sexes have also been linked to reproductive costs (Jing \& Coley, 1990). While both sexes illustrated a tendency for larger leaves on islands, this was not as strong in females (intercept parameter less than zero). Differences in reproductive expenditure may result in male individuals having more resources available for vegetative growth. Therefore, selection acting to increase leaf size on islands may be slightly more constrained in females, leading to unpredictable patterns of SSD.

A recent test for size changes of insular plants in the south-west Pacific suggested that selection might be acting specifically on leaf size (Burns et al., 2012; but see Kavanagh \& Burns, 2014). This is consistent with my results and increasing leaf size may have important consequences for insular flora. For example, differences in herbivore communities between islands and mainlands may promote evolutionary changes in leaf size. Small leaves are thought to deter browsing by large herbivores, however islands typically house fewer herbivore species than comparable mainland areas (Carlquist, 1974; Bond et al., 2004; Lee et al., 2010). This reduction in herbivory pressure may relax selection for smaller leaves. The depauperate nature of islands increases levels of intraspecific competition and this has been attributed to size changes of insular animals (Grant, 1965; Case, 1978; Lomolino, 2005). It may also promote increases in leaf size. Increasing leaf size may provide a competitive advantage to insular plants, as plants with larger leaves tend to have wider distributions and are more competitive (Carlquist, 1974; Bond et al., 2004; Lee et al., 2010). Consequently, stem sizes may increase via correlated evolution with leaf size. 
SSD did not vary predictably between insular and mainland plants, contrary to predictions of the niche variation hypothesis. However, leaves and stems of both sexes were consistently larger on islands. Larger leaves may be selectively advantageous where intraspecific competition is high and herbivores are scarce. Stem sizes may then increase via correlated evolution with leaves. Male and female plants may respond to selection for increased size at different rates, perhaps due to differences in reproductive costs, and this deserves further attention. The majority of island-mainland comparisons in the dataset were between fleshy-fruited taxa (see Appendix A3). Results were consistent for the one comparison between taxa with wind-dispersed seeds, however future analyses are needed to determine if life-history traits influence insular patterns of SSD. Furthermore, incorporating estimates of divergence times, differences in environmental conditions, and extending analyses to a global scale will further our understanding of SSD in island plants. 


\section{Chapter 4 - Herbivory and the evolution of divaricate plants: structural defenses lost on an offshore island}

Publication: Kavanagh P.H. (2015) Herbivory and the evolution of divaricate plants: structural defenses lost on an offshore island. Austral Ecology, 40, 206211, doi: $10.1111 /$ aec. 12196 


\begin{abstract}
Many island plants are characterised by unique morphology. For example, the high branching angles and small leaves of divaricate plants are a common feature of the New Zealand flora. The divaricate growth form may be an adaptation to deter browsing by extinct avian herbivores (moa); alternatively aspects of the insular climate may be responsible. However, our understanding of the selective pressures responsible for the high branching angles and small leaves of divaricate plants is incomplete. Here, I tested for differences in traits associated with the divaricate growth form between plants from Chatham Island and the New Zealand mainland. Moa never reached the Chatham Islands and its flora is derived from plants on mainland New Zealand. Therefore, I predicted Chatham Island plants to have lost morphological adaptations that may have deterred moa herbivory. Traits were quantified on 316 individuals in the field, allowing for 12 island-mainland taxonomic comparisons. Chatham Island plants consistently produced smaller branching angles, larger leaves, shorter internodes, and larger stems than related mainland plants. Results are therefore consistent with the hypothesis that selection for small leaves and high angled branching may be relaxed on the Chatham Islands due to an absence of moa. Smaller branching angles and larger leaves may offer a competitive advantage to Chatham Island plants.
\end{abstract}




\section{Introduction}

Many island plants are characterized by leaf and shoot morphology that is uncommon in mainland floras. For example, the divaricate growth form (small, widely spaced leaves, narrow stems, and high branching angles) is a feature of more than 50 species from 16 families in New Zealand (Greenwood \& Atkinson, 1977). Plants sharing similar traits are also common in Madagascar ('wire plants' - see Bond \& Silander, 2007). Large birds were dominant herbivores in both New Zealand (Moa - Aves: Dinornithiformes) and Madagascar (Elephant birds - Aves: Aepyornithidae), leading to the hypothesis that the divaricate growth form is an adaptation to deter large avian browsers (Greenwood \& Atkinson, 1977; Bond et al., 2004; Bond \& Silander, 2007). Although direct tests are not possible (due to the extinction of elephant birds and moa), feeding trials with extant ratites support the anti-herbivore hypothesis (Bond et al., 2004). Alternatively, the high branching angles and small leaves may be an adaptive response to wind, cold, temperature fluctuations (McGlone \& Webb, 1981), or a mechanism to avoid photoinhibition (Howell et al., 2002; Christian et al., 2006).

Moa were present on the main islands of New Zealand (North and South Islands, 'mainland' hereafter - see Figure 1) until hunting and habitat loss lead to their extinction less than 1000 years ago (Holdaway \& Jacomb, 2000). However, many of the offshore islands surrounding the mainland were never reached by moa (see Greenwood \& Atkinson, 1977). For example, moa were not present on the Chatham Islands, yet the flora of the islands is derived primarily from taxa that arrived via overwater dispersal from the New Zealand mainland (Heenan et al., 2010). These dispersal events are estimated to have occurred approximately $3 \mathrm{Ma}$, long after the diversification of moa in New Zealand (Bunce et al., 2009; Heenan et al., 2010). While anti-herbivore defenses may be under strong selection on the mainland (New Zealand), selection for these traits may be relaxed after island colonization. For example, plant-ant mutualisms that deter insect herbivores are often lost on islands (Janzen, 1973; Rickson, 1977) and morphological and chemical defenses are absent or less effective (Bryant et al., 1989; Bowen \& VanVuren, 1997; Vourc'h 
et al., 2001). Chatham Island plants tend to display reduced levels of heteroblasty when compared to related mainland plants, potentially due to an absence of moa herbivory (Burns \& Dawson, 2009). A similar situation may be occurring with divaricating plants (see Greenwood, 1992), however this is yet to be tested.

Despite four decades of investigation, the functional significance of divaricate traits remains unresolved (Greenwood \& Atkinson, 1977; McGlone \& Webb, 1981; Day, 1998; Howell et al., 2002; Bond et al., 2004; Bond \& Silander, 2007). The absence of moa on the Chatham Islands, along with climatic similarities and the flora being derived from plants on the New Zealand mainland, offers a unique opportunity to further test the anti-herbivore hypothesis. Under the anti-herbivore hypothesis, it is suggested that the high branching angles and small leaves of divaricate plants would make feeding difficult and unproductive for browsing birds (Greenwood \& Atkinson, 1977; Bond et al., 2004). Therefore, selection for these traits may be relaxed on the Chatham Islands. This may also apply to species that are not strictly defined as divaricate. For example, a plant with higher branching angles and smaller leaves than a co-occurring plant should be better defended against browsing birds, regardless of growth form.

I predicted Chatham Island plants to have lost morphological adaptations thought to deter moa herbivory. Branching angles, internode lengths and the sizes of leaves and stems were quantified on 316 individuals, representing 12 island-mainland comparisons from nine families and a range of growth-forms. First, I tested for differences in branching angles between related Chatham Island and mainland plants, as high angled branching may have made feeding difficult for moa (see Bond et al., 2004). Second, I tested for differences in scaling relationships between internode length and leaf size, as small widely spaced leaves make feeding unproductive for large avian browsers (Bond et al., 2004). Lastly, I tested for differences in the size of leaves and stems between Chatham Island and mainland plants. 


\section{Methods}

Numerous smaller islands surround the main islands of New Zealand (North and South Island). One group of satellite islands is the Chatham Islands, located $850 \mathrm{~km}$ to the east of the main islands of New Zealand at $44^{\circ} \mathrm{S}$ (see Figure 4.1). The flora of the Chatham Islands consists mainly of taxa that have dispersed overwater from New Zealand. The islands also have a long history of isolation, emerging between 3.0 and $2.0 \mathrm{Ma}$ and remaining isolated from the main islands of New Zealand during the Pleistocene (Heenan et al., 2010). Compared to locations at similar latitude on the New Zealand mainland, the Chatham Islands experience similar mean temperatures (Chatham Is $=11.4^{\circ} \mathrm{C}$; Christchurch $=12.1^{\circ} \mathrm{C}$ ), slightly more annual rainfall (Chatham Is $=855 \mathrm{~mm}$; Christchurch $=648 \mathrm{~mm}$ ), higher average wind speeds (Chatham Is $=25 \mathrm{~km} / \mathrm{h}$; Christchurch $=15 \mathrm{~km} / \mathrm{h}$ ), more days per year with gale force winds (Chatham Is $=16$; Christchurch $=3$ ) and fewer frost days per year (Chatham Is $=4$; Christchurch = 70; (National Institute of Water and Atmospheric research, 2014).

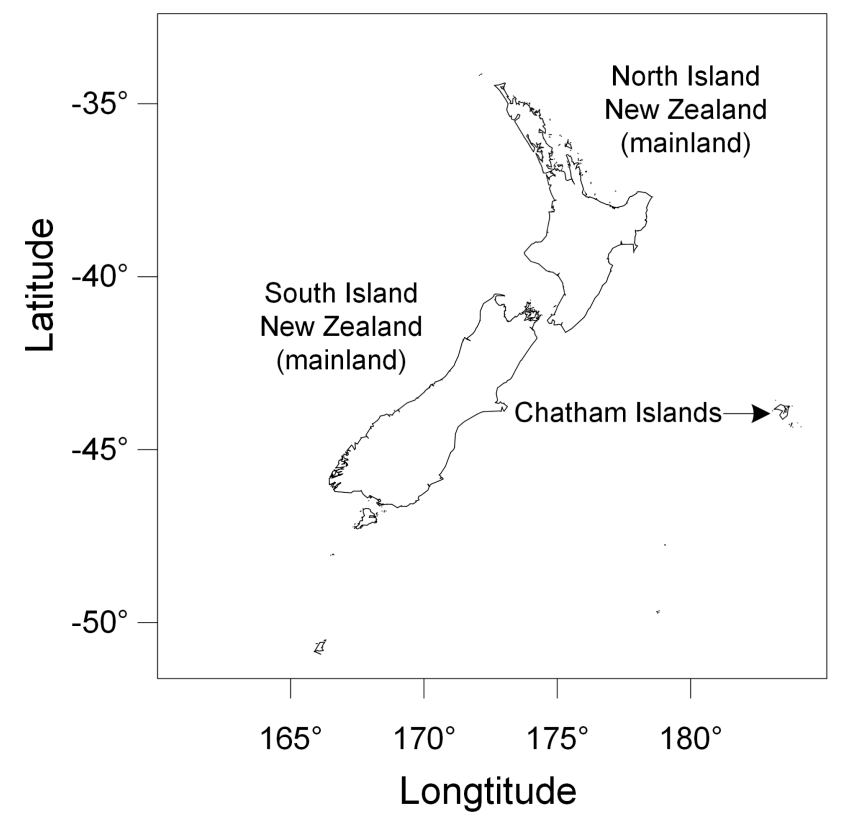

Figure 4.1 Map of New Zealand and Chatham Islands 
Data were collected on Chatham Island in February 2013 and plants

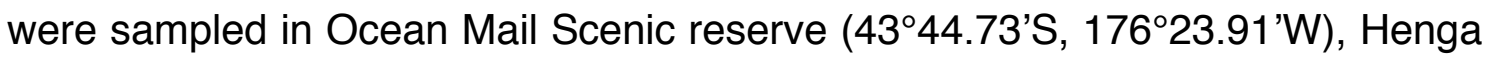

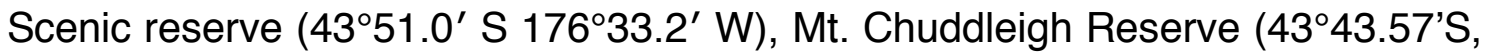

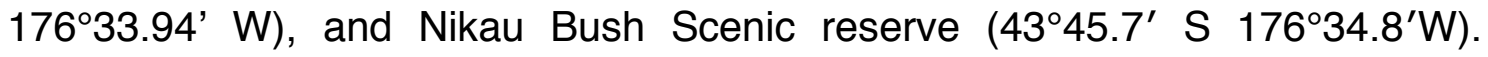

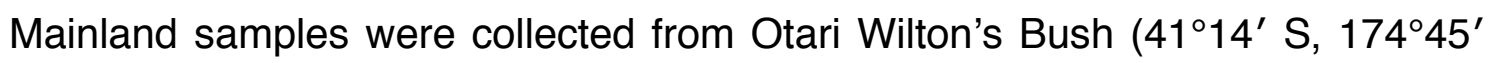
E), Nelson Lakes National Park $\left(41^{\circ} 48^{\prime} \mathrm{S}, 172^{\circ} 50^{\prime} \mathrm{E}\right)$, Wellington Eastern Walkway $\left(41^{\circ} 19.86^{\prime}\right.$ S, $174^{\circ} 49.77^{\prime}$ E), Keith George Memorial Park $\left(41^{\circ} 08.36^{\prime} \mathrm{S}, 175^{\circ} 00.18^{\prime} \mathrm{E}\right)$, Castle Point Scenic Reserve $\left(40^{\circ} 54.32^{\prime} \mathrm{S}\right.$, $\left.176^{\circ} 13.25^{\prime} \mathrm{E}\right)$, Lowes Bush Scenic Reserve $\left(41^{\circ} 00.03^{\prime} \mathrm{S}, 175^{\circ} 35.91^{\prime} \mathrm{E}\right)$ and Titahi Bay $\left(41^{\circ} 06.40^{\prime} \mathrm{S}, 174^{\circ} 50.10^{\prime} \mathrm{E}\right)$. Where possible, at least 10 adult individuals were sampled per taxon (mean $\pm \mathrm{SE}=13.74 \pm 0.37$ ). Differences in leaf and branching traits are often associated with light conditions (Cornelissen et al., 2003). Therefore, only plants growing in well-lit areas were sampled. On each individual, two terminal stems were randomly selected and the following traits were measured: stem length, internode length, branching angle, stem diameter, and leaf size. I chose to focus on the aforementioned traits, as they have often been associated with adaptations to deter browsing by moa (Greenwood \& Atkinson, 1977; Bond et al., 2004; Bond \& Silander, 2007). Five branching events were randomly selected and angles were measured to the nearest degree using a protractor. When fewer than five branching events were present, all were measured. Three fully expanded leaves from each stem were randomly selected for leaf area measurements. Leaf size was estimated by quantifying leaf length (linear distance between the leaf tip and the base of the petiole) and leaf width (maximum distance perpendicular to the length measurement at the widest point of the leaf). The area of an ellipsoid $(A=\pi \times$ $L / 2 \times W / 2$ ) was then used as a proxy for leaf area. Stem diameter was measured at the base of each stem, $1 \mathrm{~cm}$ towards the stem tip to avoid any swelling at the node. Leaf and stem measurements were taken using digital vernier calipers (accurate to $0.01 \mathrm{~mm}$ ). Measurements were then averaged within each individual prior to analyses.

Determining mainland relatives for taxa endemic to Chatham Island was achieved using the recent molecular analysis by Heenan et al. (2010). In this 
study, DNA sequence data were used to identify the closest relatives on mainland New Zealand for 35 taxa endemic to the Chatham Islands. In one instance, two insular taxa (Coprosma propinqua var. martinii and $C$. aff martini) were descended from the same mainland taxon (C. propinqua var. propinqua), yet they display remarkably different growth habits (Coprosma propinqua var. martinii is an upright shrub to small tree growing in swamps and bogs; $C$. aff martini is a prostrate to decumbent shrub restricted to sand dunes - see Heenan et al., 2010). Therefore, they were treated as independent comparisons. In two cases, the Chatham Island taxa were undifferentiated taxonomically from well known mainland taxa.

To test for differences in mean branching angle between related Chatham Island and mainland plants I first ran Watson-Williams tests, equivalent to a t-test for circular data (see Jammalamadaka \& SenGupta, 2001), for each taxonomic pairing. Following this, I conducted Rayleigh's test of uniformity on the pooled Chatham Island data, and then mainland data, to test whether the distribution of branching angles was non-random in each location (see Jammalamadaka \& SenGupta, 2001). The circular mean and von Mises bootstrapped 95\% confidence intervals were also calculated for Chatham Island and mainland branching angles. Lastly, I conducted a Watson-Williams test on the pooled Chatham Island and mainland branching angles.

The density of leaves on a stem could be quantified in a variety of ways. One option is to take the ratio of leaf size to internode length, providing an indication of the gap between adjacent leaves (Kelly, 1994). However, the use of ratios in statistical analyses can often be problematic (see Smith, 1999). To avoid the potential complications associated with the analysis of ratios, scaling relationships between leaf size (dependent variable) and internode length (independent variable) were used. Reduced major axis regression (RMA) of leaf size and internode length was carried out separately for Chatham Island and mainland data. RMA was utilized instead of Ordinary Least Squares (OLS) regression due to variables being subject to sampling and measurement error (see Price \& Phillimore, 2007). Resulting slope and intercept parameters indicate whether leaf sizes differ for a given internode length between Chatham 
Island and mainland plants. Mean values for Chatham Island and mainland taxa could be used when calculating regression parameters. However, the use of mean values per taxon ignores among-individual variation. This may be particularly important when analyzing plant traits that are potentially influenced by differences in age or growing conditions between individuals. In order to account for this a bootstrapping procedure was implemented (see Kavanagh et al., 2011). During each bootstrap replicate one individual was randomly selected from each taxon and RMA was used to obtain slope and intercept parameters. After 10,000 iterations mean slope and intercept parameters were calculated, along with associated standard deviations and 95\% confidence intervals.

Lastly, leaf and stem sizes were compared between related Chatham Island and mainland taxa. To test for size differences in leaves and stems between island and mainland taxa the RMA procedure described above was implemented (Chatham Island trait size as dependent variable and mainland trait size as independent variable). Secondly, I ran ANCOVA to test for differences in the allometric scaling of leaf and stem sizes. Leaf size was treated as the dependent variable, stem size as a covariate and location (island or mainland) as a fixed factor.

Leaf size and internode data were natural logarithm-transformed to conform to assumptions. All analyses were conducted in the R environment for statistical computing (R Development Core Team, 2013). RMA analyses were conducted with the smatr package (Warton et al., 2012b). Watson-Williams tests, Rayleigh's tests of uniformity, circular means and von Mises bootstrapped 95\% confidence intervals were calculated with the CircStats package (Lund \& Agostinelli, 2009). 


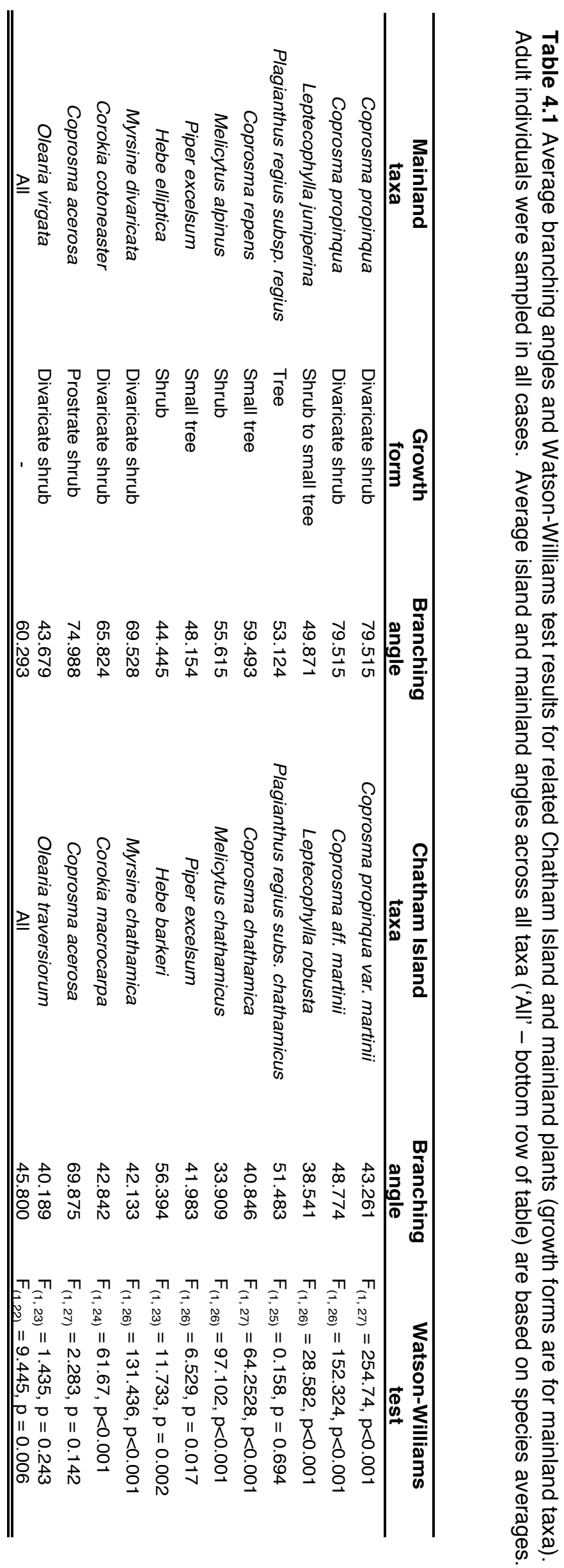




\section{Results}

Mean branching angles were significantly different in 9 of the 12 Chatham island-mainland comparisons and the majority displayed lower branching angles for Chatham Island taxa (see Table 4.1). Results of Rayleigh's test of uniformity indicated that branching angles did cluster about a mean, for both mainland and Chatham Island plants (mainland $-P<0.001$; Chatham Island $-P<0.001$ ). The Watson-Williams test indicated that Chatham Island and mainland branching angles were significantly different (see Table 4.1), and average branching angles were lower for Chatham Island taxa (Chatham Island: mean = $45.800^{\circ}, 95 \% \mathrm{Cl}=41.310^{\circ}-51.243^{\circ}$; mainland: mean $=60.293^{\circ}, 95 \% \mathrm{Cl}=$ $53.598^{\circ}-67.681^{\circ}$; see Table 4.1 \& Figure 4.2).

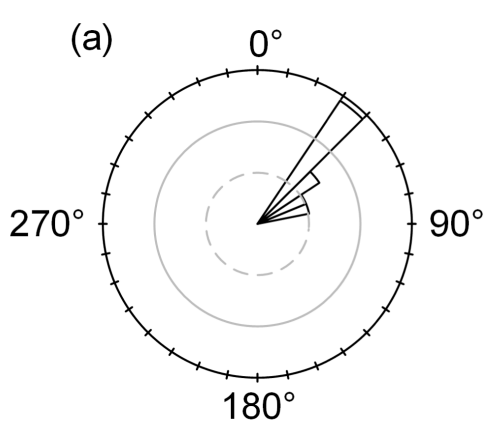

Chatham Island

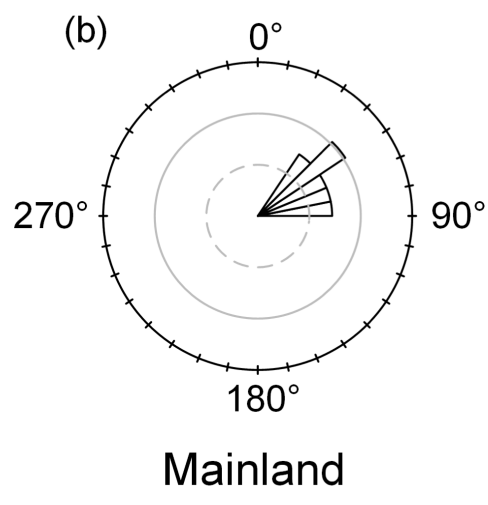

Figure 4.2 Rose diagrams representing average branching angles for (a) Chatham Island and (b) mainland taxa. Dashed grey circles indicate a frequency of 1 ; solid grey circles a frequency of 4 ; and the outer black circle a frequency of 8 (i.e. 8 taxa). Mainland: mean $=60.293^{\circ}, 95 \% \mathrm{Cl}$ $=53.598^{\circ}-67.681^{\circ}$. Chatham Island: mean $=45.800^{\circ}, 95 \% \mathrm{Cl}=41.310^{\circ}-51.243^{\circ}$ 
Leaf sizes scaled positively with internode lengths (see Figure 4.3). However, the relationship differed for island and mainland plants. The slope parameter was 2.329 (see Table 4.2) for Chatham Island taxa and the intercept value was greater than zero. For mainland plants, the slope parameter was marginally smaller (2.213) and the intercept parameter was less than zero (see Table 4.2). These results suggest that Chatham Island taxa consistently produce larger leaves than mainland taxa for a given internode length (see Figure 4.3).

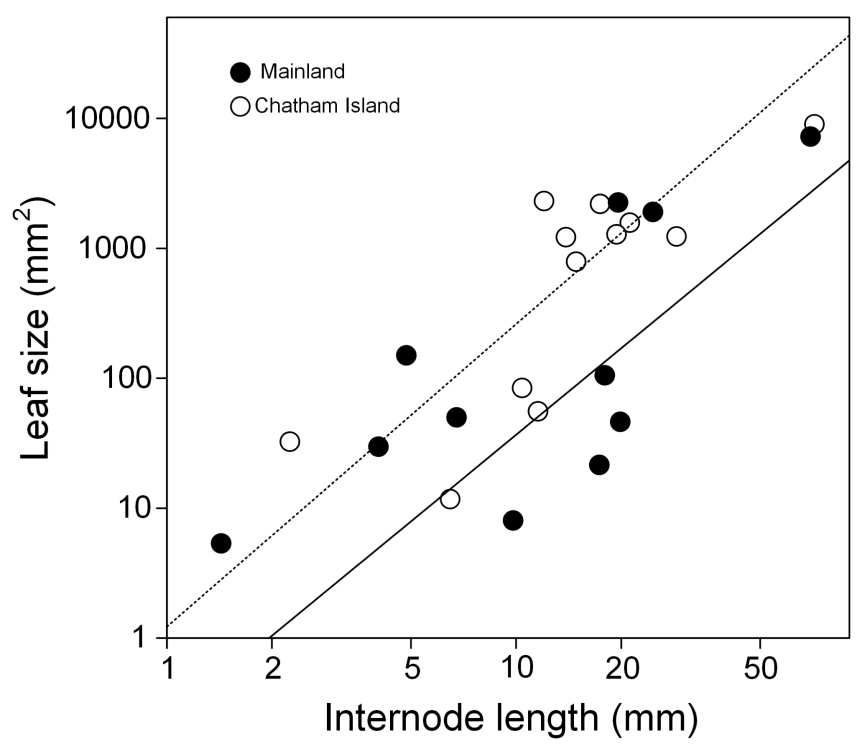

Figure 4.3 Relationship between leaf size and internode length for mainland and island plants. Closed circles are mainland taxa and open circles are insular taxa. The dotted line represents RMA results for island plants, the solid line for mainland plants. Both axes are logarithm transformed.

Chatham Island leaf sizes scaled positively with mainland leaf sizes (Chatham Island leaf size as dependent variable, mainland leaf size as independent variable; slope $=0.952)$. However, the intercept parameter of the RMA analysis was greater than zero (1.703, see Table 4.2). This indicates that leaf sizes were consistently larger for Chatham Island taxa. Results were similar in the analysis of stem sizes (see Table 4.2). Leaf sizes scaled positively with stem sizes $\left(\mathrm{F}_{1,19}=42.146, P<0.001\right)$, relationships had similar slopes $\left(F_{1,19}=0.068, P=0.797\right)$ and intercepts $\left(F_{1,20}=0.359, P=0.556\right)$ for Chatham Island and mainland datasets. 
Table 4.2 Results of RMA regression analyses. In leaf size - internode length comparisons, leaf size was the dependent variable and internode length was the independent variable. In comparisons of leaf and stem size between Island and mainland plants (two bottom rows of table), Chatham Island data were the dependent variable and mainland data the independent variable.

\begin{tabular}{cccc}
\hline & & Slope & Intercept \\
\cline { 3 - 4 } Trait & Location & Mean value \pm SD $(95 \%$ Cl) & Mean value \pm SD $(95 \%$ Cl) \\
\hline $\begin{array}{c}\text { Leaf size v } \\
\text { Internode length } \\
\text { Leaf size v } \\
\text { Internode length }\end{array}$ & Island & $2.329 \pm 0.187(2.325-2.332)$ & $0.088 \pm 0.555(0.077-0.0989)$ \\
Stem size & Mainland & $2.213 \pm 0.156(2.21-2.216)$ & $-0.648 \pm 0.390(-0.656$ to -0.641$)$ \\
Leaf size & Island v Mainland & $0.974 \pm 0.421(0.966-0.982)$ & $1.124 \pm 1.313(1.10-1.15)$ \\
\hline \hline
\end{tabular}

\section{Discussion}

High branching angles, small leaves that are widely spaced, and narrow stems may have deterred moa herbivory (Greenwood \& Atkinson, 1977; Bond et al., 2004). Chatham Island plants tended to have lower branching angles, larger leaves, smaller spaces between leaves, and stouter stems than related mainland plants. These results suggest that the absence of moa on the Chatham Islands has relaxed selection for morphology thought to deter browsing moa.

The wide angled branching of divaricate plants may be a response to browsing moa, making shoots difficult for birds to swallow (see Greenwood \& Atkinson, 1977; Bond et al., 2004; Bond \& Silander, 2007). Chatham Island plants tended to display lower branching angles than mainland relatives (see Figure 4.2), even in cases where the mainland taxa were not described as divaricate (Allan, 1961). The absence of moa on Chatham Island may have relaxed selection for high branching angles. Branching angle also influences overall plant architecture and light capture efficiency (Honda \& Fisher, 1978). 
Simulation models suggest that trees with tall narrow crowns (i.e. small branching angles) are more competitive (Borchert \& Tomlinson, 1984). Evolutionary changes on islands are often associated with increased intraspecific competition (Grant, 1965; Case, 1978; Lomolino, 2005) and this may also contribute to evolutionary changes in plant branching angles.

Results of a recent investigation into evolutionary changes of island plants suggest that selection is acting to increase leaf size (Burns et al., 2012; but see Kavanagh \& Burns, 2014). Chatham Island plants tended to produce larger leaves than mainland relatives, consistent with the results of Burns et al. (2012). Furthermore, Chatham Island taxa produced larger leaves for a given internode length. Selection may favour small, widely spaced leaves on the mainland to deter large browsers (e.g. moa) by making feeding unproductive (Bond et al., 2004; Lee et al., 2010). The absence of moa on the Chatham Islands may have relaxed selection for small, widely spaced leaves. Selection may then favour increased leaf size as plants with larger leaves are more competitive and occupy wider distributions (Schmitt \& Wulff, 1993; Grime et al., 1997; Westoby et al., 2002; Thuiller et al., 2004). Stem sizes of Chatham Island plants were also larger than those of mainland relatives. Stems provide biomechanical support for leaves and the two traits are often associated allometrically (Corner, 1949; Niklas, 1994). Therefore, stem size may increase via correlated evolution with leaves.

The high branching angles and small leaves of divaricating plants may provide tolerance to wind and frost (McGlone \& Webb, 1981), improve light capture efficiency (Day, 1998) and reduce photoinhibition (Howell et al., 2002). Compared to locations at the same latitude on the New Zealand mainland, the Chatham Islands have similar mean temperatures but are much windier (National Institute of Water and Atmospheric research, 2014). A reduction in leaf size and number is associated with increased tolerance to wind stress (Stokes et al., 1995; Niklas, 1996). Yet, Chatham island taxa consistently displayed larger, more closely spaced leaves than related mainland plants. The wide-angled branching of divaricate plants may provide a 'frost-screen'; protecting interior leaves from frost damage (McGlone \& Webb, 1981). The 
Chatham Islands experience fewer frost days than comparable mainland areas. However, tests are yet to demonstrate significant climate based benefits to traits associated with the divaricate growth form (Kelly \& Ogle, 1990; Darrow et al., 2001; Howell et al., 2002; Christian et al., 2006).

Chatham Island plants consistently produced larger leaves, smaller spaces between leaves, lower branching angles, and stouter stems than related mainland plants. These results are consistent with the prediction that an absence of moa has relaxed selection for plant traits that deter moa herbivory. Furthermore, increasing leaf size and reducing branching angles may provide a competitive advantage in response to elevated intraspecific competition. Insular climate has been advocated as an alternative to the anti-herbivore hypothesis for the evolution of divaricate plants (see McGlone \& Webb, 1981). However, structural differences between related Chatham Island and mainland plants are inconsistent with predictions of the climate-based hypothesis. While direct tests are not possible, the results of this study lend further support to the antiherbivore hypothesis for the evolution of the divaricate growth form. Furthermore, results were consistent among island-mainland pairings regardless of whether mainland taxa were defined as divaricate. Increased tensile strength of stems may be a further adaptation to deter browsing moa (Bond et al., 2004; Bond \& Silander, 2007). Future studies comparing stem tensile strength between Chatham Island and mainland plants may provide further insights into the importance of this defensive strategy. Investigations including a variety of growth forms and island systems are now needed, in addition to further cafeteria-style experiments, to establish the importance of moa herbivory in the evolution of structural traits in the New Zealand flora. 


\section{Chapter 5 - The ontogeny of signal honesty:} new insights from an aposematic tree 


\section{Abstract}

Young animals often have less energy to devote to defense and are therefore more likely to utilize dishonest defensive signals. Here, I demonstrate dishonest defensive signals (i.e. aposematism) in plants for the first time, by investigating signals on both the upper and lower surfaces of leaves, which have hitherto been neglected. I demonstrate that Pseudopanax crassifolius (Araliaceae), a tree species that is endemic to New Zealand, produces leaves with marginal teeth that peak in size during the sapling stage of development. However, warning coloration on upper leaf surfaces peaked at the seedling stage, providing a dishonest signal of defense. Signals on lower leaf surfaces peaked in the sapling stage, providing an honest defensive signal later in ontogeny. Marginal teeth and all warning coloration were absent in adults, after they grow above the reach of the largest known native megaherbivores (Moa Aves: Dinornithiformes). Overall results illustrate the importance of considering the changing perspective of herbivores as plants develop and unify our understanding of dishonest signals in plants and animals. 


\section{Introduction}

Dishonesty is common in animal-signaling systems (Searcy \& Nowicki, 2005; Rowell et al., 2006). Furthermore, rates of dishonesty often vary predictably through ontogeny. Human children begin to lie at an early age (Lee, 2013). However, rates of dishonesty tend to decline in early adulthood (Jensen et al., 2004; Evans \& Lee, 2011; Levine et al., 2013). While lying in humans is an action carried out intentionally and may be tightly linked to theory of mind (Lee, 2013), other forms of dishonest signaling also decline through ontogeny in nonhuman animals. For example, small male green frogs (Rana clamitans) produce dishonest signals of size more frequently than large males (Bee et al., 2000). Nestlings of Laniocera hypopyrra resemble toxic caterpillars (both morphologically and behaviourally), however individuals lack these traits later in ontogeny (Londono et al., 2015). Young male birds often delay plumage maturation, thus providing a dishonest signal of sex (Rohwer et al., 1980; Hawkins et al., 2012). Similar patterns of dishonest signaling may also occur in plants. However, the honesty of signaling through plant ontogeny has yet to be investigated.

Animals often advertise their level of defense to predators by being brightly coloured (i.e. aposematism) (Mappes et al., 2005). Similarly, recent research suggests aposematism may also be common in plants (Lev-Yadun, 2001, 2003; Lev-Yadun \& Ne'eman, 2004; Lev-Yadun \& Gould, 2007; Fadzly et al., 2009; Cooney et al., 2012). Specifically, structural defenses of many plant species are brightly colored, making them conspicuous to vertebrate herbivores (Lev-Yadun, 2001; Fadzly et al., 2009). The viewing perspective of terrestrial herbivores changes as plants grow vertically and this may influence the production of aposematic signals by plants. For example, when leaves are aposematic, the changing perspective of herbivores may select for signals on upper (adaxial) and lower (abaxial) leaf surfaces to be produced at different ontogenetic stages. However, the potential for lower leaf surfaces to signal to herbivores viewing leaves from below has not been investigated. Furthermore, aposematism is generally considered to be reliable, providing an honest signal of defense (Summers \& Clough, 2001; Lev-Yadun, 2003; Bezzerides et al., 
2007; Cooney et al., 2012). However, changes in herbivore perspective and antiherbivore defense through plant ontogeny may influence the honesty of warning signals.

Many plant species display a reduction in defense once above the reach of browsing animals (Gowda \& Palo, 2003; Burns, 2014). Similarly, the strength of aposematic signals may decline as plants grow vertically and fewer herbivores are able to receive the visual signal. When leaves are aposematic this relationship may vary between upper and lower leaf surfaces. Aposematic signals on upper leaf surfaces may peak when plants are small and terrestrial herbivores of all sizes are able to receive the signal (see Figure 5.1). However, early in ontogeny plants tend to have large root:shoot ratios and lack sufficient resources for investment in structural defense (Boege \& Marquis, 2005; Hanley et al., 2007). Consequently, aposematic signals on upper leaf surfaces may peak when plant defenses are poorly developed, providing a dishonest signal (see Figure 5.1). Selection may favor aposematism on lower leaf surfaces to peak later in ontogeny. For example, when plants are of intermediate height the leaves are likely to be within reach of browsing animals and lower leaf surfaces may be visible to the greatest number of herbivores (see Figure 5.1). Plants of intermediate height are likely to have sufficient resources for the production of structural defenses (see Boege \& Marquis, 2005) and aposematism on lower leaf surfaces may tend to be a reliable, honest signal.

Pseudopanax crassifolius (Sol. ex A.Cunn) C. Koch. is a heteroblastic tree endemic to New Zealand and individuals go through a predictable series of morphological transitions (Gould, 1993). Leaves of seedlings (individuals $<10$ $\mathrm{cm}$ tall) are cryptically colored and saplings $(10-300 \mathrm{~cm}$ tall) produce leaves with marginal teeth and associated aposematic spots (see Figure 5.2a; Fadzly et al., 2009). However, leaves of adults ( $>300 \mathrm{~cm}$ tall) lack these antiherbivore defenses (Gould, 1993; Fadzly et al., 2009). Structural defenses during the sapling stage and cryptically colored seedlings may have reduced rates of herbivory by extinct browsing birds (Moa - Aves: Dinornithiformes; Greenwood \& Atkinson, 1977; Fadzly et al., 2009). P. crassifolius is not known to produce aposematic signals on lower leaf surfaces. However, color contrast from 
background vegetation may provide a signal to herbivores viewing leaves from below (see Figure 5.2b).

Here, I investigate ontogenetic changes in aposematic signals and the potential for aposematism on upper leaf surfaces to be dishonest in $P$. crassifolius. First, I used piecewise regression to test for changes in the production of teeth through plant ontogeny. Piecewise regression was used as the production of structural defense is predicted to increase early in ontogeny, and then decline once above the browsing height of moas (Greenwood \& Atkinson, 1977; Fadzly et al., 2009). I then tested whether the strength of aposematic signals on upper leaf surfaces peaked early in plant ontogeny, providing a dishonest signal of defense (see Figure 5.1). The colors of lower leaf surfaces may be aposematic, however this has not yet been tested. I tested for color contrasts of lower leaf surfaces from background vegetation using an avian vision model. I then tested whether the contrast of lower leaf surfaces peaked at intermediate plants heights, providing an honest signal of defense.

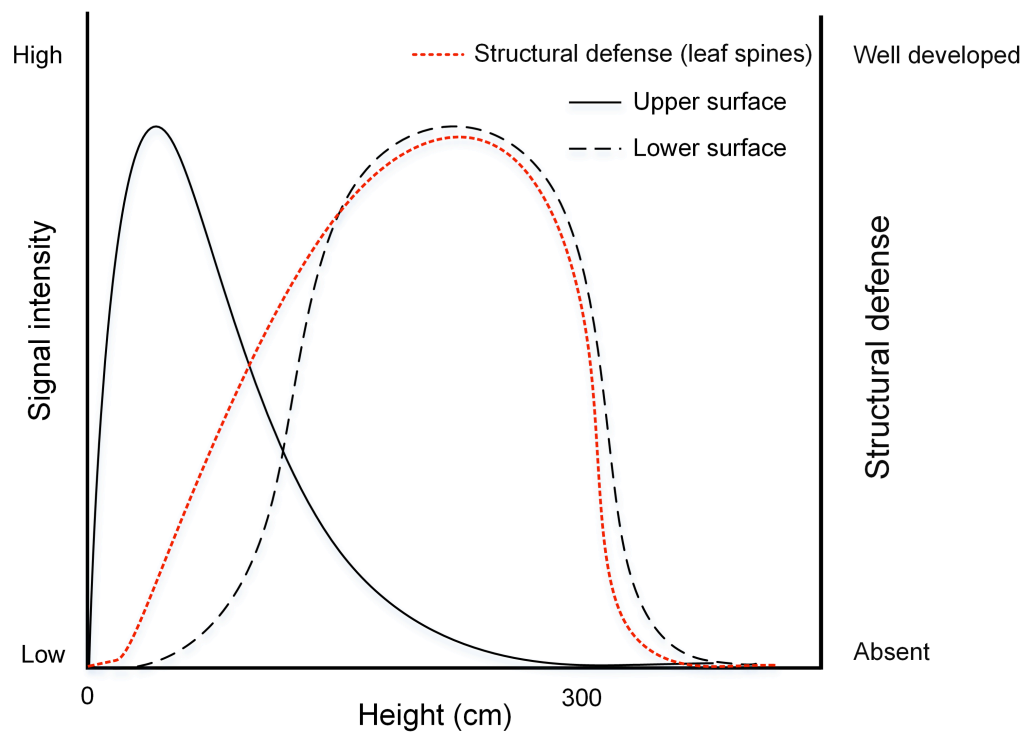

Figure 5.1 Diagrammatical representation of hypotheses. Signaling on upper leaf surfaces is predicted to peak early in ontogeny (solid line) when structural defenses are poorly developed (dotted red line). However, signals produced on lower leaf surfaces are predicted to peak later in plant ontogeny (dashed line) when structural defenses are well developed. Structural defenses and signaling of lower leaf surfaces decline once individuals attain a height refuge from herbivory. 
Figure 5.2 Upper (a) and lower (b) leaf surfaces of typical leaves produced by $P$. crassifolius though plant ontogeny, from seedling to adult. The inset box in panel (a) illustrates a magnification of marginal teeth and associated aposematic spots.
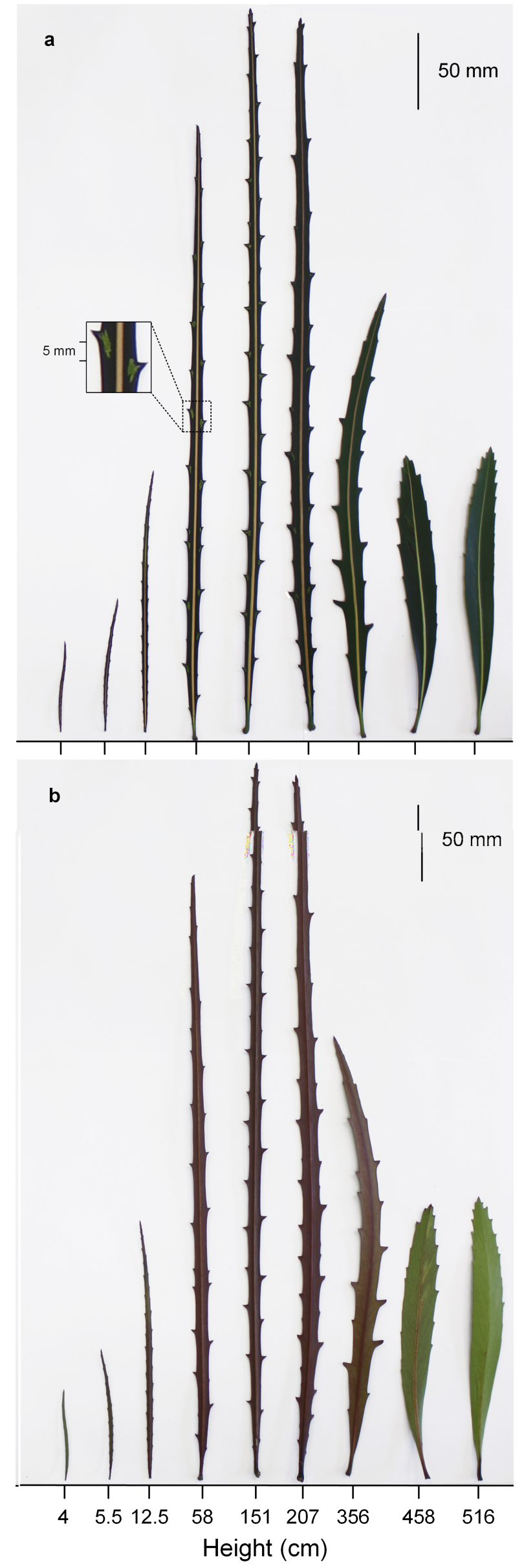


\section{Methods}

Pseudopanax crassifolius individuals were sampled in Nelson Lakes National

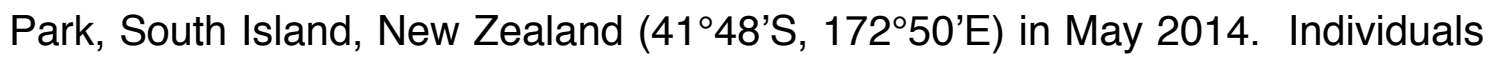
were randomly selected, height $(\mathrm{cm})$ was measured with a $10 \mathrm{~m}$ measuring tape and the youngest fully expanded leaf was removed for analysis. The final dataset consisted of 113 individuals ranging from $3-526 \mathrm{~cm}$ tall, capturing all four ontogenetic stages of leaf morphology described for $P$. crassifolius (Gould, 1993).

\section{Upper leaf surface}

Leaves were scanned using a Canoscan 8400F color image scanner at $600 \mathrm{dpi}$. On each leaf, the size of four randomly selected teeth and their associated aposematic spots were measured using the image analysis software Image J (Schneider et al., 2012). I quantified the size of marginal teeth by drawing a polygon around the tooth margin and calculating its area $\left(\mathrm{mm}^{2}\right)$. Adjusting the threshold level of the image allowed aposematic spots to be selected and the area calculated. When a single marginal tooth had multiple small aposematic spots associated with it, all were measured and the combined area was calculated. Tooth size and spot size data were then averaged within leaves prior to analyses.

If teeth are produced in response to moa herbivory, tooth size is predicted to decline above the browsing height of moa. Therefore, I tested for scaling relationships between tooth size and plant height using piecewise regression. I used an iterative approach, following Crawley (2007), where the breakpoint value was determined by the model with the lowest residual MSE (mean squared error). Seedlings $(<10 \mathrm{~cm})$ were not included due to an absence of marginal teeth (see Fadzly et al., 2009). Therefore, the dataset consisted of 86 individuals $(12.5-526 \mathrm{~cm}$ tall). Tooth size data were logarithm transformed prior to analysis to conform to model assumptions.

Previously, it has been suggested that 'saplings' (10-300 cm tall) produce both marginal teeth and aposematic spots (Fadzly et al., 2009). However, individuals taller than $3 \mathrm{~m}$ may still produce marginal teeth (see (Gould, 1993)). I used a Generalized Linear Model (GLM) with a binary response function to test 
whether the presence of aposematic spots was determined by tooth size, plant height, or an interaction between tooth size and height. I then tested the prediction that the strength of aposematic signals on upper leaf surfaces will peak early in ontogeny (see Figure 5.1). One option would be to test for scaling relationships between the size of aposematic spots and plant height. However, the size of leaves and marginal teeth varies through ontogeny (Gould, 1993), potentially constraining the size of aposematic spots. Therefore, I calculated signal intensity as the percentage of spot size relative to tooth size (signal intensity $=100 \times$ spot size/tooth size). Ordinary Least Squares (OLS) regression could then be used to test for scaling relationships between signal intensity and plant height. However, the use of OLS regression minimizes the sum of squared variation in the $Y$ direction and is not appropriate when measurement error in $X$ and $Y$ variables is likely (Price \& Phillimore, 2007). To avoid these confounding sources of bias, I ran Reduced Major Axis (RMA) regression. Leaves without aposematic spots provide a signal intensity value equal to zero and were omitted from RMA analyses as their inclusion created a highly skewed distribution (logistic regression analyses described above account for ontogenetic changes in the presence/absence of aposematic spots). Signal intensity was square root transformed to conform to model assumptions.

\section{Lower leaf surface}

Anthocyanin is commonly responsible for red pigmentation in leaves and differences in anthocyanin concentration strongly influence leaf optical properties (Neill \& Gould, 2000). Therefore, I measured anthocyanin content of lower leaf surfaces using an opti-sciences CCM-200 chlorophyll content meter that was adapted (by the manufacturer) to calculate anthocyanin content index ((ACl; see Schreiber \& Wade, 2007)). Three measurements were taken per leaf, one at the midpoint of the leaf and $3 \mathrm{~cm}$ either side of the first measurement. When leaves were too small for this protocol, the entire surface of the probe was covered with the leaf and three consecutive measurements were taken. $\mathrm{ACl}$ measures were then averaged within leaves prior to analyses. 
To determine if changes in $\mathrm{ACl}$ would result in differences in perception by moa I used reflectance properties of leaves.

Due to the potential degradation of leaves over time, a subsample of leaves was randomly selected for reflectance measurements. This ensured reflectance properties obtained reflected values of fresh leaf tissue (within $24 \mathrm{hrs}$ of collection). To ensure all stages of $P$. crassifolius ontogeny were captured in the subsample, I randomly selected at least five individuals from the following height classes: $0-10 \mathrm{~cm}(\mathrm{n}=7), 11-100 \mathrm{~cm}(\mathrm{n}=6), 101-200 \mathrm{~cm}(\mathrm{n}=6), 201-300$ $\mathrm{cm}(\mathrm{n}=5), 301+\mathrm{cm}(\mathrm{n}=5)$. Reflectance spectra of the lower surface of $P$. crassifolius leaves were measured with an Ocean Optics USB2000 spectroradiometer and Xenon Pulse X2 lamp Ocean Optics light source (Dunedin, FL, USA). Leaves reflectance properties were measured as the proportion of a diffuse, Teflon-based, white reflectance standard. The fiber optics probe was mounted inside a matte black plastic tube to exclude ambient light. The angle of illumination was fixed at $45^{\circ}$ to minimize glare and the distance between the probe and leaf surface was fixed at $1 \mathrm{~cm}$. Spectra were calculated between 300 to $700 \mathrm{~nm}$ at $5 \mathrm{~nm}$ intervals with SpectraSuite software. Three measurements were made per leaf (as for anthocyanin indices above) and reflectance spectra were then averaged for each leaf. Reflectance spectra for the lower leaf surface of five common co-occurring trees (Carpodetus serratus, Griselinia littoralis, Kunzea ericoides, Nothofagus fusca, Nothofagus solandri and Raukaua simplex) were also measured using the same protocols (three leaves per species). The reflectance spectra for these species were then averaged to provide a 'background canopy reflectance'.

I assessed color contrasts of $P$. crassifolius leaves and background canopy according to avian vision. Specifically, I plotted reflectance data in three-dimensional tetrahedral color space. Exact spectral discrimination data are not available for moa, therefore I used the $\mathrm{V}$ model based on its closest living relative, Strithio camelus (ostrich) (Turvey et al., 2005). Euclidian distances of $P$. crassifolius points from average background canopy were calculated. Greater Euclidean distances between $P$. crassifolius leaves and background canopy represent greater color contrasts. To test whether $\mathrm{ACl}$ 
scales with contrast of P.crassifolius leaves from background foliage I carried out OLS regression of Euclidean distances against $\mathrm{ACl}$. A reflected inverse transformation was used on Euclidean distance data to conform to normality assumptions. Regression parameters were then used to predict Euclidean distances for all 113 leaves based upon $\mathrm{ACl}$ values. ANOVA of observed versus predicted values was carried out to test the robustness of Euclidean distance predictions. I then carried out piecewise regression of predicted Euclidean distances (dependent variable) and plant height (independent variable).

Lastly, I tested for scaling relationships between the size of marginal teeth and $\mathrm{ACl}$. Seedlings $(<10 \mathrm{~cm})$ were not included in this analysis due to an absence of marginal teeth. Therefore, a sub-sample of 86 individuals (12.5 $526 \mathrm{~cm}$ tall) was used. Scaling relationships were tested for using RMA regression and tooth size data were logarithm transformed to conform to assumptions.

All analyses were carried out in the $R$ environment for statistical computing (R-Development-Core-Team, 2011). The smatr package was used for RMA regression (Warton et al., 2012) and the pavo package was used for the analysis of reflectance data (Maia et al., 2013). Break-point regression was carried out using an iterative approach (see Crawley, 2007).

\section{Results}

Initially, the size of marginal teeth scaled positively with plant height (breakpoint regression: slope $=0.006$; see Figure $5.3 ; R^{2}=0.435 ; p<0.001$ ). However, above a height of $377 \mathrm{~cm}$ (break-point value with lowest Mean Squared Error- MSE) tooth size scaled negatively with increasing plant height (slope $=-0.007 ;$ see Figure $5.3 a)$ 


\section{Upper leaf surface}

The probability of aposematic spots being produced increased with the size of marginal teeth $(b=1.873 ; z=5.395 ; p<0.001$; Generalized Linear Model). Plant height did not influence the probability of aposematic spot presence $(b=0.001 ; z=0.394 ; p=0.694 ; \mathrm{GLM})$, as aposematic spots are not produced at the lower and upper ends of the height spectrum (see Fig 5.3b). However, there was a significant interaction between tooth size and plant height, indicating a decrease in the probability of aposematic spots being produced with increasing tooth size and plant height $(b=-0.006 ; z=-4.715 ; p<$ 0.001 ; GLM). Furthermore, signal intensity ( $\mathrm{SI}=100 \times$ spot size/tooth size $)$ scaled negatively with plant height and peaked early in plant ontogeny (Reduced Major Axis regression: $\mathrm{R}^{2}=0.610 ; p<0.001$; slope $=-0.064$; intercept $=18.015$; see Fig 5.3b).

\section{Lower leaf surface}

Euclidean distances of $P$. crassifolius leaves from background vegetation (obtained from tetrahedral color space based upon avian vision model - see materials and methods) scaled positively with Anthocyanin Content Index (ACl; $R^{2}=0.554 ; p<0.001$; Ordinary Least Squares regression). Therefore, increased $\mathrm{ACl}$ resulted in greater contrasts of leaves from background foliage. Reflectance data were not available for all leaves in the dataset (see materials and methods). Therefore, I predicted Euclidean distance values based upon $\mathrm{ACl}$ measurements for cases where reflectance data were not available. Estimates of Euclidean distance calculated using the regression equation did not differ significantly from observed values $\left(\mathrm{F}_{1,56}=0 ; p=1\right.$; ANOVA), indicating that estimates accurately reflect real Euclidean distance measures. Piecewise regression of predicted Euclidean distances initially scaled positively with plant height $\left(R^{2}=0.692 ; p<0.001\right.$; slope $=0.003$; see Fig 5.3c). However, above a height of $138 \mathrm{~cm}$ (breakpoint value with lowest MSE) Euclidean distances scaled negatively with increasing plant height (slope $=-0.0007$; see Fig 5.3c). 
Lastly, the size of marginal teeth scaled positively with ACl (RMA regression: $\left.\mathrm{R}^{2}=0.234 ; p<0.001\right)$. This indicates that $P$. crassifolius leaves with greater contrasts from the background foliage also produced larger teeth.
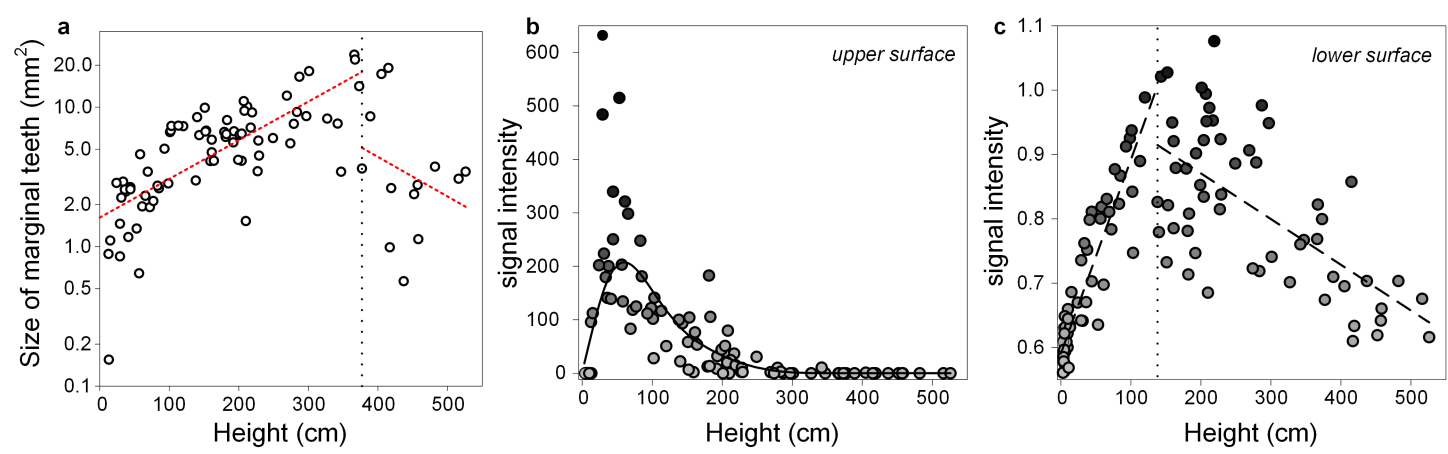

Figure 5.3 Variation in the size of marginal teeth (a) and intensity of signals produced on upper (b) and lower (c) surfaces of leaves through plant ontogeny. The dashed red lines in panel (a) represent the result of piecewise regression analysis. The dotted vertical line is at the breakpoint of height $=377 \mathrm{~cm}$. Tooth size data were natural logarithm transformed to conform to assumptions. Upper leaf surface (b) signal intensity calculated as size of aposematic spots relative to marginal teeth (signal intensity $=100 \times$ spot size/tooth size). The black line is a smoothed spline $(\mathrm{df}=7$ ). Lower leaf surface (c) signal intensity is the contrast of leaves from background vegetation based on avian vision (see methods for detailed description). Dashed lines are the result of piecewise regression; the dotted vertical line is at the breakpoint of 138 $\mathrm{cm}$.

\section{Discussion}

The production of marginal teeth by $P$. crassifloius varied through ontogeny, consistent with predictions based on moa herbivory (Greenwood \& Atkinson, 1977; Atkinson \& Greenwood, 1989). Furthermore, the contrast of lower leaf surfaces from background foliage scaled positively with the size of marginal teeth. This suggests optical properties of lower leaf surfaces may be aposematic, providing a reliable signal of defense to herbivores viewing leaves from below. Conversely, the strength of aposematic signals on upper leaf surfaces peaked early in plant ontogeny when marginal teeth are poorly 
developed. Selection may favor signal intensity to be highest early in plant ontogeny, as the signal is likely to be viewed most frequently by potential herbivores when plants are small in stature. For example, the tallest ( $3 \mathrm{~m}$ at full stretch; Berentson, 2012) and the shortest (50 cm tall; Berentson, 2012) moa species are likely to have co-occurred with $P$. crassifolius (Allan, 1961; Worthy, 1990). Thus, the aposematic signals on upper leaf surfaces would have been visable to the widest range of browsing moa (juveniles and adults of both species) early in plant ontogeny. Furthermore, analysis of moa coprolites suggests plants less than $1 \mathrm{~m}$ tall accounted for much of their diet (Wood et al., 2008).

The contrast of signals with the background environment strongly influences signal effectiveness. For example, the contrast of aposematic animals with the background determines rates of predator avoidance (Aronsson \& Gamberale-Stille, 2009) and the contrast of fruits with background foliage increases fruit detection by birds (Burns \& Dalen, 2002; Schaefer et al., 2006). Anthocyanin concentration in lower cell layers of $P$. crassifolius leaves varied through ontogeny and scaled positively with the contrast of leaves from background foliage. The contrast with background foliage peaked during the sapling stage and scaled positively with the size of marginal teeth. Therefore, optical properties of lower leaf surfaces potentially provided a reliable signal of structural defense to moa. While the largest moa species is suggested to have been approximately $2 \mathrm{~m}$ tall ( $3 \mathrm{~m}$ at full stretch), there was extreme sexual size dimorphism with males half the size of females (Worthy \& Holdaway, 2002; Berentson, 2012). Juveniles and sub-adults are also thought to have accounted for more than $25 \%$ of some moa populations (Turvey \& Holdaway, 2005). Therefore, selection may have favored the contrast of lower leaf surfaces from background foliage to peak at intermediate heights, when the greatest number of browsing moa would have been likely to receive the signal effectively.

Alternatively, lower cell layers may contain high concentrations of anthocyanins to maximize photosynthetic efficiency in low-light environments (Smith, 1909; Hughes et al., 2008). One functional explanation is that anthocyanins in the lower epidermis may reflect red light back into the 
mesophyll, maximizing light capture (Hughes et al., 2008). The total amount of ambient light increases vertically within a forest and ambient light levels are lowest at the forest floor (Pukkala et al., 1991; Endler, 1993; Terborgh \& Mathews, 1999). However, anthocyanin concentrations in lower cell layers of $P$. crassifolius leaves were lowest early in plant ontogeny, but increased with increasing plant height. Anthocyanins are also suggested to play a photoprotective role when shade-adapted plants are exposed to intermittent high-intensity sunlight (Gould et al., 1995). However, the anatomy and morphology of juvenile $P$. crassifolius leaves is typical of a sun-adapted, xeromorphic plant (Gould, 1993). Therefore, it is unlikely that physiological functional explanations can fully account for the ontogenetic changes I observed in $P$. crassifolius.

The intensity of aposematic spots on the upper surface of $P$. crassifolius leaves peaked when marginal teeth were small. Furthermore, the probability of aposematic spots being present decreased with increasing plant height and tooth size. This suggests aposematic spots may be providing a dishonest signal of defense. During early stages of ontogeny plants tend to have large root:shoot ratios and may lack sufficient resources for structural defense (Boege \& Marquis, 2005; Hanley et al., 2007). Therefore, dishonest warning signals may provide an effective deterrent to herbivores when plants are vulnerable but resource limited. To my knowledge, this is the first time dishonest aposematism has been documented in a plant species.

Dishonesty is common in signaling systems and is often employed by individuals that would suffer adversely if signals were honest. For example, young male animals frequently mimic females to reduce the risk of injury caused by confrontation with older males (Forsyth \& Alcock, 1990; Saetre \& Slagsvold, 1996; Shine et al., 2000; Whiting et al., 2009; Hawkins et al., 2012). Furthermore, individuals producing dishonest signals are often resource limited or disadvantaged compared to honest signalers (Steger \& Caldwell, 1983; Backwell et al., 2000; Bee et al., 2000; Wilson et al., 2007; Valkonen et al., 2014). Aposematic signals produced by $P$. crassifolius were dishonest early in ontogeny, when defenses were poorly developed. However, individuals at later 
ontogenetic stages tended to produce honest signals of defense. Aposematism often develops later in ontogeny due to an absence of defense at earlier life-history stages (Grant, 2007; Fadzly et al., 2009; Higginson \& Ruxton, 2010; Valkonen et al., 2014), perhaps due to energetic requirements of growth early in ontogeny (Nylin et al., 2001; West et al., 2001; Boege \& Marquis, 2005; Ojala et al., 2007). Early stages of aposematism may tend to be dishonest in both plants and animals, with signal reliability increasing as defenses fully develop. Future studies of aposematism that consider variation in signals through ontogeny, and the changing perspective of signal receivers, will further our understanding of warning signal reliability. 


\section{Chapter 6 - General discussion}


Overall, the results of this thesis provide further insights into the evolution of plants on islands. First, seed sizes (Chapter 2) of insular plants were consistently larger than those of mainland relatives. Furthermore, differences in life-history traits did not influence the island-mainland seed size relationship. Second, the results of Chapter 3 suggest selection is acting to increase the size of both sexes of dioecious plants simultaneously on islands. Third, traits associated with the divaricate growth form (Chapter 4) have been secondarily lost on the Chatham Islands. Lastly, P. crassifolius (Chapter 5) displayed predictable changes in aposematic signaling and defense through ontogeny, potentially in response to unique insular herbivores.

Islands are renowned for producing repeated evolutionary pathways. This has been documented many times, particularly in the animal literature (e.g. the island rule, see Van Valen, 1973b; Lomolino, 2005). However, insular plants have received less attention and our understanding of predictable evolutionary changes in island plants is incomplete. For example, well-known phenomena, such as the evolution of woodiness on islands, remain unresolved with multiple hypotheses proposed (Darwin, 1859; Wallace, 1880; Carlquist, 1974; Bohle et al., 1996; Givnish, 1998). Plants are modular organisms and selection acting on one trait may cause a correlated evolutionary response in another. Therefore, the results of this thesis may shed light on the processes responsible for macroevolutionary changes of plants on islands.

In the following discussion I address the broader implications the results of this thesis have for our understanding of the evolution of island plants.

\section{Insular size changes in plants}

Recent research suggests selection is acting to increase leaf size on islands (Burns et al., 2012). Results of Chapters 3 and 4 are consistent with the findings of Burns et al. (2012), suggesting evolutionary increases in leaf size are common on islands. In dioecious taxa there was a consistent increase in leaf size of both sexes on islands (Chapter 3). Furthermore, plants of a variety of growth forms displayed consistent increases in leaf size on the Chatham Islands (Chapter 4). The depauperate nature of islands increases levels of 
intraspecific competition and this is suggested to contribute to size changes of insular animals (Grant, 1965; Case, 1978; Lomolino, 2005). Similarly, increased intraspecific competition may influence evolutionary changes in leaf size. Selection may favour increases in leaf size on islands, as plants with larger leaves have wider distributions and are more competitive (Schmitt \& Wulff, 1993; Grime et al., 1997; Westoby et al., 2002; Thuiller et al., 2004).

Seeds are arguably the earliest life-history stage to experience strong selective pressures on islands. For example, a reduction in dispersibility of island seeds has been noted in as few as five generations after island colonization (Cody \& Overton, 1996). In Chapter 2, I provided the first test for macroevolutionary changes in island seed size and results suggest a repeated tendency for seed sizes to increase on islands. Size patterns evident in mature individuals may be a response of selection acting earlier in ontogeny. For example, adult body size is strongly influenced by size at birth in a variety of animal taxa (Olsson \& Madsen, 2001; Kaplan \& Phillips, 2006; Ong, 2006; Garant et al., 2007; Wilson et al., 2009). Furthermore, a recent investigation suggests body size patterns of insular tiger snakes are a result of selection acting on birth size (Aubret, 2012). The same may be true in plants, as seed size is correlated with a number of plant traits evident later in ontogeny. For example, plant height and stem size are correlated with seed size (Corner, 1949; Leishman et al., 1995; Moles et al., 2004). Furthermore, seed size strongly influences seedling establishment and survival at later life-history stages (Moles \& Westoby, 2004).

Hypotheses for the evolution of insular woodiness suggest that selection may favour overall changes in plant size on islands (see Darwin, 1859; Wallace, 1880; Carlquist, 1974; Bohle et al., 1996; Givnish, 1998). However, they neglect the modularity of plant structure and the potential for woodiness to evolve due to selection acting on other plant traits. Furthermore, the action of selection may vary through plant ontogeny. Herbaceous colonists of islands are suggested to obtain a competitive advantage by developing secondary woodiness (Darwin, 1859; Carlquist, 1974; Givnish, 1998). Selection may first act on seeds to promote a competitive advantage, as larger seeds produce 
larger, more competitive seedlings (Leishman et al., 1995; Moles \& Westoby, 2004). Later in ontogeny selection may favour larger leaves, due to competitive ability being positively associated with leaf size (Grime et al., 1997; Westoby et al., 2002; Thuiller et al., 2004). Stems must provide mechanical support for leaves and seeds and the sizes of these traits are associated allometrically (Corner, 1949; Niklas, 1994). Therefore, selection acting to increase seed and leaf sizes may cause a correlated evolutionary response in stem size. Furthermore, seed size is positively associated with plant height (Leishman et al., 1995; Moles et al., 2004). Selection acting on other plant traits may facilitate the evolution of woodiness due to the structural support it provides. Previous hypotheses for the evolution of woodiness have neglected the possibility for the action of selection to vary with ontogeny. Investigating evolution in specific plant traits, at different stages of ontogeny, may improve our understanding of the processes responsible for overall size changes in island plants.

\section{Unique herbivores}

Plants often evolve unique adaptations to deter herbivores. For example, many plants produce prickles, thorns, or spines to deter mammalian browsers (Brown \& Lawton, 1991; Ronel \& Lev-Yadun, 2012). Furthermore, recent research suggests aposematism (warning signals) may be common in plants (LevYadun, 2001, 2003; Lev-Yadun \& Ne'eman, 2004; Lev-Yadun \& Gould, 2007; Fadzly et al., 2009). Islands are renowned for housing unique herbivore communities (e.g. Moa-nalos of Hawaii, Elephant birds of Madagascar, and Moa of New Zealand). Although many insular herbivores are now extinct, some of the unique traits expressed by island plants may be anti-herbivory adaptations.

Several features of the New Zealand flora are suggested to be adaptations to deter browsing moa (see Atkinson \& Greenwood, 1989b). For example, the remarkable series of morphological transitions (heteroblasty) displayed by $P$. crassifolius may have evolved in response to moa herbivory. The leaf morphology of juveniles is suggested to have deterred browsing moa, 
while adult morphology is more ordinary, perhaps due to attaining a height refuge (Greenwood \& Atkinson, 1977; Fadzly et al., 2009). The divaricate growth form is another unique characteristic of the New Zealand flora. More than 50 species in New Zealand, from a diverse range of lineages, produce the small leaves, high branching angles and narrow stems that characterize divaricate plants (Greenwood \& Atkinson, 1977). This growth form may also be an evolutionary adaptation to deter browsing moa (Greenwood \& Atkinson, 1977; Bond et al., 2004). Plants sharing similar characteristics are also common in Madagascar, where Elephant birds were a dominant component of the herbivore fauna (Bond \& Silander, 2007). Alternatively, it is suggested that the divaricate growth form is an adaptation to environmental conditions (McGlone \& Webb, 1981; Howell et al., 2002; Christian et al., 2006). Similarly, environmental adaptations are suggested as alternative explanations for the unique morphology of $P$. crassifolius (Gould, 1993).

Anti-herbivore defenses are often lost on islands, perhaps due to a reduction in herbivory pressure (Janzen, 1973; Rickson, 1977; Bowen \& VanVuren, 1997; Vourc'h et al., 2001; Burns, 2014). Pseudopanax chathamicus is endemic to the Chatham Islands and is derived from a $P$. crassifolius ancestor (Heenan et al., 2010). P. chathamicus lacks pronounced ontogenetic colour changes and morphological transitions in leaf morphology (Fadzly et al., 2009). This suggests an absence of moa on the Chatham Islands has relaxed selection for traits that may have deterred browsing moa. The results of Chapter 5 further support the anti-herbivory hypothesis for the morphology of $P$. crassifolius. Juveniles produced structural defenses, however investment in defense declined once individuals were above the height of moa. Furthermore, investment in aposematic signals was consistent with the potential feeding behavior of moa.

The results of Chapter 4 provide further support for the hypothesis that the divaricate growth form is an adaptive response to moa herbivory. Plants on Chatham Island produced larger leaves, shorter internodes, smaller branching angles, and stouter stems than related mainland plants. Furthermore, these results were inconsistent with climate-based hypotheses. This suggests an 
absence of moa on Chatham Island has relaxed selection for divaricate traits. The occurrence of unrelated plants sharing similar features on Madagascar also suggests that the unique features of divaricate plants may have deterred large avian browsers (Bond \& Silander, 2007).

\section{Conclusions \& Future directions}

Insularity is known to promote novel evolutionary changes in plants. However, the modularity of plant structure has not been appreciated in the past. By examining a range of trait specific changes in island plants the results of this thesis further our understanding of the action of selection on islands.

The results of Chapters 3 and 4 suggest that selection may be acting to increase leaf size on islands. Allometry between the size of leaves and stems may promote increased woodiness due to mechanical requirements of stems to support leaves. Furthermore, results of Chapter 2 suggest selection is acting to increase seed size on islands. A recent investigation suggests body size patterns of insular animals may be a reflection of selection acting on birth size (Aubret, 2012). The same may be true in plants and this deserves further attention. The evolution of insular woodiness suggests selection may be promoting overall size changes on islands. However, selection acting on specific plant traits, at different stages of ontogeny, may be facilitating this evolutionary pathway.

The unique herbivores of islands have often been suggested to play an important role in the evolution of insular plants. However, the significance of insular herbivory is frequently questioned, with physiological explanations suggested as alternatives. The results of Chapters 4 and 5 add further support to the role of herbivores in the evolution of island plants. Furthermore, results were inconsistent with physiological explanations. Rates of extinction are often high on islands and many insular herbivores are now extinct. However, feeding trials with extant relatives of extinct insular herbivores (see Bond et al., 2004) may improve our understanding of the role herbivory played in the evolution of island plants. 
Appendices 
Appendix A: Chapter 3 supplementary material 


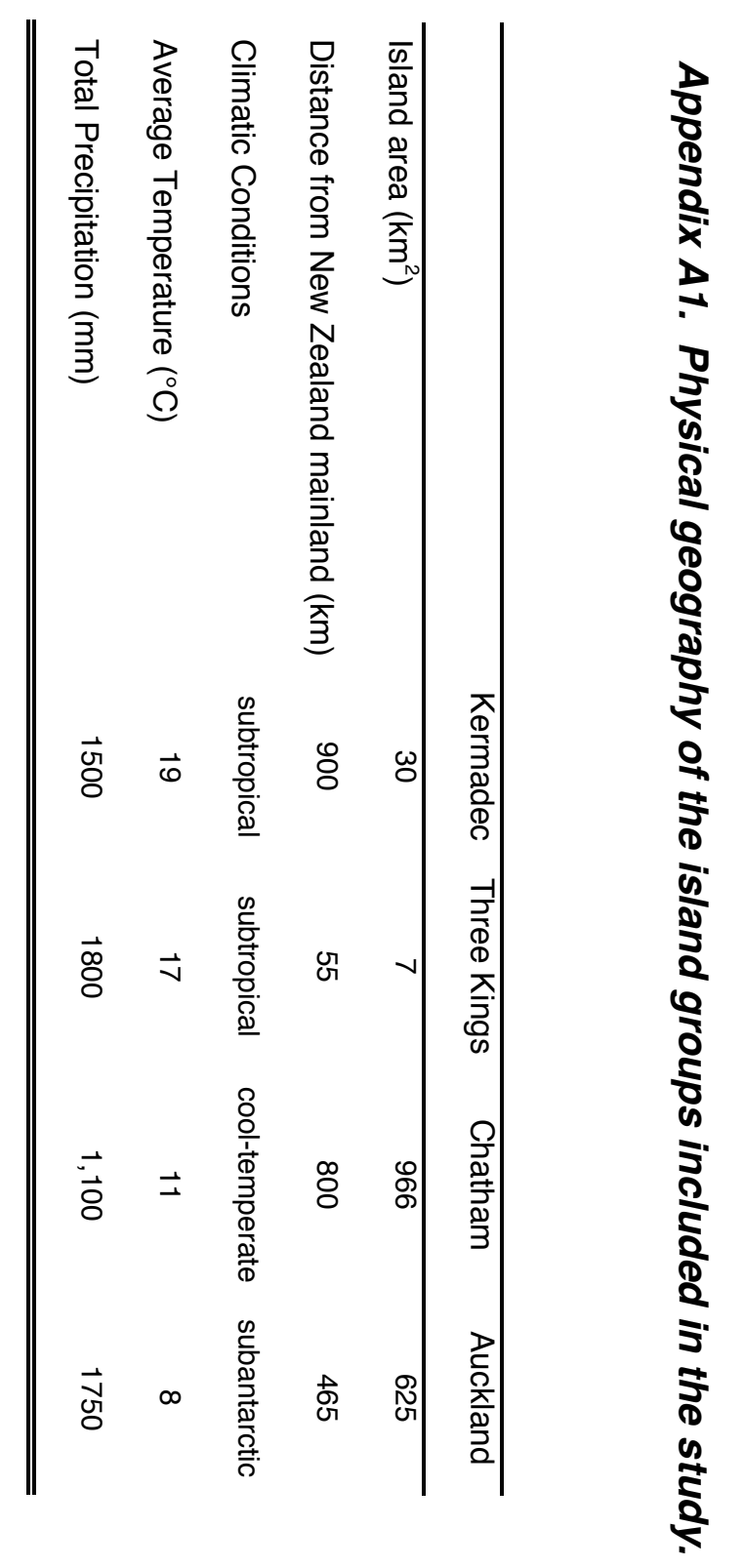


Appendix A2. Results of analyses after removing taxa with $n<3$ for any sex.

Degree of SSD

Wilcoxon test results:

\begin{tabular}{ccc}
\hline Trait & W & $P$ \\
\hline Leaves & 41 & 0.1934 \\
Stems & 13 & 0.1602 \\
\hline \hline
\end{tabular}

\section{Direction of SSD}

Rayleigh's test of uniformity, mean angles and von Mises bootstrapped confidence intervals

\begin{tabular}{cccc}
\hline & Rayleigh's test & & \\
\cline { 2 - 2 } Trait & $P$ & Mean angle & $95 \%$ C.I \\
\hline Leaves & 0.012 & 97.86 & $69.58-125.86$ \\
& & & \\
Stems & 0.036 & 67.36 & $34.27-119.99$ \\
\hline \hline
\end{tabular}

RMA analyses of island and mainland leaf and stem sizes

\begin{tabular}{cccc}
\hline & & Slope & Intercept \\
\cline { 3 - 4 } Trait & Sex & Mean value \pm SD $(95 \% \mathrm{Cl})$ & Mean value \pm SD $(95 \% \mathrm{Cl})$ \\
\hline Leaves & & $1.073 \pm 0.05(1.072-1.074)$ & $-0.213 \pm 0.324(-0.22$ to -0.207$)$ \\
& Female & $1.025 \pm 0.046(1.024-1.026)$ & $0.286 \pm 0.273(0.281-0.292)$ \\
& Male & & \\
Stems & & & \\
& Female & $1.433 \pm 0.351(1.426-1.439)$ & $-0.074 \pm 0.157(-0.077$ to -0.071$)$ \\
& Male & $1.174 \pm 0.612(1.162-1.186)$ & $0.034 \pm 0.234(0.03-0.039)$ \\
\hline \hline
\end{tabular}




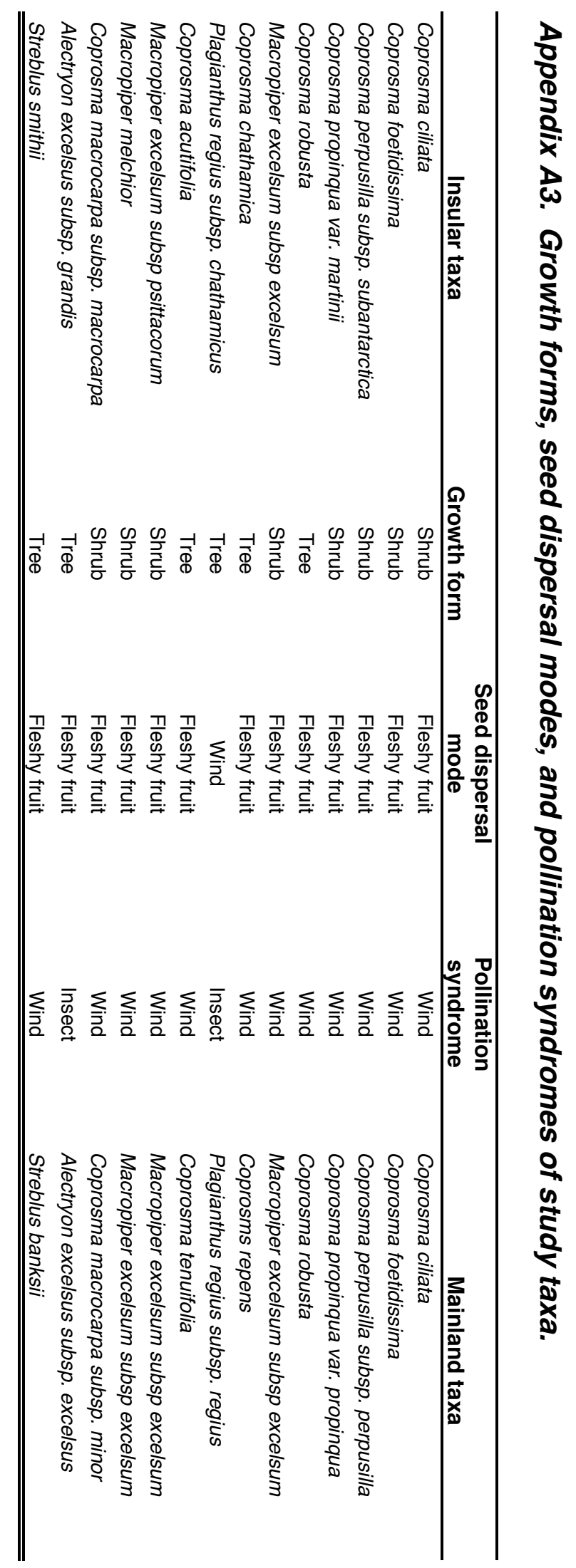




\section{References}

Ackerly, D.D. \& Cornwell, W.K. (2007) A trait-based approach to community assembly: partitioning of species trait values into within- and amongcommunity components. Ecology Letters, 10, 135-145.

Agostinelli, C. \& Lund, U. (2011) R package "circular": Circular Statistics.

Allan, H.H. (1961) The Flora of New Zealand. Government Printer, Wellington, New Zealand.

Aronsson, M. \& Gamberale-Stille, G. (2009) Importance of internal pattern contrast and contrast against the background in aposematic signals. Behavioral Ecology, 20, 1356-1362.

Atkinson, I.A. \& Greenwood, R. (1989a) Relationships between moas and plants. New Zealand journal of ecology, 12, 67-96.

Atkinson, I.A.E. \& Greenwood, R.M. (1989b) Relationships between Moas and Plants. New Zealand Journal of Ecology, 12, 67-96.

Aubret, F. (2012) Body-size evolution on islands: are adult size variations in tiger snakes a nonadaptive consequence of selection on birth size? American Naturalist, 179, 756-767.

Augspurger, C.K. (1986) Morphology and dispersal potential of wind-dispersed diaspores of neotropical trees. American Journal of Botany, 73, 353-363.

Backwell, P.R.Y., Christy, J.H., Telford, S.R., Jennions, M.D. \& Passmore, N.I. (2000) Dishonest signalling in a fiddler crab. Proceedings of the Royal Society B-Biological Sciences, 267, 719-724.

Baker, H.G. \& Cox, P.A. (1984) Further Thoughts on Dioecism and Islands. Annals of the Missouri Botanical Garden, 71, 244-253.

Barrett, S.C.H. \& Hough, J. (2013) Sexual dimorphism in flowering plants. Journal of Experimental Botany, 64, 67-82.

Bawa, K.S. (1980) Evolution of Dioecy in Flowering Plants. Annual Review of Ecology and Systematics, 11, 15-39.

Bawa, K.S. (1982) Outcrossing and the Incidence of Dioecism in Island Floras. American Naturalist, 119, 866-871.

Bayly, M. \& Kellow, A. (2006) An illustrated guide to New Zealand hebes. Te Papa Press, Wellington. 
Bazzaz, F.A., Chiariello, N.R., Coley, P.D. \& Pitelka, L.F. (1987) Allocating Resources to Reproduction and Defense. Bioscience, 37, 58-67.

Bee, M.A., Perrill, S.A. \& Owen, P.C. (2000) Male green frogs lower the pitch of acoustic signals in defense of territories: a possible dishonest signal of size? Behavioral Ecology, 11, 169-177.

Benkman, C.W. (1995) Wind dispersal capacity of pine seeds and the evolution of different seed dispersal modes in pines. Oikos, 73, 221-224.

Berentson, Q. (2012) Moa: The Life and Death of New Zealand's Legendary Bird. Craig Potton Publishing, Nelson, NZ.

Bezzerides, A.L., McGraw, K.J., Parker, R.S. \& Husseini, J. (2007) Elytra color as a signal of chemical defense in the Asian ladybird beetle Harmonia axyridis. Behavioral Ecology and Sociobiology, 61, 1401-1408.

Boege, K. \& Marquis, R.J. (2005) Facing herbivory as you grow up: the ontogeny of resistance in plants. Trends in Ecology \& Evolution, 20, 441448.

Bohle, U.R., Hilger, H.H. \& Martin, W.F. (1996) Island colonization and evolution of the insular woody habit in Echium $L$ (Boraginaceae). Proceedings of the National Academy of Sciences of the United States of America, 93, 11740-11745.

Bond, W.J. \& Midgley, J. (1988) Allometry and Sexual Differences in Leaf Size. American Naturalist, 131, 901-910.

Bond, W.J. \& Silander, J.A. (2007) Springs and wire plants: anachronistic defenses against Madagascar's extinct elephant birds. Proceedings of the Royal Society B-Biological Sciences, 274, 1985-1992.

Bond, W.J., Lee, W.G. \& Craine, J.M. (2004) Plant structural defenses against browsing birds: a legacy of New Zealand's extinct moas. Oikos, 104, 500-508.

Borchert, R. \& Tomlinson, P.B. (1984) Architecture and Crown Geometry in Tabebuia-Rosea Bignoniaceae. American Journal of Botany, 71, 958969.

Bowen, L. \& VanVuren, D. (1997) Insular endemic plants lack defenses against herbivores. Conservation Biology, 11, 1249-1254.

Brown, V.K. \& Lawton, J.H. (1991) Herbivory and the Evolution of Leaf Size and Shape. Philosophical Transactions of the Royal Society of London Series B-Biological Sciences, 333, 265-272. 
Bryant, J.P., Tahvanainen, J., Sulkinoja, M., Julkunen-Tiitto, R., Reichardt, P. \& Green, T. (1989) Biogeographic Evidence for the Evolution of Chemical Defense by Boreal Birch and Willow against Mammalian Browsing. American Naturalist, 134, 20-34.

Bunce, M., Worthy, T.H., Phillips, M.J., Holdaway, R.N., Willerslev, E., Haile, J., Shapiro, B., Scofield, R.P., Drummond, A., Kamp, P.J.J. \& Cooper, A. (2009) The evolutionary history of the extinct ratite moa and New Zealand Neogene paleogeography. Proceedings of the National Academy of Sciences of the United States of America, 106, 2064620651.

Burns, K.C. (2013) What causes size coupling in fruit-frugivore interaction webs? Ecology, 94, 295-300.

Burns, K.C. (2014) Are there general patterns in plant defense against megaherbivores? Biological Journal of the Linnean Society, 111, 38-48.

Burns, K.C. \& Dalen, J.L. (2002) Foliage color contrasts and adaptive fruit color variation in a bird-dispersed plant community. Oikos, 96, 463-469.

Burns, K.C. \& Dawson, J.W. (2009) Heteroblasty on Chatham Island: a comparison with New Zealand and New Caledonia. New Zealand Journal of Ecology, 33, 156-163.

Burns, K.C., Herold, N. \& Wallace, B. (2012) Evolutionary size changes in plants of the south-west Pacific. Global Ecology and Biogeography, 21, 819-828.

Carlquist, S.J. (1966) Biota of Long-Distance Dispersal .I. Principles of Dispersal and Evolution. Quarterly Review of Biology, 41, 247-\&.

Carlquist, S.J. (1974) Island biology. Columbia University Press, New York.

Case, T.J. (1978) General Explanation for Insular Body Size Trends in Terrestrial Vertebrates. Ecology, 59, 1-18.

Christian, R., Kelly, D. \& Turnbull, M.H. (2006) The architecture of New Zealand's divaricate shrubs in relation to light adaptation. New Zealand Journal of Botany, 44, 171-186.

Clarke, A. \& Gaston, K.J. (2006) Climate, energy and diversity. Proceedings of the Royal Society B-Biological Sciences, 273, 2257-2266.

Clegg, S.M. \& Owens, I.P.F. (2002) The 'island rule' in birds: medium body size and its ecological explanation. Proceedings of the Royal Society BBiological Sciences, 269, 1359-1365. 
Cody, M.L. \& Overton, J.M. (1996) Short-term evolution of reduced dispersal in island plant populations. Journal of Ecology, 84, 53-61.

Cooney, L.J., van Klink, J.W., Hughes, N.M., Perry, N.B., Schaefer, H.M., Menzies, I.J. \& Gould, K.S. (2012) Red leaf margins indicate increased polygodial content and function as visual signals to reduce herbivory in Pseudowintera colorata. New Phytologist, 194, 488-497.

Cooper, S.M. \& Owensmith, N. (1986) Effects of Plant Spinescence on Large Mammalian Herbivores. Oecologia, 68, 446-455.

Cornelissen, J.H.C., Lavorel, S., Garnier, E., Diaz, S., Buchmann, N., Gurvich, D.E., Reich, P.B., ter Steege, H., Morgan, H.D., van der Heijden, M.G.A., Pausas, J.G. \& Poorter, H. (2003) A handbook of protocols for standardised and easy measurement of plant functional traits worldwide. Australian Journal of Botany, 51, 335-380.

Corner, E.J.H. (1949) The durian theory or the origin of the modern tree. Annals of Botany, 13, 367-414.

Crawley, M.J. (2007) The R Book. Wiley Publishing.

Darrow, H.E., Bannister, P., Burritt, D.J. \& Jameson, P.E. (2001) The frost resistance of juvenile and adult forms of some heteroblastic New Zealand plants. New Zealand Journal of Botany, 39, 355-363.

Darwin, C. (1859) On the origin of species by means of natural selection, or the preservation of favoured races in the strugle for life. John Murray, London.

Dawson, J. \& Lucas, R. (2011) New Zealand's native trees. Craig Potton Publishers, Nelson, New Zealand.

Day, J.S. (1998) Light conditions and the evolution of heteroblasty (and the divaricate form) in New Zealand. New Zealand Journal of Ecology, 22, 43-54.

Dayan, T. \& Simberloff, D. (1998) Size patterns among competitors: Ecological character displacement and character release in mammals, with special reference to island populations. Mammal Review, 28, 99-124.

Dayan, T., Simberloff, D., Tchernov, E. \& Yomtov, Y. (1989) Interspecific and Intraspecific Character Displacement in Mustelids. Ecology, 70, 15261539.

Delph, L.F., Galloway, L.F. \& Stanton, M.L. (1996) Sexual dimorphism in flower size. American Naturalist, 148, 299-320. 
Diaz, S., Cabido, M. \& Casanoves, F. (1998) Plant functional traits and environmental filters at a regional scale. Journal of Vegetation Science, 9, 113-122.

Ebenman, B. \& Nilsson, S.G. (1982) Components of Niche Width in a Territorial Bird Species - Habitat Utilization in Males and Females of the Chaffinch (Fringilla-Coelebs) on Islands and Mainland. American Naturalist, 119, 331-344.

Endler, J.A. (1993) The Color of Light in Forests and Its Implications. Ecological Monographs, 63, 1-27.

Evans, A.D. \& Lee, K. (2011) Verbal Deception From Late Childhood to Middle Adolescence and Its Relation to Executive Functioning Skills. Developmental Psychology, 47, 1108-1116.

Fadzly, N., Jack, C., Schaefer, H.M. \& Burns, K.C. (2009) Ontogenetic colour changes in an insular tree species: signalling to extinct browsing birds? New Phytologist, 184, 495-501.

Fairbairn, J. \& Shine, R. (1993) Patterns of Sexual Size Dimorphism in Seabirds of the Southern-Hemisphere. Oikos, 68, 139-145.

Felsenstein, J. (1985) Phylogenies and the Comparative Method. American Naturalist, 125, 1-15.

Forsyth, A. \& Alcock, J. (1990) Female Mimicry and Resource Defense Polygyny by Males of a Tropical Rove Beetle, Leistotrophus-Versicolor (Coleoptera, Staphylinidae). Behavioral Ecology and Sociobiology, 26, 325-330.

Fox, J. \& Weisberg, S. (2011) $A n\{R\}$ companion to applied regression. Sage, Thousand Oaks, CA.

Garant, D., Kruuk, L.E.B., McCleery, R.H. \& Sheldon, B.C. (2007) The effects of environmental heterogeneity on multivariate selection on reproductive traits in female great tits. Evolution, 61, 1546-1559.

Gibbs, G. (2006) Ghosts of Gondwana. Craig Potton Publishers, Nelson, New Zealand.

Givnish, T.J. (1998) Adaptive plant evolution on islands: classical patterns, molecular data, new insights. Evolution on islands (ed. by P. Grant), pp. 281-304. Oxford University Press, Oxford 
Givnish, T.J., Sytsma, K.J., Smith, J.F. \& Hahn, W.J. (1994) Thorn-Like Prickles and Heterophylly in Cyanea - Adaptations to Extinct Avian Browsers on Hawaii. Proceedings of the National Academy of Sciences of the United States of America, 91, 2810-2814.

Glenny, D. (2004) A revision of the genus Gentianella in New Zealand. New Zealand Journal of Botany, 42, 361-530.

Godley, E.J. (1979) Flower Biology in New-Zealand. New Zealand Journal of Botany, 17, 441-466.

Gould, K.S. (1993) Leaf Heteroblasty in Pseudopanax crassifolius: Functional Significance of Leaf Morphology and Anatomy. Annals of Botany, 71, 6170.

Gould, K.S., Kuhn, D.N., Lee, D.W. \& Oberbauer, S.F. (1995) Why Leaves Are Sometimes Red. Nature, 378, 241-242.

Gowda, J.H. \& Palo, R.T. (2003) Age - related changes in defensive traits of Acacia tortilis Hayne. African Journal of Ecology, 41, 218-223.

Grant, J.B. (2007) Ontogenetic colour change and the evolution of aposematism: a case study in panic moth caterpillars. Journal of Animal Ecology, 76, 439-447.

Grant, P.R. (1965) The Adaptive Significance of Some Size Trends in Island Birds. Evolution, 19, 355-367.

Greene, D.F. \& Johnson, E.A. (1993) Seed mass and dispersal capacity in wind-dispersed diaspores. Oikos, 67, 69-74.

Greenwood, R.M. (1992) Some Differences between Plants of the Chatham Islands and the New-Zealand Mainland. New Zealand Journal of Ecology, 16, 51-52.

Greenwood, R.M. \& Atkinson, I.A.E. (1977) Evolution of divaricating plants in New Zealand in relation to moa browsing. Proceedings of the New Zealand Ecological Society, 24, 21-33.

Grime, J.P., Thompson, K., Hunt, R., Hodgson, J.G., Cornelissen, J.H.C., Rorison, I.H., Hendry, G.A.F., Ashenden, T.W., Askew, A.P., Band, S.R., Booth, R.E., Bossard, C.C., Campbell, B.D., Cooper, J.E.L., Davison, A.W., Gupta, P.L., Hall, W., Hand, D.W., Hannah, M.A., Hillier, S.H., Hodkinson, D.J., Jalili, A., Liu, Z., Mackey, J.M.L., Matthews, N., Mowforth, M.A., Neal, A.M., Reader, R.J., Reiling, K., RossFraser, W., Spencer, R.E., Sutton, F., Tasker, D.E., Thorpe, P.C. \& Whitehouse, J. (1997) Integrated screening validates primary axes of specialisation in plants. Oikos, 79, 259-281. 
Hanley, M.E., Lamont, B.B., Fairbanks, M.M. \& Rafferty, C.M. (2007) Plant structural traits and their role in anti-herbivore defense. Perspectives in Plant Ecology Evolution and Systematics, 8, 157-178.

Harper, J.L., Lovell, P.H. \& Moore, K.G. (1970) The shapes and sizes of seeds. Annual Review of Ecology and Systematics., 1, 327-56.

Hawkins, G.L., Hill, G.E. \& Mercadante, A. (2012) Delayed plumage maturation and delayed reproductive investment in birds. Biological Reviews, 87, 257-274.

Heenan, P.B., Mitchell, A.D., de Lange, P.J., Keeling, J. \& Paterson, A.M. (2010) Late-Cenozoic origin and diversification of Chatham Islands endemic plant species revealed by analyses of DNA sequence data. New Zealand Journal of Botany, 48, 83-136.

Henery, M.L. \& Westoby, M. (2001) Seed mass and seed nutrient content as predictors of seed output variation between species. Oikos, 92, 479-490.

Higginson, A.D. \& Ruxton, G.D. (2010) Optimal Defensive Coloration Strategies during the Growth Period of Prey. Evolution, 64, 53-67.

Himmelreich, S., Breitwieser, I. \& Oberprieler, C. (2012) Phylogeny, biogeography, and evolution of sex expression in the southern hemisphere genus Leptinella (Compositae, Anthemideae). Molecular Phylogenetics and Evolution, 65, 464-481.

Holdaway, R.N. \& Jacomb, C. (2000) Rapid extinction of the moas (Aves: Dinornithiformes): Model, test, and implications. Science, 287, 22502254.

Honda, H. \& Fisher, J.B. (1978) Tree branch angle: maximizing effective leaf area. Science, 199, 888-890.

Howell, C.J., Kelly, D. \& Turnbull, M.H. (2002) Moa ghosts exorcised? New Zealand's divaricate shrubs avoid photoinhibition. Functional Ecology, 16, 232-240.

Hughes, N.M., Vogelmann, T.C. \& Smith, W.K. (2008) Optical effects of abaxial anthocyanin on absorption of red wavelengths by understorey species: revisiting the back-scatter hypothesis. Journal of Experimental Botany, 59, 3435-3442.

Jammalamadaka, S.R. \& SenGupta, A. (2001) Topics in circular statistics. World Scientific Press, Singapore.

Janzen, D.H. (1973) Dissolution of Mutualism between Cecropia and Its Azteca Ants. Biotropica, 5, 15-28. 
Jensen, L.A., Arnett, J., Feldman, S.S. \& Cauffman, E. (2004) The right to do wrong: Lying to parents among adolescents and emerging adults. Journal of Youth and Adolescence, 33, 101-112.

Jing, S.W. \& Coley, P.D. (1990) Dioecy and Herbivory - the Effect of GrowthRate on Plant Defense in Acer-Negundo. Oikos, 58, 369-377.

Kaplan, R.H. \& Phillips, P.C. (2006) Ecological and developmental context of natural selection: Maternal effects and thermally induced plasticity in the frog Bombina orientalis. Evolution, 60, 142-156.

Kavanagh, P.H. \& Burns, K.C. (2014) The repeated evolution of large seeds on islands. Proceedings of the Royal Society B, $\mathbf{2 8 1}$

Kavanagh, P.H., Lehnebach, C.A., Shea, M.J. \& Burns, K.C. (2011) Allometry of sexual size dimorphism in dioecious plants: do plants obey Rensch's rule? American Naturalist, 178, 596-601.

Kelly, D. (1994) Towards a Numerical Definition for Divaricate (Interlaced SmallLeaved) Shrubs. New Zealand Journal of Botany, 32, 509-518.

Kelly, D. \& Ogle, M.R. (1990) A Test of the Climate Hypothesis for Divaricate Plants. New Zealand Journal of Ecology, 13, 51-61.

Kreft, H. \& Jetz, W. (2007) Global patterns and determinants of vascular plant diversity. Proceedings of the National Academy of Sciences of the United States of America, 104, 5925-5930.

Lee, K. (2013) Little Liars: Development of Verbal Deception in Children. Child Development Perspectives, 7, 91-96.

Lee, W.G., Wood, J.R. \& Rogers, G.M. (2010) Legacy of avian-dominated plantherbivore systems in New Zealand. New Zealand Journal of Ecology, 34, 28-47.

Leishman, M.R. \& Westoby, M. (1994) The role of seed size in seedling establishment in dry soil-conditions - experimental-evidence from semiarid species. Journal of Ecology, 82, 249-258.

Leishman, M.R., Westoby, M. \& Jurado, E. (1995) Correlates of seed size variation - a comparison among 5 temperate floras. Journal of Ecology, 83, 517-529.

Lev-Yadun, S. (2001) Aposematic (warning) coloration associated with thorns in higher plants. Journal of Theoretical Biology, 210, 385-U1.

Lev-Yadun, S. (2003) Why do some thorny plants resemble green zebras? Journal of Theoretical Biology, 224, 483-489. 
Lev-Yadun, S. \& Ne'eman, G. (2004) When may green plants be aposematic? Biological Journal of the Linnean Society, 81, 413-416.

Lev-Yadun, S. \& Gould, K.S. (2007) What do red and yellow autumn leaves signal? Botanical Review, 73, 279-289.

Levey, D.J. (1987) Seed size and fruit-handling techniques of avian frugivores. American Naturalist, 129, 471-485.

Levine, T.R., Serota, K.B., Carey, F. \& Messer, D. (2013) Teenagers lie a lot: A further investigation into the prevalence of lying. Communication Research Reports, 30, 211-220.

Lindenfors, P., Gittleman, J.L., Jones, K.E. (2007) Sexual size dimorphism in mammals. Sex, Size \& Gender Roles (ed. by W.U.B.T.S. D. Fairbairn), pp. 16-26. Oxford University Press, New York.

Livezey, B.C. (1993) An Ecomorphological Review of the Dodo (RaphusCucullatus) and Solitaire (Pezophaps-Solitaria), Flightless Columbiformes of the Mascarene Islands. Journal of Zoology, 230, 247292.

Lomolino, M.V. (2005) Body size evolution in insular vertebrates: generality of the island rule. Journal of Biogeography, 32, 1683-1699.

Londono, G.A., Garica, D.A. \& Martinez, M.A.S. (2015) Morphological and Behavioral Evidence of Batesian Mimicry in Nestlings of a Lowland Amazonian Bird. American Naturalist, 185, 135-141.

Lord, J., Westoby, M. \& Leishman, M. (1995) Seed size and phylogeny in 6 temperate floras - constraints, niche conservatism, and adaptation. American Naturalist, 146, 349-364.

Lovich, J.E. \& Gibbons, J.W. (1992) A Review of Techniques for Quantifying Sexual Size Dimorphism. Growth Development and Aging, 56, 269-281.

Lund, U. \& Agostinelli, C. (2009) CircStats: Circular Statistics. Topics in circular Statistics.

Maia, R., Eliason, C.M., Bitton, P.P., Doucet, S.M. \& Shawkey, M.D. (2013) pavo: an $R$ package for the analysis, visualization and organization of spectral data. Methods in Ecology and Evolution, 4, 906-913.

Mappes, J., Marples, N. \& Endler, J.A. (2005) The complex business of survival by aposematism. Trends in Ecology \& Evolution, 20, 598-603.

McGlone, M.S. \& Webb, C.J. (1981) Selective Forces Influencing the Evolution of Divaricating Plants. New Zealand Journal of Ecology, 4, 20-28. 
Meiri, S., Dayan, T. \& Simberloff, D. (2005) Variability and sexual size dimorphism in carnivores: Testing the niche variation hypothesis. Ecology, 86, 1432-1440.

Meiri, S., Dayan, T. \& Simberloff, D. (2006) The generality of the island rule reexamined. Journal of Biogeography, 33, 1571-1577.

Meiri, S., Cooper, N. \& Purvis, A. (2008) The island rule: made to be broken? Proceedings of the Royal Society B-Biological Sciences, 275, 141-148.

Midgley, J. \& Bond, W. (1989) Leaf Size and Inflorescence Size May Be Allometrically Related Traits. Oecologia, 78, 427-429.

Midgley, J.J. (2010) Causes of secondary sexual differences in plants Evidence leaf dimorphism in Leucadendron (Proteaceae). South African Journal of Botany, 76, 588-592.

Moles, A.T. \& Westoby, M. (2000) Do small leaves expand faster than large leaves, and do shorter expansion times reduce herbivore damage? Oikos, 90, 517-524.

Moles, A.T. \& Westoby, M. (2004) Seedling survival and seed size: a synthesis of the literature. Journal of Ecology, 92, 372-383.

Moles, A.T., Falster, D.S., Leishman, M.R. \& Westoby, M. (2004) Small-seeded species produce more seeds per square metre of canopy per year, but not per individual per lifetime. Journal of Ecology, 92, 384-396.

Nathan, R. (2006) Long-distance dispersal of plants. Science, 313, 786-788.

National Institute of Water and Atmospheric research (2014) NIWA climate summaries: 1971-2000. Available at: http://www.niwa.co.nz/educationand-training/schools/resources/climate/summary (accessed 15/05/2014)

Neill, S. \& Gould, K.S. (2000) Optical properties of leaves in relation to anthocyanin concentration and distribution. Canadian Journal of Botany, 77, 1777-1782.

Niklas, K.J. (1994) Plant Allometry: The scaling of form and process. The University of Chicago Press, Chicago, USA.

Niklas, K.J. (1996) Differences between Acer saccharum leaves from open and wind-protected sites. Annals of Botany (London), 78, 61-66.

Nylin, S., Gamberale-Stille, G. \& Tullberg, B.S. (2001) Ontogeny of defense and adaptive coloration in larvae of the comma butterfly, Polygonia c-album (Nymphalidae). Journal of the Lepidopterists Society, 55, 69-73. 
Obeso, J.R. (2002) The costs of reproduction in plants. New Phytologist, 155, 321-348.

Ojala, K., Lindstrom, L. \& Mappes, J. (2007) Life-history constraints and warning signal expression in an arctiid moth. Functional Ecology, 21, $1162-1167$.

Olson, S.L. \& James, H.F. (1982) Fossil Birds from the Hawaiian-Islands Evidence for Wholesale Extinction by Man before Western Contact. Science, 217, 633-635.

Olsson, M. \& Madsen, T. (2001) Between-year variation in determinants of offspring survival in the Sand Lizard, Lacerta agilis. Functional Ecology, 15, 443-450.

Ong, K.K. (2006) Size at birth, postnatal growth and risk of obesity. Hormone Research, 65, 65-69.

Panero, J.L., Francisco-Ortega, J., Jansen, R.K. \& Santos-Guerra, A. (1999) Molecular evidence for multiple origins of woodiness and a New Would biogeographic connection of the Macaronesian Island endemic Pericallis (Asteraceae : Senecioneae). Proceedings of the National Academy of Sciences of the United States of America, 96, 13886-13891.

Parkhurst, D.F. \& Loucks, O.L. (1972) Optimal Leaf Size in Relation to Environment. Journal of Ecology, 60, 505-537.

Pearson, D., Shine, R. \& Williams, A. (2002) Geographic variation in sexual size dimorphism within a single snake species (Morelia spilota, Pythonidae). Oecologia, 131, 418-426.

Percy, D.M. \& Cronk, Q.C.B. (2002) Different fates of island brooms: Contrasting evolution in Adenocarpus, Genista, and Teline (Genisteae, Fabaceae) in the Canary Islands and Madeira. American Journal of Botany, 89, 854-864.

Perrie, L.R. \& Shepherd, L.D. (2009) Reconstructing the species phylogeny of Pseudopanax (Araliaceae), a genus of hybridising trees. Molecular Phylogenetics and Evolution, 52, 774-783.

Price, T.D. \& Phillimore, A.B. (2007) Reduced major axis regression and the island rule. Journal of Biogeography, 34, 1998-1999.

Pukkala, T., Becker, P., Kuuluvainen, T. \& Okerblom, P. (1991) Predicting Spatial-Distribution of Direct-Radiation Below Forest Canopies. Agricultural and Forest Meteorology, 55, 295-307.

R Development Core Team (2013) R: a language and environment for statistical computing. 
R-Development-Core-Team (2011) R: a language and environment for statistical computing.

Reeve, J.P. \& Fairbairn, D.J. (1996) Sexual size dimorphism as a correlated response to selection on body size: An empirical test of the quantitative genetic model. Evolution, 50, 1927-1938.

Renner, S.S. \& Ricklefs, R.E. (1995) Dioecy and Its Correlates in the Flowering Plants. American Journal of Botany, 82, 596-606.

Ricklefs, R.E. \& Bermingham, E. (2002) The concept of the taxon cycle in biogeography. Global Ecology and Biogeography, 11, 353-361.

Rickson, F.R. (1977) Progressive Loss of Ant Related Traits of Cecropia-Peltata on Selected Caribbean Islands. American Journal of Botany, 64, 585592.

Rohwer, S., Fretwell, S.D. \& Niles, D.M. (1980) Delayed Maturation in Passerine Plumages and the Deceptive Acquisition of Resources. American Naturalist, 115, 400-437.

Ronel, M. \& Lev-Yadun, S. (2012) The spiny, thorny and prickly plants in the flora of Israel. Botanical Journal of the Linnean Society, 168, 344-352.

Rothstein, S.I. (1973) Niche-Variation Model - Is It Valid. American Naturalist, 107, 598-620.

Rowell, J.T., Ellner, S.P. \& Reeve, H.K. (2006) Why animals lie: How dishonesty and belief can coexist in a signaling system. American Naturalist, 168, E180-E204.

Saetre, G.P. \& Slagsvold, T. (1996) The significance of female mimicry in male contests. American Naturalist, 147, 981-995.

Sakai, A.K., Wagner, W.L., Ferguson, D.M. \& Herbst, D.R. (1995) Origins of Dioecy in the Hawaiian Flora. Ecology, 76, 2517-2529.

Sanchez-Vilas, J., Turner, A. \& Pannell, J.R. (2011) Sexual dimorphism in intraand interspecific competitive ability of the dioecious herb Mercurialis annua. Plant Biology, 13, 218-222.

Santiago-Alarcon, D. \& Parker, P.G. (2007) Sexual size dimorphism and morphological evidence supporting the recognition of two subspecies in the Galapagos Dove. Condor, 109, 132-141. 
Schaefer, H.M., Levey, D.J., Schaefer, V. \& Avery, M.L. (2006) The role of chromatic and achromatic signals for fruit detection by birds. Behavioral Ecology, 17, 784-789.

Schmitt, J. \& Wulff, R.D. (1993) Light spectral quality, phytochrome and plant competition. Trends in Ecology and Evolution, 8, 47-51.

Schneider, C.A., Rasband, W.S. \& Eliceiri, K.W. (2012) NIH Image to ImageJ: 25 years of image analysis. Nature Methods, 9, 671-675.

Schreiber, H.D. \& Wade, N.A. (2007) Field-portable analysis of anthocyanin concentration in sepals of Hydrangea macrophylla. Hortscience, 42, 1323-1325.

Searcy, W.A. \& Nowicki, S. (2005) The evolution of animal communication: reliability and deception in signaling systems. Princeton University Press, Princeton, New Jersey, USA.

Shine, R. (1989) Ecological Causes for the Evolution of Sexual Dimorphism - a Review of the Evidence. Quarterly Review of Biology, 64, 419-461.

Shine, R., Harlow, P., Lemaster, M.P., Moore, I.T. \& Mason, R.T. (2000) The transvestite serpent: why do male garter snakes court (some) other males? Animal Behaviour, 59, 349-359.

Simberloff, D., Dayan, T., Jones, C. \& Ogura, G. (2000) Character displacement and release in the small Indian mongoose, Herpestes javanicus. Ecology, 81, 2086-2099.

Smith, A. (1909) On the internal temperature of leaves in tropical insolation, with special reference to the effect of their colour on the temperature; also observations on the periodicity of the appearance of young coloured leaves of trees growing in Peradeniya gardens.

Smith, R.J. (1999) Statistics of sexual size dimorphism. Journal of Human Evolution, 36, 423-458.

Steger, R. \& Caldwell, R.L. (1983) Intraspecific Deception by Bluffing - a Defense Strategy of Newly Molted Stomatopods (Arthropoda, Crustacea). Science, 221, 558-560.

Stillwell, R.C., Blanckenhorn, W.U., Teder, T., Davidowitz, G. \& Fox, C.W. (2010) Sex Differences in Phenotypic Plasticity Affect Variation in Sexual Size Dimorphism in Insects: From Physiology to Evolution. Annual Review of Entomology, 55, 227-245.

Stockler, K. (2001) Origins and Evolution of the New Zealand Forest Flora: a Molecular Phylogenetic Approach. PhD, Massey University, Palmerston North, New Zealand 
Stokes, A., Fitter, A.H. \& Coutts, M.P. (1995) Responses of young trees to wind and shading: Effects on root architecture. Journal of Experimental Botany, 46, 1139-1146.

Summers, K. \& Clough, M.E. (2001) The evolution of coloration and toxicity in the poison frog family (Dendrobatidae). Proceedings of the National Academy of Sciences, 98, 6227-6232.

Székely, T., Lislevand, T., Figuerola, J. (2007) Sexual size dimorphsim in birds. Sex, Size \& Gender Roles (ed. by D. Fairbairn, Blanckenhorn, W., Székely, T.), pp. 27-37. Oxford University Press, New York.

Terborgh, J. \& Mathews, J. (1999) Partitioning of the understorey light environment by two Amazonian treelets. Journal of Tropical Ecology, 15, 751-763.

Thomson, J.D. \& Brunet, J. (1990) Hypotheses for the Evolution of Dioecy in Seed Plants. Trends in Ecology \& Evolution, 5, 11-16.

Thuiller, W., Lavorel, S., Midgley, G., Lavergne, S. \& Rebelo, T. (2004) Relating plant traits and species distributions along bioclimatic gradients for 88 Leucadendron taxa. Ecology, 85, 1688-1699.

Turvey, S.T. \& Holdaway, R.N. (2005) Postnatal ontogeny, population structure, and extinction of the giant moa Dinornis. Journal of Morphology, 265, 7086.

Turvey, S.T., Green, O.R. \& Holdaway, R.N. (2005) Cortical growth marks reveal extended juvenile development in New Zealand moa. Nature, 435, 940-943.

Valkonen, J.K., Nokelainen, O., Jokimaki, M., Kuusinen, E., Paloranta, M., Peura, M. \& Mappes, J. (2014) From deception to frankness: Benefits of ontogenetic shift in the anti-predator strategy of alder moth Acronicta alni larvae. Current Zoology, 60, 114-122.

Van Valen, L. (1965) Morphological Variation and Width of Ecological Niche. The American Naturalist, 99, 377-390.

Van Valen, L. (1973a) Pattern and the balance of nature. Evolutionary Theory, 1, 31-49.

Van Valen, L. (1973b) A new evolutionary law. Evolutionary theory, 1, 1-30.

Vourc'h, G., Martin, J.-L., Duncan, P., Escarre, J. \& Clausen, T.P. (2001) Defensive adaptations of Thuja plicata to ungulate browsing: A 
comparative study between mainland and island populations. Oecologia, 126, 84-93.

Wagstaff, S.J., Breitwieser, I. \& Swenson, U. (2006) Origin and relationships of the austral genus Abrotanella (Asteraceae) inferred from DNA sequences. Taxon, 55, 95-106.

Wagstaff, S.J., Breitwieser, I. \& Ito, M. (2011) Evolution and biogeography of Pleurophyllum (Astereae, Asteraceae), a small genus of megaherbs endemic to the Subantarctic Islands. American Journal of Botany, 98, 6275.

Wallace, A.R. (1880) Island Life: or, The phenomena and causes of insular faunas and floras, including a revision and attempted solution of the problem of geological climates. Macmillan, London.

Wallace, C.S. \& Rundel, P.W. (1979) Sexual Dimorphism and ResourceAllocation in Male and Female Shrubs of Simmondsia chinensis. Oecologia, 44, 34-39.

Wallis, G.P. \& Trewick, S.A. (2009) New Zealand phylogeography: evolution on a small continent. Molecular Ecology, 18, 3548-3580.

Wardle, P. (1991) Vegetation of New Zealand. Cambridge University Press, Cambridge.

Warton, D.I., Duursma, R.A., Falster, D.S. \& Taskinen, S. (2012a) smatr 3 - an $\mathrm{R}$ package for estimation and inference about allometric lines. Methods in Ecology and Evolution, 3, 257-259.

Warton, D.I., Duursma, R.A., Falster, D.S. \& Taskinen, S. (2012b) smatr 3-an R package for estimation and inference about allometric lines. Methods in Ecology and Evolution, 3, 257-259.

Webb, C.J. \& Simpson, M.J.A. (2001) Seeds of New Zealand gymnosperms and dicotyledons. Manuka Press, Christchurch.

West, G.B., Brown, J.H. \& Enquist, B.J. (2001) A general model for ontogenetic growth. Nature, 413, 628-631.

Westoby, M., Leishman, M. \& Lord, J. (1996) Comparative ecology of seed size and dispersal. Philosophical Transactions of the Royal Society of London Series B-Biological Sciences, 351, 1309-1317.

Westoby, M., Falster, D.S., Moles, A.T., Vesk, P.A. \& Wright, I.J. (2002) Plant ecological strategies: Some leading dimensions of variation between species. Annual Review of Ecology and Systematics, 33, 125-159. 
Wheelwright, N.T. (1985) Fruit size, gape width, and the diets of fruit-eating birds. Ecology, 66, 808-818.

White, P.S. (1983) Corners Rules in Eastern Deciduous Trees - Allometry and Its Implications for the Adaptive Architecture of Trees. Bulletin of the Torrey Botanical Club, 110, 203-212.

Whiting, M.J., Webb, J.K. \& Keogh, J.S. (2009) Flat lizard female mimics use sexual deception in visual but not chemical signals. Proceedings of the Royal Society B-Biological Sciences, 276, 1585-1591.

Whittaker, R.J. \& Fernández-Palacios, J.M. (2007) Island Biogeography: ecology, evolution, and conservation, 2nd edn. Oxford University Press, New York.

Wikelski, M. \& Trillmich, F. (1997) Body size and sexual size dimorphism in marine iguanas fluctuate as a result of opposing natural and sexual selection: An island comparison. Evolution, 51, 922-936.

Wilson, A.J., Pemberton, J.M., Pilkington, J.G., Clutton-Brock, T.H. \& Kruuk, L.E.B. (2009) Trading offspring size for number in a variable environment: selection on reproductive investment in female Soay sheep. Journal of Animal Ecology, 78, 354-364.

Wilson, R.S., Angilletta, M.J., James, R.S., Navas, C. \& Seebacher, F. (2007) Dishonest signals of strength in male slender crayfish (Cherax dispar) during agonistic encounters. American Naturalist, 170, 284-291.

Winkworth, R.C., Grau, J., Robertson, A.W. \& Lockhart, P.J. (2002) The origins and evolution of the genus Myosotis L. (Boraginaceae). Molecular Phylogenetics and Evolution, 24, 180-193.

Wood, J.R., Rawlence, N.J., Rogers, G.M., Austin, J.J., Worthy, T.H. \& Cooper, A. (2008) Coprolite deposits reveal the diet and ecology of the extinct New Zealand megaherbivore moa (Aves, Dinornithiformes). Quaternary Science Reviews, 27, 2593-2602.

Worthy, T.H. (1990) An Analysis of the Distribution and Relative Abundance of Moa Species (Aves, Dinornithiformes). New Zealand Journal of Zoology, $17,213-241$.

Worthy, T.H. \& Holdaway, R.N. (2002) The lost world of the moa: prehistoric life of New Zealand. Indiana University Press, Indiana, USA. 